\title{
Three Essays on the Gender Differentials in Mortality and Undernutrition in Pakistan
}

Dissertation

zur Erlangung des wirtschaftswissenschaftlichen Doktorgrades

der Wirtschaftswissenschaftlichen Fakultät

der Universität Göttingen

vorgelegt am 8. April 2008

von Mohammad Asim Syed

aus Peshawar (Pakistan) 
To

My Parents

...........your prayers are always a source of strength 


\section{Author's Preface}

"In the name of God, the most beneficent, the most merciful"

I am really and ever grateful to the Almighty God for blessing me with His help and enabling me to achieve this greatest milestone in my academic life. Getting a Ph.D. in any field is the ultimate point of highest prestige. The process is tiring, and at times, tense. But the outcome is wonderful, and once you are finally finished with your work, you realize that effort was worth for the pleasure and honour you get at the end.

When I got the scholarship from the Government of Pakistan for higher studies in Germany, I was a bit hesitant to come here. I was not sure whether coming to Germany would be a good choice or not. For this, I consulted the issue with many friends and my colleagues at the University of Peshawar (Pakistan). Surprisingly, everyone recommended and encouraged me to definitely come to Germany because they all had high regards for this great country. And, I can still remember the words of one of my colleague (who has also done his Ph.D. from Germany) that you should not only go to Germany because of its higher academic standings, but also because you shall not find such nice and wonderful people that the Germans are. The point clicked. And now, when I think in retrospect, I can say with confidence, and with the core of my heart, that I found Germany, and particularly its people, to be much nicer and more wonderful than I could have imagined. It is not the place to mention all those good experiences that I had here, but I could only say that my first gesture of thanks goes to this great land of wonderful people called Germany.

I think you would be very lucky if you get a Ph.D. supervisor of the level and nature of Professor Stephan Klasen. His competence and place in the field of Development Economics is definitely beyond any doubt, but what makes him so special is the way he discusses, interacts and helps his students and clarifies all the confusing issues coming out in the course of research project. It was really a pleasure and honour to be a Ph.D. student of Prof. Klasen. There were many times (as it usually happens with every Ph.D. student) when I was losing faith in my work and was not very confident of my direction, but each time Prof. Klasen was a source of getting back my confidence and clearance of my worries. I would like to extend my gratitude to Prof. Klasen for his patience and constant guidance during the course of my study. 
I would like to mention two persons in the Centre for Statistics (ZfS) at the University of Göttingen, who I shall always remember for their good nature and great teaching qualities. Prof. Manfred Denker (former Director ZfS) was like a fatherly figure who was always willing to help and guide whenever we needed that. The other one is Prof. Walter Zucchini who, I would like to say, is the best teacher that I can find in my own academic life. Not only is he a brilliant teacher, but also an extra-ordinary humble and sweet personality. Prof. Zucchini has the quality to clarify the most difficult concepts in an easy to understand style. He is really an ideal teacher to be followed.

I would also like to mention the company of so many good friends and colleagues at the University of Göttingen (not possible to mention all of them by name) who gave their sincere input and help during the course of my project. I would like to extend my thanks to all the colleagues at the chair of Development Economics (of Prof. Klasen), most notably, Ahmad Nawaz, Dr. Dirk Herzer, Yvonne Sperlich, Dr. Ken Harttgen. Dr. Mark Misselhorn, Dr. Julian Weisbrod, Jan Priebe and Sebastian Vollmer. My friend Dr. Sajid Malik (at the University of Marburg) was a constant source of inspiration for me and I enjoyed his company a lot during my stay in Germany.

I am also thankful to the Higher Education Commission (HEC) of Pakistan and DAAD in Germany for providing financial support for my Doctoral studies.

Last, but not the least, my family was with me here in Göttingen and gave me much comfort during all these tiring years. I am thankful to my wife and my three children who gave me many moments of pleasure and mental peace, and in return also endured with me the hard times of living away from the comforts of our home back in Peshawar. I shall always remember these memorable moments that I spent along with my family in Germany. I would particularly mention our youngest daughter Maimoona who was born here in Göttingen during my Ph.D. studies and in whose form, we got many moments of happiness. I would like to thank my parents back in Pakistan who always kept praying for my success and well-being. They are a constant source of strength and affection in my life. And they are, naturally, the one to whom I would like to dedicate this thesis.

\section{Mohammad Asim Syed}

Göttingen, den 8. April 2008. 


\section{Contents}

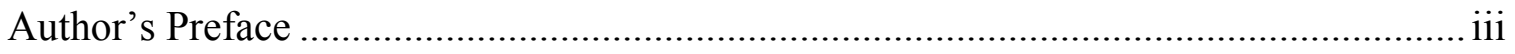

List of Tables .................................................................................................. vii

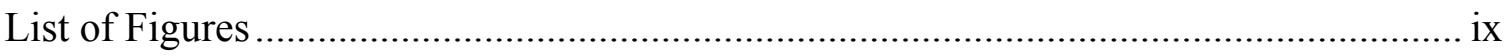

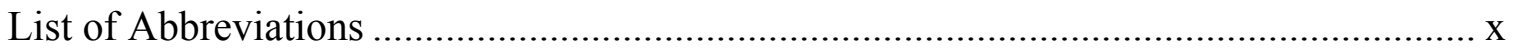

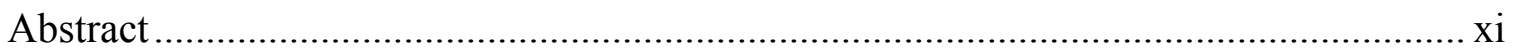

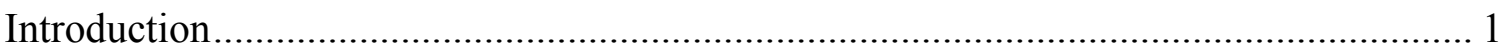

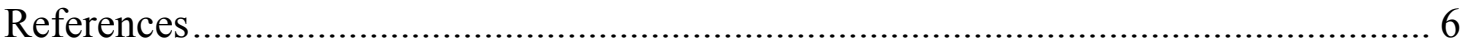

1 Determinants of Gender Differences in Infant and Child Mortality in Pakistan ............. 8

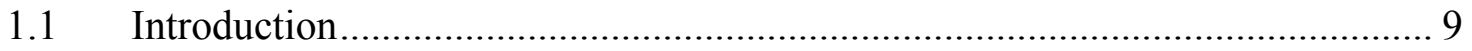

1.1.1 Strategies versus Causes of Gender Bias in Mortality......................... 10

1.1.2 Gender Bias in Mortality in Pakistan................................................... 12

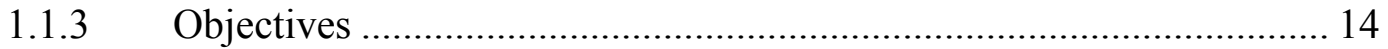

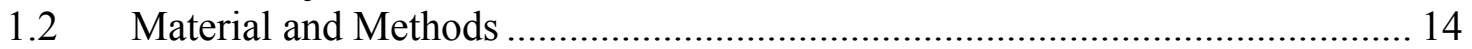

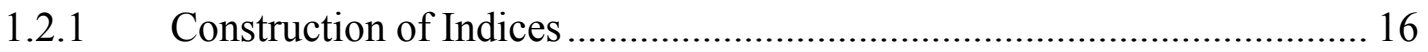

$1.3 \quad$ Empirical Framework ................................................................................ 17

1.3.1 Discrete Time Survival Model........................................................... 17

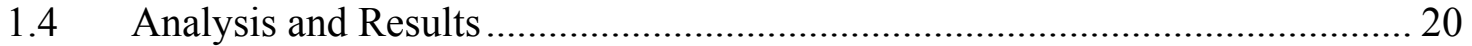

1.4.1 Results: fixed and smooth effects for children 0-3 years of age ............... 20

1.4.2 Results: fixed and smooth effects for children 1-3 years of age ............... 23

1.4.3 Results: fixed and smooth effects for Infants ......................................... 26

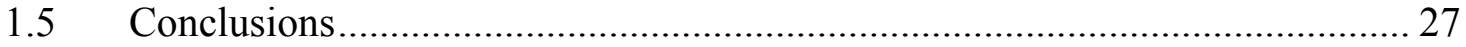

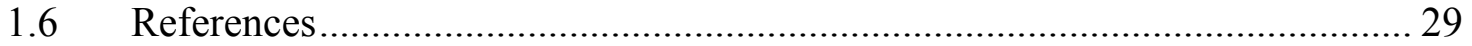

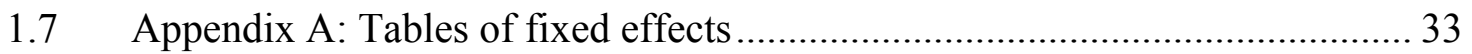

1.8 Appendix B: Smooth effects of non-parametric functions .................................... 36

2 Gender Bias in Mortality in Pakistan: Trends and Determinants 1990-2000 ................ 42

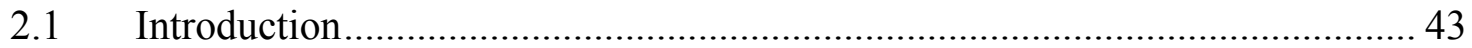

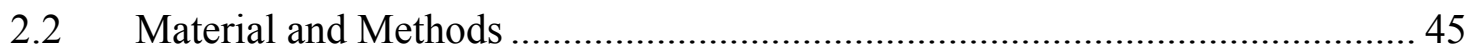

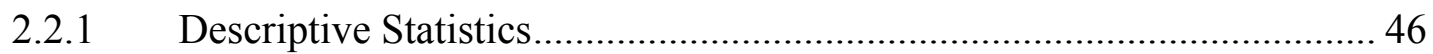

$2.3 \quad$ Empirical Framework …………................................................................ 48

2.3.1 Structured Hazard Regression Model ..................................................... 48

2.3.2 Prior Specifications ............................................................................. 49

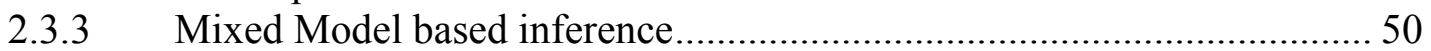

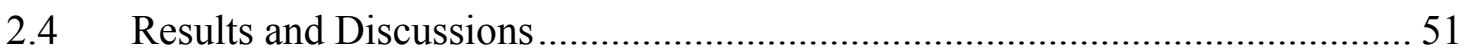

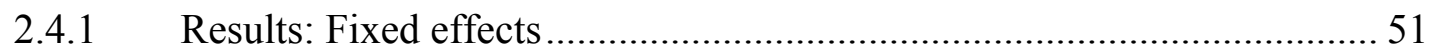

2.4.2 Results: Smooth (non-parametric) effects ................................................... 56

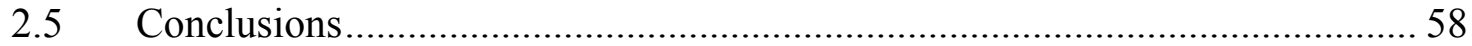

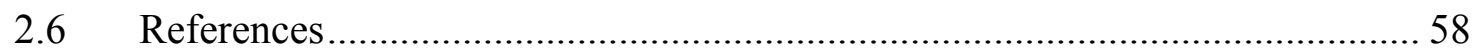

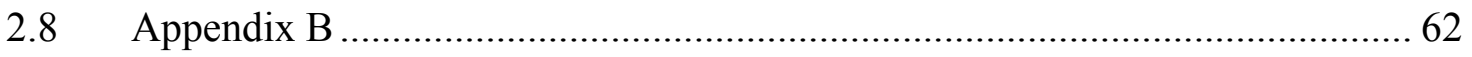




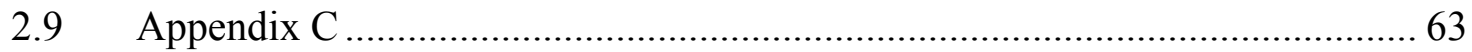

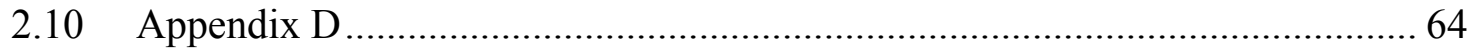

3 Determinants of Undernutrition in Pakistan: An Investigation into Gender Differentials

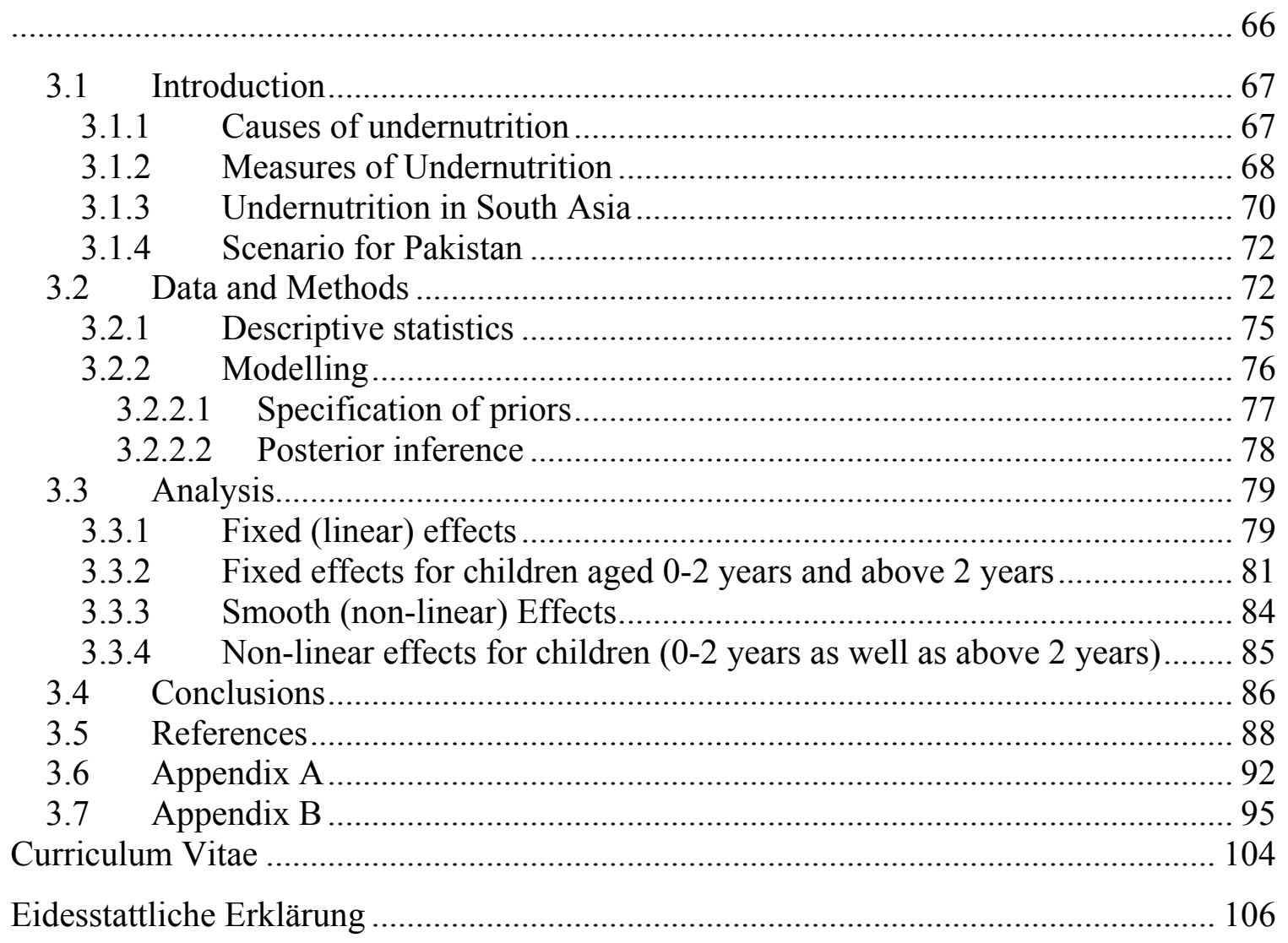




\section{List of Tables}

Table1. 1 Sex Ratios in Pakistan................................................................................ 13

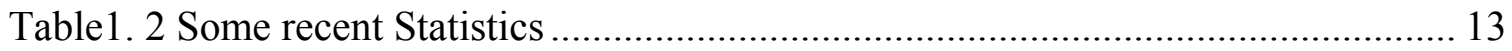

Table1. 3 Infant and Child Mortality rates for Pakistan from the DHS data .................... 13

Table1. 4 Variables included in the analysis ............................................................ 15

Table A 1 Fixed effects for Children aged 0-3 years...................................................... 33

Table A 2 Fixed effects for Female Children aged 0-3 years ............................................. 33

Table A 3 Fixed effects for Male Children aged 0-3 years................................................ 33

Table A 4 Fixed effects for Children aged 1-3 years...................................................... 34

Table A 5 Fixed effects for Female Children aged 1-3 years ........................................... 34

Table A 6 Fixed effects for Male Children aged 1-3 years............................................ 34

Table A 7 Fixed effects for Infants (aged under 1 year).................................................... 35

Table A 8 Fixed effects for Female Infants ............................................................... 35

Table A 9 Fixed effects for Male Infants.................................................................... 35

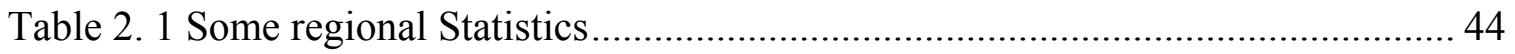

Table 2. 2 Infant and Child Mortality based on the two selected surveys ........................ 46

Table 2. 3 Categorical variables included in the analysis............................................... 47

Table 2. 4 Continuous variables included in the analysis................................................. 48

Table 2. 5 Fixed effects for Female and Male Children (under 3) from PDHS ............... 53

Table 2. 6 Fixed effects for Female and Male children (under 3) from PRHFPS ............. 53

Table 2. 7 Fixed effects for Female and Male Children (over 1 and under 3) from PDHS

Table 2. 8 Fixed effects for Female and Male children (over 1 and under 3) from

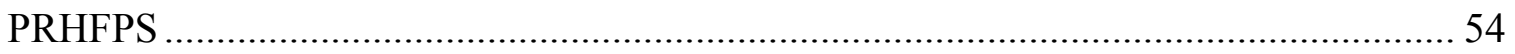

Table 2. 9 Fixed effects for Female and Male Infants from PDHS …………………...... 56

Table 2. 10 Fixed effects for Female and Male Infants from PRHFPS ............................ 56

Table 3. 1 Under five mortality and levels of undernutrition in selected regions ........... 71

Table 3. 2 Under five mortality and rates of undernutrition in South Asia ...................... 72

Table 3. 3 Categorical variables selected for the study ……………………………......... 74

Table 3. 4 Continuous variables selected for the study ……………………………....... 74

Table 3. 5 Rates of Undernutrition by Gender (PDHS 1990-91) .................................... 75 
Table 3. 6 Rates of Undernutrition by Region (PDHS 1990-91) .................................. 75

Table A3. 1 Posterior means, S.D. and 80\% Credible Interval: All children .................. 92

Table A3. 2 Posterior means, S.D. and 80\% Credible Interval: Female children ........... 92

Table A3. 3 Posterior means, S.D. and 80\% Credible Interval: Male children................ 92

Table A3. 4 Posterior means, S.D. and 80\% Credible Interval: Children (0-2 years)...... 93

Table A3. 5 Posterior means, S.D. and 80\% Credible Interval: Female children (0-2

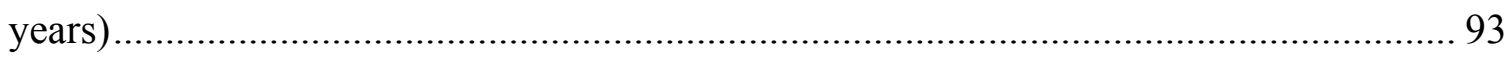

Table A3. 6 Posterior means, S.D. and 80\% Credible Interval: Male children (0-2 years)

Table A3. 7 Posterior means, S.D. and 80\% Credible Interval: Children (above 2 years)

Table A3. 8 Posterior means, S.D. and 80\% Credible Interval: Female children (above 2 years)

Table A3. 9 Posterior means, S.D. and 80\% Credible Interval: Male children (above 2 years) 


\section{List of Figures}

Figure B1. 1 Smooth effects for children aged 0-3 years …………………………......... 36

Figure B1. 2 Smooth effects for children aged 0-3 years (by gender).............................. 37

Figure B1. 3 Smooth effects for children aged 1-3 years ............................................. 38

Figure B1. 4 smooth effects for children aged 1-3 years (by gender) ............................ 39

Figure B1. 5 Smooth effects for Infants..................................................................... 40

Figure B1. 6 Smooth Effects for Infants (by gender) ……………………………….... 41

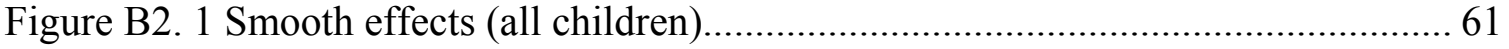

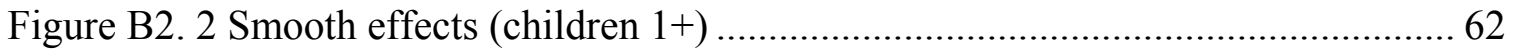

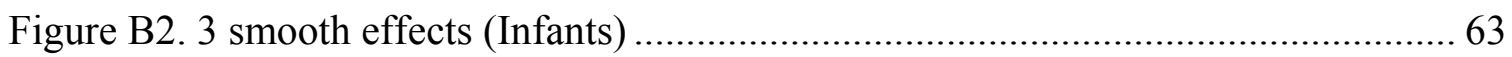

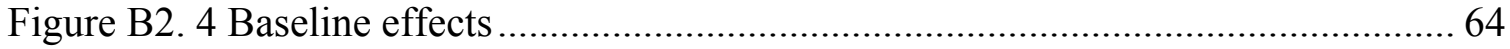

Figure 3. 1 UNICEF Conceptual Framework for causes of malnutrition (1998) ............. 68

Figure B3. 1 Non-linear effects (All children).............................................................. 95

Figure B3. 2 Non-linear effects for female children......................................................... 96

Figure B3. 3 Non-linear effects for Male children ...................................................... 97

Figure B3. 4 Non-linear effects for Children (0-2 years) ………………………….... 98

Figure B3. 5 Non-linear effects for Female Children (0-2 years)................................... 99

Figure B3. 6 Non-linear effects for Male Children (0-2 years) ……………………... 100

Figure B3. 7 Non-linear effects for Children (above 2 years) ....................................... 101

Figure B3. 8 Non-linear effects for Female Children (above 2 years) .......................... 102

Figure B3. 9 Non-linear effects for Male Children (above 2 years) .............................. 103 
List of Abbreviations

$\begin{array}{ll}\text { AI } & \text { Asset Index } \\ \text { CDC } & \text { Centre for Disease Control and Prevention } \\ \text { DHS } & \text { Demographic and Health Survey } \\ \text { HSB } & \text { Health Seeking Behaviour Index } \\ \text { MDG } & \text { Millennium Development Goals } \\ \text { NCHS } & \text { National Centre for Health Statistics } \\ \text { NIPS } & \text { National Institute for Population Studies } \\ \text { PDHS } & \text { Pakistan Demographic and Health Survey } \\ \text { PRHFPS } & \text { Pakistan Reproductive Health and Family planning Survey } \\ \text { U5M } & \text { Under five Mortality } \\ \text { UNDP } & \text { United Nations Development Programme } \\ \text { UNICEF } & \text { United Nations Children Fund } \\ \text { USAID } & \text { United States Agency for International Development } \\ \text { WHO } & \text { World Health Organisation }\end{array}$




\begin{abstract}
Child Mortality and Undernutrition are the two major public health problems in the developing world. An associated phenomenon is gender discrimination against the female child. South Asia, in particular, suffers from worst forms of gender discrimination against daughters in access to health care and nutrition. This dissertation explores these two issues in Pakistan and empirically investigates the determinants of gender differentials in mortality and undernutrition. Recently developed Bayesian structured additive models are estimated using two micro datasets from Pakistan.
\end{abstract}





\section{Introduction}

Child Mortality and undernutrition are two major public health problems faced by countries in the developing world today. The United Nations' Millennium Development Goals (MDGs) specifically address these issues and recommend plans of action and targets for reducing/ eliminating these problems. The MDGs are eight goals to be achieved by 2015 that respond to the world's main development challenges. The goals are the outcome of the targets and actions set in the Millennium Declaration adopted by the Millennium Summit in September 2000. The 8 MDGs break down into 18 quantifiable targets that are measured by 48 indicators (UNDP, 2008). The target date for achieving these goals has been set at 2015. Goal 1 relates to eradicating extreme poverty and hunger, whereas goal 4 relates to reduction of child mortality. It has been agreed to reduce by half the proportion of people living below the poverty line (less than $\$ 1$ a day) as well as those who suffer from hunger. Similarly, goal 4 concentrates on reducing by two thirds the mortality rate among children under 5 . One of the indicators for achieving reduction in hunger is the prevalence of underweight children under five years of age. The indicators for goal 4 are chosen to be the under-five mortality rate and the infant mortality rate.

Child as well as infant mortality remains higher in the developing world despite a considerable decline in mortality levels in the last decades. According to the latest State of the World Children Report (UNICEF 2008), approximately 26000 children are dying each day around the world mostly from preventable causes and one third of these deaths occur in first month of life. Nearly all of these deaths occur in 60 developing countries. Moreover, nearly half of the under-five deaths are due to undernutrition. Sub-Saharan Africa is the region worst hit by higher under-five mortality followed by South Asia. Similarly, undernutrition remains to be grave public health problem in developing world with South Asia having the most affected region followed by Sub-Saharan Africa. In fact, more than half of the underweight children in the world live in only three countries of South Asia, namely India, Pakistan and Bangladesh (UNICEF, 2008). 
Another issue at stake is gender equality. Gender discrimination has been part of every culture and it is still pervasive in many parts of developing world. In particular, the regions where gender discrimination is still visible in various forms are South and SouthEast Asia, and parts of the Middle East and North Africa. The gender discrimination against girl child is deeply rooted in the culture of mentioned regions. Sons are preferred over girls due to many reasons. In general, sons are considered to be better investment in future, as an old-age security and means of better social standings, whereas daughters are considered to be expensive specifically in regions (such as South Asia) where the parents have to give a dowry to the family of the bridegroom at the time of marriage of the daughter. In these cultures, the daughter has to leave her parents' home after marriage and to live with and serve her husband's family. So parents may consider girls as poor returns to investment. Another reason is lower access to the labour market for women as compared to males. All these factors lead certain behaviour patterns on the part of the parents which result in discrimination against the girl child in the form of lower access to adequate nutritional supplement and health care. So the girls are less likely to be taken to a health facility when sick relative to the same case for boys, and are more likely to be treated at home with certain home remedies. Poverty and lack of education of the mother may also reinforce such behaviour patterns. The consequence is the poor nutritional status of girls and in extreme forms of gender discrimination results into the death of the girl child. Such issues have been extensively studied by various researchers (Belitz et.al. 2007; Das Gupta, 1987; Das Gupta and Bhat, 1997; Kishor, 1993, 1995; Klasen and Wink, 2002, 2003, Murthi et.al., 1995; and many more). The Noble Laureate Economist Prof. Amartya Sen (1990) in his seminal work on the issue introduced the term "Missing Women" to refer to the additional number of women expected to be alive today in the absence of any past or present discrimination, and provided the figure to be nearly 100 million. Further work by Coale (1991), Klasen(1994) and Klasen and Wink (2002, 2003) elaborated the issue raised by Sen and arrived at better estimates of the number of "Missing Women" using model life tables. Similarly, abundant literature is now available that focuses on levels of undernutrition among children (under five years of age) and some of them have focused on the gender differentials of undernutrition in order to determine any gender discrimination against the girl child (Klasen, 1996; Mishra et.al., 
1999; Menon et.al. 2000; Kandala et.al. 2001, 2002; Maleta, 2006; and many more). Most popular measures used are the anthropometric indices of height-for-age, weight-forheight, and weight-for-age commonly known as stunting, wasting and underweight respectively. Klasen $(1999,2007)$ has pointed an important puzzle when comparing the mortality and undernutrition phenomena for South Asia and Sub-Saharan Africa. While mortality levels are much higher in Sub-Saharan Africa as compared to South Asia, the opposite is the case for undernutrition where the undernutrition levels are far greater in South Asia relative to the Sub-Saharan Africa. This issue has also been discussed by Harttgen and Misselhorn (2006).

Most of the studies on mortality and undernutrition differentials have been conducted on India where much work is still going on. Some studies have also focused on Bangladesh and Nepal. Comparatively, few studies have been carried out on Pakistan, a country where gender discrimination against the girl child is believed to be stronger than that in India and other South Asian countries. More specifically, studies based on microdata at the household level are rare. In fact, Pakistan with an under-five mortality rank of 42 has the highest mortality rate (97 per 1000 live births) in South Asia (UNICEF, 2008). In comparison to mortality levels, the undernutrition levels (more specifically, stunting) are relatively lower in Pakistan in comparison to other South Asian counterparts. There is, however, a need not only to study the levels and determinants of mortality and undernutrition in Pakistan but also look at the gender-specific differentials in order to determine the pattern and extent of gender discrimination, if any, against the girl child.

The present dissertation, therefore, is an attempt to contribute to the active research of gender discrimination in mortality and undernutrition with a focus on Pakistan. Two datasets, namely, from Pakistan Demographic and Health Survey (PDHS) of 1990-91 and that from Pakistan Reproductive Health and Family Planning Survey (PRHFPS) of 200001 have been used for the analysis. For our analysis, new datasets were created from the available datasets by constructing new variables. The dissertation basically consists of three papers mentioned here as essays 1,2, and 3 respectively. The planning of the thesis is as following:

Essay 1 deals with the determinants of gender differentials of infant and child mortality in Pakistan using the PDHS 1990-91 data. The data analysis were restricted to children 
aged 3 years or below because only one death occurred beyond 36 months of age. Recently developed techniques of Bayesian Structured Hazard Regression using MCMC methodology (Fahrmeir and Lang, 2001; Brezger and Lang, 2006) were applied for data analysis. Results indicated that on the whole, mortality was higher for male children and infants as compared to female children/ infants. However, there is an excess female mortality in the age range 1-3 years. The result was though statistically insignificant. Furthermore, we observed that higher age of mother (at the birth of her child), longer birth interval, full vaccination coverage, socio-economic status of the household, education and health seeking behaviour of mother play an important role in reducing infant and child mortality. In particular, higher socio-economic status of the household contributes to the survival of female children whereas positive health seeking behaviour of the mother has a more conducive effect on the survival of male children.

Essay 2 attempts to explore the trends and determinants of gender bias in Pakistan over a period of time (1990-2000) with the purpose of seeing whether gender discrimination has changed over time and what are the basic patterns of such effect. For this purpose, we have taken the dataset from the Pakistan Reproductive Health and Family Planning Survey (PRHFPS) 2000-2001, which is ten years apart from the Pakistan Demographic and Health Survey (PDHS) 1990-1991. As the data analysis based on PDHS was restricted to children aged three years or below, we did the same for the PRHFPS. Further, the data analysis based on PRHFPS was restricted to the years 1991 and above so as to avoid any overlapping with the results from PDHS data. For the data analyses, we have used the Bayesian Structured Hazard Regression model using mixed-model methodology (Kneib and Fahrmeir, 2006). Results indicated that although the mortality levels have dropped in the ten year period, the overall pattern of gender differentials remains almost unchanged. Notable exceptions being the higher mortality associated with higher age of the mother and low mortality in urban areas for the data in the PRHFPPS 200-01 as compared to that of PDHS 1990-91. Further, we noted that mother's education now has a more significant impact on the mortality reduction of her children and this effect is more dominant for the girl child. This perhaps indicates that with the passage of time, improved access to education by the mother has brought significant improvement in the mortality of children, in particular, the girl child. 
Essay 3 deals with the study of gender differentials in undernutrition in Pakistan using the Pakistan Demographic and Health Survey (PDHS) 1990-91 data. The data for the analysis were restricted to all children aged under five who were alive and on whom exact anthropometric information (such as height, weight and age) were available. Stunting (insufficient height-for-age) was considered as a response variable. Bayesian semi-parametric regression model (Fahrmeir and Lang, 2001; Brezger and Lang, 2006) was used for the data analysis. The data analyses were first performed for all under-five children. Keeping in view the nature of the reference population, the dataset was separately analyzed for the age groups $0-2$ years and above 2 years. Gender-wise models were fitted to examine the gender differential in undernutrition. Results indicate that education of mother, long birth interval, and full vaccination coverage, better economic conditions of the household and positive health seeking behaviour of the mother play an important role for better nourishment of the children, most of them having stronger effect for the girl child. Splitting the data into two age groups indicated that there is an excess female undernutrition in the age group above two years. We suspect that this might reflect gender bias against female children in access to nutrition.

The thesis would hopefully add to the active research area of "gendered" approach towards mortality and undernutrition with reference to Pakistan and may also add to the ongoing efforts of gender mainstreaming and women empowerment by the Government of Pakistan as well as other sections of the civil society. 


\section{References}

Belitz, C., Hübner, J., Klasen, S. and Lang, S. (2007). Determinants of the Socioeconomic and spatial pattern of undernutrition by sex in India: A geo-additive semiparametric regression approach. Working paper, Department of Statistics, University of Munich.

Brezger, A. and Lang, S. (2006). Generalized Structured Additive Regression based on Bayesian P-Splines. Computational Statistics and Data Analysis, 50, 967-991.

Coale, A. J. (1991). Excess female mortality and the balance of the sexes in the population: An estimate of the number of missing females. Population and Development Review, 17, 517-523.

Das Gupta, M. (1987). Selective discrimination against female children in rural Punjab, India, Population and Development Review 13(1): 77-100.

Das Gupta, M. and Bhat, P.N.M. (1997). Fertility decline and increased manifestation of sex bias in India, Population Studies 51(3): 307-315.

Fahrmeir, L. and Lang, S. (2001). Bayesian Inference for Generalized Additive Mixed Models Based on Markov Random Field Priors. Applied Statistics (JRSS C), 50, 201-220.

Harttgen, K. and M. Misselhorn (2006). A multilevel approach to explain child mortality and undernutrition in South Asia and Sub-Saharan Africa. Mimeographed, University of Göttingen.

Kandala, N.B., S. Lang, Klasen,S. and Fahrmeir, L. (2001). Semiparametric Analysis of the Socio-Demographic Determinants of Undernutrition in Two African Countries. Research in Official Statistics, EUROSTAT, Vol. 4 No.1:81-100

Kandala, N.B., L. Fahrmeir, and S. Klasen (2002). Geo-additive models of Childhood

Undernutrition in three Sub-Saharan African Countries. Sonderforschungsbereich 386:

Discussion Paper no. 287., Deutsche Forschungsgemeinschaft.

Kishor, S. (1993). May god give sons to all: Gender and child mortality in India, American Sociological Review 58(2): 247-265.

Kishor, S. (1995). Gender Differentials in Child Mortality: A Review of the Evidence, Pp. 19-54 in Women's Health in India: Risk and Vulnerability, edited by M. Das Gupta, L.C. Chen, and T.N. Krishnan. Bombay: Oxford University Press. 
Klasen, S. (1994). Missing Women Reconsidered. World Development. 22: 1061-71.

Klasen, S. (1996). Nutrition, Health, and Mortality in Sub-Saharan Africa: Is there a Gender Bias? Journal of Development Studies 32: 913-932.

Klasen, S. (2000). Malnourished and low mortality in South Asia, better nourished and dying young in Africa: What can explain this puzzle? SFB 386 Discussion Paper No. 214. University of Munich.

Klasen, S. and Wink, C. (2002), A Turning Point in Gender Bias in Mortality? An Update on the Number of Missing Women, Population and Development Review, 28, 285-312.

Klasen,S. and Wink, C.(2003). Missing women: revisiting the debate. Feminist Econ 9: 263-300.

Klasen, S. (2007). Poverty, undernutrition, and child mortality: Some inter-regional puzzles and their implications for research and policy. Journal of Economic Inequality, (1): 89-115.

Kneib, T and Fahrmeir, L. (2006). A mixed Model Approach for Geoadditive Hazard Regression. Scandinavian J.Stat., 34, 207-228.

Maleta, K. (2006). "Epidemiology of Undernutrition in Malawi", chapter 8 in The Epidemiology of Malawi, edited by Eveline Geubbles and Cameron Bowie, available on http://www.medcol.mw/commhealth/publications/epi\%20book/Undernutrition\%20chapte r\%208.pdf .

Mishra, V., S. Lahiri, and N. Luther (1999). Child Nutrition in India. National family health survey subject reports number 14, International Institute for Population Sciences. Mumbai, India. East-West Center, Population and Health Studies, Honolulu, Hawaii, U.S.A.

Menon, P., Ruel, M., \& Morris, S. (2000). Socio-economic differentials in child stunting: Results from 11 DHS data sets. Food and Nutrition Bulletin, 21(3), 282-289.

Murthi, M., Guio, A., and Dreze, J. 1995. Mortality, fertility and gender bias in India: A district-level analysis, Population and Development Review 21(4): 745-781.

Sen, A. (1990), "More Than 100 Million Women Are Missing", The New York Review of Books, December $20^{\text {th }} 1990$.

UNDP (2008). http://www.undp.org/mdg/basics.shtml .

UNICEF (2008). State of the World Children 2008. New York: UNICEF. 


\title{
Essay 1
}

\section{Determinants of Gender Differences in Infant and Child Mortality in Pakistan}

\begin{abstract}
South Asia is a region marred by extreme levels of gender bias against female children. The most severe form of such gender bias exists in the form of gender differences in mortality leading to excess female mortality. This paper looks into the phenomena for Pakistan and tries to document the extent and determinants of gender differentials in infant and child mortality in Pakistan using the Pakistan Demographic and Health Survey 1990-91. Use of Bayesian structured hazard regression model indicates that higher age of mother (at the birth of her child), longer birth interval, full vaccination coverage, socio-economic status of the household, education and health seeking behaviour of mother play an important role in reducing infant and child mortality. In particular, higher socio-economic status of the household contributes to the survival of female children whereas positive health seeking behaviour of mother has more conducive effect on the survival of male children.
\end{abstract}




\subsection{Introduction}

Gender discrimination against the females has been present in every culture in various degrees and is still pervasive in many parts of the world, notably, North Africa and South/Southeast Asia, despite economic and social development. This gender bias against the females manifests itself in many forms such as low access to health care, nutrition, education, and job market. The most serious of the gender bias is the gender bias in mortality, also referred to as Excess Female Mortality (EFM). More specifically, it refers to the mortality of females that is due to gender inequities in the access to survival-related resources and opportunities (such as food, health care, clean water, clear air etc). If females get less access to food or health care than males, or if they are, compared to males, forced to spend more of the time in unsafe environments (at home or at work), the resulting mortality is then referred to as 'excess female mortality' (Klasen and Wink, 2003).

The debate on the gender bias in mortality gained worldwide attention when Amartya Sen (1990) coined the phrase "Missing Women". He estimated that about 100 million women were "missing" as a result of "excess female mortality" in parts of South Asia, Middle East/ North Africa and China. Using the female survival patterns of the SubSaharan Africa (a region with negligible gender bias) as a standard, he estimated, for South Asia, China, the Middle East and North Africa, the number of women that would have been alive if there was no gender discrimination in the allocation of survival related goods. This number turned out to be close to 100 million which he referred to as the "Missing Women" (Klasen and Wink, 2003). This number, in a way, was proposed to asses the cumulative impact of gender bias in mortality. This seminal work of Sen opened gateway for a new and exciting area of research in the development economics and related fields. Important contributions/improvements were made by Coale (1991), Klasen (1994), Klasen and Wink (2003). Since then, numerous studies have been conducted in various parts of the world, India being at the forefront, for determining and explaining the phenomena of gender bias and son preference. 


\subsubsection{Strategies versus Causes of Gender Bias in Mortality}

Gender Bias is more striking at the childhood level. This can be partly explained in terms of the deep rooted socio-economic and cultural practice of son preference and partly due to other factors. Some of the underlying mechanisms are:

Pre-birth strategies: Parents may decide a deliberate "fertility strategy" whereby they can influence the sex composition of their offspring. According to this strategy, parents may decide on the desired number of children depending on how many children of a particular sex (usually the male children) they want to have. Once they reach the desired number of sons, they may stop producing more. The official one-child policy in China is a classic example where parents would stop having further children if a male baby is born (Klasen, 2003). The stopping rule may be subjective and reflects, in a way, the socioeconomic needs of parents to have desired number of sons. An extreme form of such a pre-birth strategy which is increasing in alarming proportions in parts of India and South East Asia is "Sex-selective abortions". Modern medical technology has now made it possible to know the sex of the child before birth. In regions with high gender bias against the female child, the horrible practice of "killing" (aborting) the female child before even her birth has become a grave public health concern.

\section{Post-birth strategies:}

Possible post-birth strategies adopted by parents for influencing the sex composition of their children include (sex-specific) infanticide, adoption, or differential neglect (Klasen, 2003).

Sex-specific infanticide (usually of female children) has been practiced in the past in many cultures. However, in modern times, it has become very rare. As a consequence, its contribution to the overall size of imbalance in the population sex ratios is negligible (Hausfater and Hrdy, 1994).

Klasen (2003) also mentions that the parents may adopt in/out children of a particular sex. In historical aristocratic families, this was a common practice for having child of a particular sex (usually male). The same method is also known to have been used by the parents in China for complying with the one-child policy. They may adopt in a son by adopting out their daughter with another family (Johannsson and Nygren, 1991). 
Sex-specific neglect refers to gender discrimination in preferential treatment of boys over the girls in as far the access to health care and nutrition is concerned. The higher than expected female mortality as compared to males (also called the excess female mortality) is a direct consequence of preferential treatment of son over daughters in case of access to health care. This phenomenon is commonly practiced in societies having strong son preference (Klasen, 2003). In case of illness, parents, having limited resources, tend to be more willing for the medical treatment of boys as compared to girls. The same, though not very stronger, is the case with nutrition. The end result is that girls are malnourished leaving them more exposed to illness and death.

The mentioned strategies can be elaborated in terms of various causes that explain the rationale for particular behavioural response on part of the parents. Son preference, in fact, is a complex issue and many cultural, behavioural and socio-economic factors are responsible for the phenomenon. There exists abundant literature on the issue (Abeykoon, 1995; Ali, 1989; Bairagi, 1994; Cain, 1984; Ehrlich and Lui, 1991, 1997, 1998; Karim, 1994; Khan and Serageldin, 1977; Nugent, 1985; Nugent and Anker, 1990; Schultz, 1997; and many more). The causes can be summarized into following:

(a) Sons as old age security: In traditional conservative societies, with no public safety nets, sons are considered as old age financial security. In such societies, parents usually live with their sons, in most cases with eldest one. The daughters live with their husband's parents after the marriage and are supposed to look after her husband's family. Thus sons are considered as a guaranty for old age security.

(b) Returns to investment: Sons have better returns to investment as compared to daughters. Sons are more likely to get into the labour market and with a better wage structure.

(c) Social returns: In regions of South Asia and South-East Asia, cultural factors such as kinship systems and religious traditions also tend to value males more highly than females. In a more traditional tribal society, sons are means for social returns. A household with more sons is considered to be a source of strength and desirable for better standing in social relationship. Further, in case of conflicts and cases of inheritance, sons are preferred over daughters in the context of prevailing cultural norms. 
(d) Relative costs of investments (Dowry for girls): In societies with common practice of Dowry, girls are much more expensive. Parents have to pay dowry at the time of marriage of their daughters.

\subsubsection{Gender Bias in Mortality in Pakistan}

The phenomenon of gender bias in mortality in South Asia is now well documented. However, most of these studies are in the context of India where people have identified a clear North-South-divide in the incidence of gender bias. The phenomenon is more pronounced in the northern Indian states as compared to the southern states. There is, however, a shortage of literature on Pakistan with regard to gender bias in mortality. The studies so far conducted mainly deal with child and infant mortality but not from a gender perspective. However, one notable study on this aspect is that of Gangadharan \& Maitra (2000) who studied the determinants of infant and child mortality in Pakistan using the data from the Pakistan Household Integrated Economic Survey (PHIES) 2000-01. They concluded that the higher mortality for female children above one year may reflect gender bias in mortality.

The phenomenon of gender bias in mortality in Pakistan is, in fact, relatively stronger than India and other South Asian neighbours. The fact comes from Sen (1990) which indicates that Pakistan has the largest percentage (9.1\%) of missing women. The actual value of the percentage has since then decreased from $9.1 \%$ to $7.8 \%$. Using the Population Census 1998 data, covering the period from 1981 to 1998, Klasen and Wink (2003) updated this number and the number of missing women in Pakistan was estimated to be 4.9 million. With such a large number of "Missing Women", it is, therefore, worth studying the phenomenon of gender bias of mortality in Pakistan and the underlying factors responsible for such a gender bias against the females.

Before going further into our main theme, let us look at some statistics showing the human and gender situation in Pakistan along with some South Asian regional outlook.

In the most recent population census (1998), Pakistan's overall sex ratio was 922 females per 1000 males (see table 1.1). 
Table1. 1 Sex Ratios in Pakistan

\begin{tabular}{|l|l|l|}
\hline & Juvenile Sex Ratio (0-4)* & Overall Sex Ratio $^{*}$ \\
\hline 1961 Census & 0.9566 & 0.8633 \\
\hline 1972 Census & 0.9921 & 0.8705 \\
\hline 1981 Census & 1.0279 & 0.9042 \\
\hline 1998 Census & 0.9586 & 0.9216 \\
\hline
\end{tabular}

Source: 1961, 1972 Feeney and Alam (2003)

* Number of females per 1 male

Table1. 2 Some recent Statistics

\begin{tabular}{|c|c|c|c|c|c|}
\hline & Bangladesh & India & Nepal & Pakistan & Sri Lanka \\
\hline Under-5 mortality rank & 62 & 54 & 58 & 46 & 133 \\
\hline $\begin{array}{l}\text { Under-5 mortality } \\
\text { rate,1960 }\end{array}$ & 248 & 242 & 315 & 227 & 133 \\
\hline $\begin{array}{l}\text { Under-5 mortality } \\
\text { rate,2003 }\end{array}$ & 69 & 87 & 82 & 103 & 15 \\
\hline $\begin{array}{l}\text { Infant mortality rate } \\
\text { (under 1),1960 }\end{array}$ & 149 & 146 & 212 & 139 & 83 \\
\hline $\begin{array}{l}\text { Infant mortality rate } \\
\text { (under } 1 \text { ), } 2003\end{array}$ & 46 & 63 & 61 & 81 & 13 \\
\hline $\begin{array}{l}\text { Life expectancy at birth } \\
\text { (years), } 2003\end{array}$ & 62 & 64 & 60 & 61 & 73 \\
\hline HDI Rank, 2003 & 139 & 127 & 136 & 135 & 93 \\
\hline GDI Rank, 2003 & 105 & 98 & 106 & 107 & 66 \\
\hline
\end{tabular}

Source: HDR 2005

Table1. 3 Infant and Children Mortality rates for Pakistan from the DHS data

\begin{tabular}{|l|c|c|c|c|}
\hline & Number & $\begin{array}{c}\text { Infant Mortality } \\
\left({ }_{1} \mathbf{q}_{\mathbf{0}}\right)\end{array}$ & $\begin{array}{c}\text { Child Mortality } \\
\left.\mathbf{(}_{1} \mathbf{q}_{\mathbf{4}}\right)\end{array}$ & $\begin{array}{c}\text { Under-Five } \\
\text { Mortality (․․․ }\end{array}$ \\
\hline Female Children & 3255 & 86 & 37 & 119 \\
Male Children & 3173 & 102 & 22 & 122 \\
Both sexes & 6428 & 94 & 29 & 120 \\
\hline
\end{tabular}

Source: Pakistan Demographic and Health Survey (PDHS) 1990-91

According to World Bank (2008), Pakistan's economy has grown by $6.5 \%$ per year since 2003. Despite this impressive turn around in economic growth, Pakistan has been the worst performer in reducing the levels of child and infant mortality. Table 1.2 indicates that Pakistan has the worst mortality indicators as compared to its other South Asian neighbouring countries. In comparison to 1960, when Pakistan was faring better in infant and child mortality than India, Nepal and Bangladesh (then East Pakistan), we observe that mortality situation has worsened relatively. Similarly, the gender index and further figures in tables 1.1 and 1.3 indicate that not only the sex ratios are more favourable for 
males but also the child mortality $\left({ }_{1} q_{4}\right)$ is higher for female children as compared to male children. All these facts emphasize the need for investigating an "engendered" approach to the phenomena of child mortality. It is known that female infants have a $10 \%$ to $15 \%$ survival advantage over male infants due to their respective biology. Females have two $\mathrm{X}$-chromosomes which help them to resist an infection or a disease even if one of the chromosomes is damaged. On the other hand, males have one $\mathrm{X}$ and one $\mathrm{Y}$ chromosome and thus are more vulnerable to an infection and greater risk of disease. This may partly explain the fact that the infant mortality rate is universally higher for males as compared to females. The same fact helps females to live longer (on the average) than males and thus we observe higher male mortality at older ages in comparison to that of females.

\subsubsection{Objectives}

The objective of the current work is to determine the socio-economic and demographic determinants associated with the gender gap in mortality in Pakistan for children as well as infants. It is desired to use recently developed Bayesian structured hazard regression models for investigating the phenomena. In general, the results are expected to aid in the ongoing efforts of the Government of Pakistan for gender equity and women empowerment.

\subsection{Material and Methods}

The data for the study were taken from the 1990-91 Pakistan Demographic and Health Survey (PDHS). This survey is part of the international DHS programme conducted by Macro International with the help of USAID. For Pakistan it was conducted in collaboration with the local organization called National Institute of Population Studies (NIPS), Ministry of Population Welfare, Islamabad (Pakistan). In the PDHS, a representative sample of 6611 ever-married women in the age range of 15-49 was taken from 8019 sampled households from all the four provinces of Pakistan. Detailed information on women's socio-economic background, birth histories and health status measures was obtained. For this paper, a new dataset was created from the DHS data where the child is taken as the unit of analysis. The dataset was created by extracting information from the mother's birth history and her personal biosocial characteristics as well as her health related behaviour. The sample of women contributed a total of 6428 
births in the five years preceding the survey on which this study is based. The survey shows that there were 526 deaths among the children born during the past five years. Of these, 452 deaths occurred during the first year of life (less than 12 months of age). For the current analysis, the data were restricted to deaths occurring up to age 3 . The reason is that there was only one death beyond age 3. So our aim was to determine gender differences in the age range 0-3 years. The analyses were further subdivided into analysis for children (under 3 years); children aged 1-3 years and infants (under 1 year).

Table1. 4 Variables included in the analysis

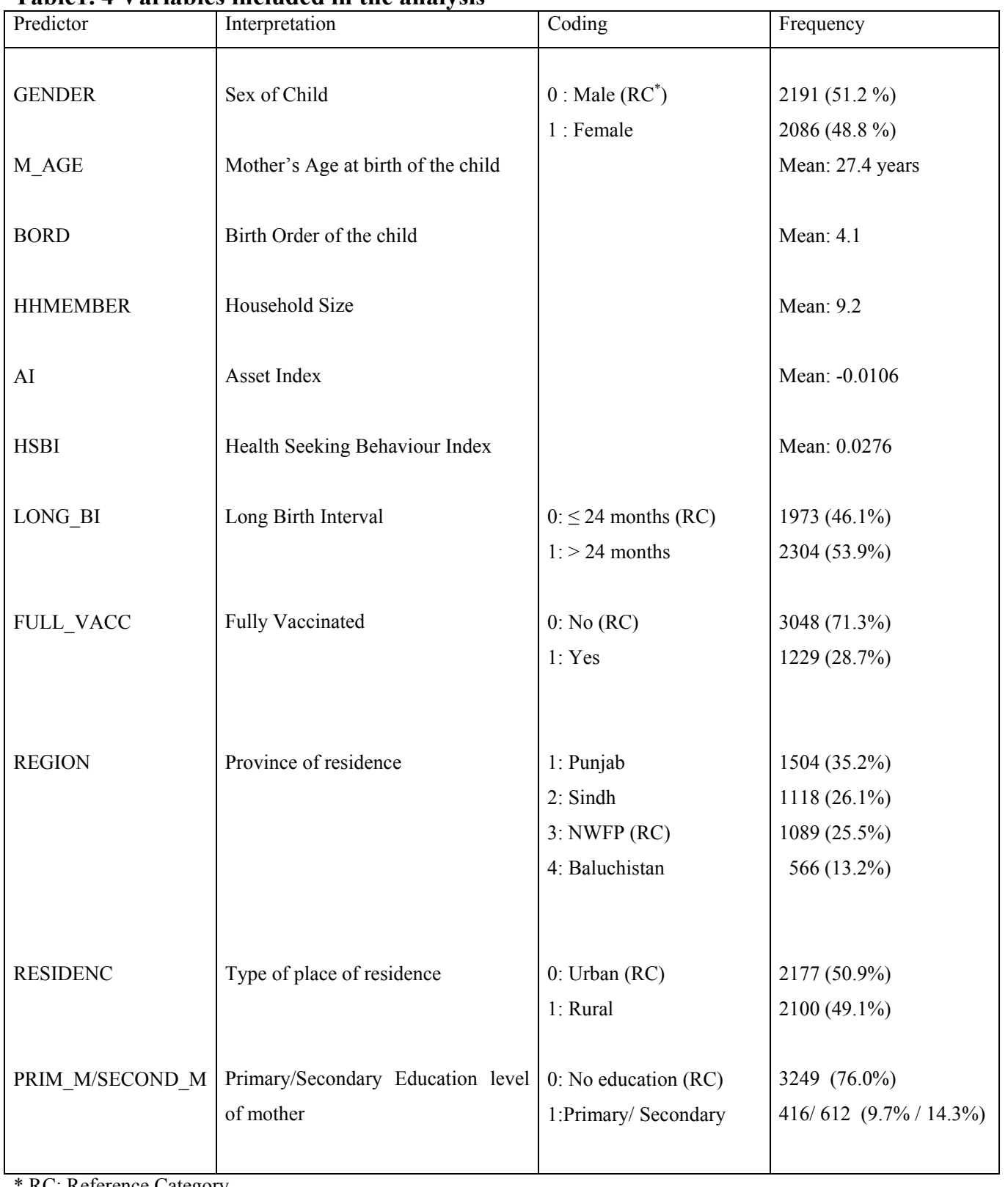




\subsubsection{Construction of Indices}

1. Asset Index: Keeping in view the problem of accuracy in collecting data on income or expenditure so as to capture the socio-economic status of the household, Filmer and Pritchett (2001) suggested using an asset index in the absence of either income or expenditure data. Several other techniques have also been proposed for getting the asset index such as Sahn and Stifel (2003) use factor analysis; Booysen et.al. (2005) make use of Multiple Correspondence Analysis (MCA); Kolenikov and Angeles (2004) use polychoric principal component analysis. Subsequent studies have extensively used the asset index as a possible determinant of infant and child mortality (e.g., Harttgen and Misselhorn (2006); Bawah and Zuberi (2004); Doctor (2004); and many more). As the DHS dataset does not contain any information on the income of the household where the index child lives, so we constructed an asset index from the possession of household valuables (such as having TV, radio, refrigerator, bike and bicycle), quality of the house currently living (such as the wall and roof material) and associated hygienic conditions (measured by the quality of the toilet, and source of drinking water). The index was constructed using factor analysis with the first factor score taken as the Asset Index For methodological details; see Sahn and Stifel $(2000,2003)$. This index was used as a proxy for income of the household in our analysis.

2. (Mother's) HSB Index: The (Mother's) health seeking behaviour index was constructed from the information on four variables, namely antenatal visits during pregnancy, tetanus injection before birth, place of delivery (a health facility or at home) and assistance at birth (whether the mother was assisted by a trained health professional). This index was also constructed through factor analysis and the first factor score was chosen as representing the (mother's) health seeking behaviour index (hsbi).

3. Vaccination Coverage: This variable was constructed to determine the effect of vaccination coverage on mortality. The variable, denoted by "full_vacc", is an indicator variable which was constructed by considering the total number of vaccinations "vacc_tot" (8 in all) up to certain age (in months). The variable was constructed as follows: 
(i) For the age group 0-1 months, full_vacc $=1$ if vacc_tot $=1$

(ii) For the age group 2-3 months, full_vacc $=1$ if vacc_tot $>2$

(iii) For the age group 4-6 months, full_vacc $=1$ if vacc_tot $>5$

(iv) For the age group 7+ months, full_vacc $=1$ if vacc_tot $=8$

\subsection{Empirical Framework}

Mortality and its various determinants have been traditionally studied in a regression modelling framework. Initial studies mostly used the usual linear regression models which, however, are not appropriate in situations where the mortality information is given by a binary indicator of death or no death. Binary regression models (logit and probit) are, therefore, a logical alternatives. There are, however, problems, with logit and probit models, namely, that they do not take into consideration the information on the survival time. Hence, most studies now utilize the survival analysis techniques. Recently, Fahrmeir and co-researchers at the LMU Munich have proposed a Bayesian GeoAdditive modelling framework which encompasses most of the known regression models and improves upon their shortcomings. The proposed model is also called Bayesian semiparametric structured regression model. We shall make use of the discrete-time survival model in this framework (Adebayo, 2005).

\subsubsection{Discrete Time Survival Model}

Let $\mathrm{T} \in\{1,2, \ldots \ldots \ldots, 36\}$ denote survival time in months. Then $\mathrm{T}=\mathrm{t}$ denotes failure time (death) in month $t$. Suppose $x_{i t}$ is a vector of covariates up to month $t$, then the discrete hazard function is defined as:

$$
\lambda\left(\mathrm{t} \mid \mathrm{x}_{\mathrm{it}}\right)=\mathrm{P}\left(\mathrm{T}=\mathrm{t} \mid \mathrm{T} \geq \mathrm{t}, \mathrm{x}_{\mathrm{it}}\right)
$$

It is the conditional probability of death in month $t$ given that the child has reached month t. The associated discrete survivor function is given by

$$
\mathrm{S}\left(\mathrm{t} \mid \mathrm{x}_{\mathrm{it}}\right)=\mathrm{P}\left(\mathrm{T}>\mathrm{t} \mid \mathrm{x}_{\mathrm{it}}\right)=\prod_{t=1}^{k}\left(1-\lambda\left(t / x_{i t}\right)\right)
$$

Survival information on each child is recorded as $\left(t_{i}, \delta_{i}, x^{*}{ }_{i t_{i}}\right), i=1,2, \ldots \ldots \ldots . .4277, t_{i} \epsilon$ $\{1,2, \ldots \ldots 36\}$ is the observed lifetime in months, $\delta_{\mathrm{i}}$ is the survival indicator with $\delta_{\mathrm{i}}=1$ if child $\mathrm{i}$ is dead and $\delta_{\mathrm{i}}=0$ if it is still alive. Thus for $\delta_{\mathrm{i}}=1, \mathrm{t}_{\mathrm{i}}$ is the age of the child at 
death, and for $\delta_{\mathrm{i}}=0, \mathrm{t}_{\mathrm{i}}$ is the current age of the child at interview. $\mathrm{x}^{*}{ }_{\mathrm{it}_{\mathrm{i}}}=\left(\mathrm{x}_{\mathrm{it}}, \mathrm{t}=1, \ldots . . \mathrm{t}_{\mathrm{i}}\right)$ is the observed covariate sequence.

Discrete time survival models can be cast into the framework of binary regression models by defining binary event indicators $\mathrm{y}_{\mathrm{it}}, \mathrm{t}=1,2, \ldots \ldots \ldots \mathrm{T}$ with

$$
y_{i t}=\left\{\begin{array}{l}
1: \text { if } t=t_{i} \text { and } \delta_{i}=1 \\
0: \text { if } t<t_{i}
\end{array}\right.
$$

The hazard function for child i can then be written as a binary response model

$$
\mathrm{P}\left(\mathrm{y}_{\mathrm{it}}=1 \mid \mathrm{x}_{\mathrm{it}}\right)=\mathrm{h}\left(\eta_{\mathrm{it}}\right)
$$

Where $\mathrm{x}_{\mathrm{it}}$ are the covariate processes for child $\mathrm{i}, \mathrm{h}$ is an appropriate response or link function, and the predictor $\eta_{\text {it }}$ is a function of the covariates.

Common choices for such survival models are the grouped Cox model, logit or probit models. We shall consider here the probit model.

The usual model is then

$$
\mathrm{P}\left(\mathrm{y}_{\mathrm{it}}=1 \mid \eta_{\mathrm{it}}\right)=\Phi\left(\eta_{i t}\right)
$$

With partially linear predictor

$$
\eta_{\mathrm{it}}=\mathrm{f}_{0 \mathrm{t}}+x_{i t}^{\prime} \gamma
$$

where $f_{0 t}$ is the baseline effect and $\gamma$ are fixed effect parameters.

The above semiparametric predictor can be generalized to an additive predictor

$$
\eta_{i t}=f_{0}(t)+\sum_{j=1}^{p} f_{j}\left(x_{i j}\right)+v_{i t}^{\prime} \gamma
$$

Here $v_{i t}$ consists of covariates with time constant effect $\gamma$, the smooth functions $f_{j}\left(x_{i j}\right)$ are non-linear effects of covariates $x_{j}, \mathrm{j}=1,2, \ldots \ldots \mathrm{p}$.

A fully Bayesian approach suggested in Fahrmeir and Lang (2001) and Lang and Brezger (2004) is used to estimate smooth effect functions and model parameters.

In the Bayesian framework, the unknown smooth functions $f_{j}$ and parameters $\gamma$ are both considered as random, and are, therefore, assigned suitable priors. Usually, diffuse priors (uninformative prior) are assigned to the parameters of the fixed effects, that is, $\gamma_{j} \propto$ constant $\quad j=1, \ldots \ldots . . r$ 
Bayesian p-spline Basis approach (Lang \& Brezger 2004) is used to estimate the unknown (smooth) functions $\mathrm{f}_{\mathrm{j}}, \mathrm{j}=1, \ldots \ldots . \mathrm{p}$. In this approach, it is assumed that the unknown functions can be approximated by a polynomial spline of degree $l$ defined by a set of equally spaced knots

$$
\xi_{0}=x_{\min }<\xi_{1}<\ldots \ldots \ldots \ldots \ldots . . .<\xi_{k-1}<\xi_{k}=x_{\max } \quad \text { (omitting the subscript } \mathrm{j} \text { for convenience) }
$$

over the domain of $\mathrm{x}$.

The spline can be expressed as a linear combination of $\mathrm{M}=\mathrm{k}+1$ B-spline basis functions, that is,

$$
f(x)=\sum_{m=1}^{M} \beta_{m} B_{m}(x)
$$

where $\mathrm{B}_{\mathrm{m}}$ is the $\mathrm{m}$-th basis function and $\boldsymbol{\beta}=\left(\beta_{1}, \beta_{2}, \ldots \ldots \ldots, \beta_{M}\right)$ is a vector of unknown regression coefficients.

If $\mathrm{X}$ be the $\mathrm{n} \mathrm{x} \mathrm{M}$ design matrix with the $(\mathrm{i}, \mathrm{m})$ th element given by

$$
\mathrm{X}(\mathrm{i}, \mathrm{m})=\mathrm{B}_{\mathrm{m}}\left(\mathrm{x}_{\mathrm{i}}\right)
$$

Then the semiparametric predictor can be expressed in matrix notations as

$$
\eta=X_{1} \beta_{1}+X_{2} \beta_{2}+\ldots \ldots \ldots \ldots+X_{p} \beta_{p}+V \gamma
$$

Here $\beta_{j}(\mathrm{j}=1, \ldots \mathrm{p})$ are the unknown regression coefficients, whereas the matrix $\mathrm{V}$ corresponds to the design matrix for linear effects. Eilers and Marx (1996), in their frequentist setting, introduced difference penalties in the form of first and second order differences in order to overcome the difficulties involved with regression splines such as non-flexibility (for smaller number of knots) or over-fitting (for large number of knots).. Lang and Brezger (2004), in their Bayesian setting, proposed replacing differences with the stochastic analogues of first and second order random walks, given by

$$
\beta_{m}=\beta_{m-1}+u_{m} \quad \text { and } \quad \beta_{m}=2 \beta_{m-1}-\beta_{m-2}+u_{m}
$$

respectively with Gaussian errors $u_{m} \sim N\left(0, \tau^{2}\right)$ and diffuse (uninformative) priors $\beta_{1} \propto$ constant or $\beta_{1}$ and $\beta_{2} \propto$ constant (for initial values). The variance parameter $\tau^{2}$ controls the amount of smoothness and is also referred to as the inverse smoothing parameter. The amount of smoothness is estimated by defining a hyperprior for the variance parameter $\tau^{2}$. Usually a conjugate prior is assigned for $\tau^{2}$ which is the inverse 
Gamma prior with hyperparameters $\mathrm{a}$ and $\mathrm{b}$, that is, $\tau^{2} \sim I G(a, b)$. Common choices for $\mathrm{a}$ and $\mathrm{b}$ are $\mathrm{a}=1$ and $\mathrm{b}=0.005$ (or $\mathrm{b}=0.0005$ ). Alternatively, one may take $\mathrm{a}=\mathrm{b}=0.001$.

Inference for the posterior distribution of the model parameters is fully Bayesian and is based on MCMC methodology (Adebayo \& Fahrmeir, 2005).

The whole model methodology has been implanted in the software BayesX, a freeware software available at http://www.stat.uni-muenchen.de/ bayesx/bayesx.html.

\subsection{Analysis and Results}

The analyses were carried out using the freeware software BayesX. Analyses were done for infant and child mortality for the overall data as well as for each sex separately.

The semiparametric predictor used in our analysis is of the form

$$
\begin{aligned}
\eta_{\text {it }} & \left.=f_{0} \text { (period }\right)+f(\text { ai })+f(\text { hsbi })+f(\text { bord })+\gamma_{1} \text { gender }+\gamma_{2} \text { m_age }+\gamma_{3} \text { long_bi } \\
& +\gamma_{4} \text { full_vacc }+\gamma_{5} \text { hhmember }+\gamma_{6} \text { prim_m }+\gamma_{7} \text { second_m }+\gamma_{8} \text { punjab } \\
& +\gamma_{9} \text { sindh }+\gamma_{10} \text { baluchis }+\gamma_{11} \text { residenc }
\end{aligned}
$$

Here $\mathrm{f}_{0}$ (period) represents the baseline hazard.

The original model proposed by Fahrmeir and Lang (2001) and Lang and Brezger (2004) contains a spatial component which, in turn, helps to capture the spatial structure present in the relationship. However, in our analysis, we have not used the spatial component as the PDHS 1990-91 data can only be identified at the regional (provincial) level. An effort was made to get the district labels for the data but neither the Macro International nor the NIPS (the local organisation in Islamabad, which collected the data) were able to provide that information. So we have to restrict our spatial information at the level of the regions rather than districts. Further, as there were only four regions, so we think the spatial component may not make much sense. Instead we used the regional dummies in our model using three of them (namely Punjab, Sindh and Baluchistan) with the fourth region N.W.F.P. being used as a reference.

\subsubsection{Results: fixed and smooth effects for children 0-3 years of age}

Tables A1 through A3 contain the results for the fixed effects in the models for overall, female and male children (aged 0-3 years) respectively. Here the posterior mean of the 
parameters expresses the impact of the covariates. Additionally the Standard Deviations, $10 \%$ and $90 \%$ quantiles of the associated $80 \%$ credible interval are also given.

As can be seen from the table A1, the sign of the variable gender is negative implying higher mortality for male children than that of female children. This is rather an expected result as male children have an overall $15 \%$ to $20 \%$ survival disadvantage as compared to female children. Higher age of mother (at the birth of her child), long birth interval ( $>24$ months) with the preceding birth, being fully vaccinated, and larger household size significantly reduce mortality of children. The positive effect of larger household size may be explained in terms of the fact (as mentioned by Berger et.al. 2002) that larger households may include relatives beyond the nuclear family and that such larger households are well-endowed households attracting additional members. Another argument may be forwarded on the ground that in Pakistan, where joint family system is common, the children are well taken care of by the elders (usually grandparents) and thus the resultant mortality risk is reduced.

Also clear is the fact that a mother has to get a threshold level of education (here secondary or higher education) before her education starts having a positive effect on the mortality of her children. The positive effect of mother's education is, however, statistically insignificant. Looking at the effects of regional dummies, we observe that the mortality is significantly higher in Punjab, higher in Sindh and Baluchistan, as compared to that in N.W.F.P. (our reference category). Interestingly, mortality is lower in rural areas as compared to urban areas. This may be due to the fact that after we control for the socio-economic status of the household (measured in the model by the smooth effect of Asset Index), and the education level of the mother, the disadvantages of the rural areas are almost adjusted. In fact, in such situation the rural areas might be even more conducive for health due to its better environmental conditions and simple food habits of the households. The effect of residential status is though statistically insignificant.

Tables A2 and A3 give the fixed effects of the models fitted separately for female and male children. The results are similar for the mother's age, long birth interval, vaccination coverage and household size, that is, higher age of mother, long birth interval, full vaccination coverage and larger household size significantly reduce 
mortality. In case of Punjab and Sindh provinces, the mortality is higher (significant for male children in Punjab) as compared to N.W.F.P. However, for Baluchistan, the female mortality is lower than that of male mortality. One reason may be the under-reporting of girls' deaths in Baluchistan. As for the mother's education, we observe that primary education of the mother has a positive (insignificant) effect on the mortality of male children (effect of secondary education is, strangely, negative), whereas if a mother has a secondary or higher education, it leads to a reduction of mortality (statistically insignificant) of their daughters. As before, we see that mortality is lower in rural areas for both male and female children.

Looking at the marginal effect of variables for male and female children, we observe that the effects of mother's (higher) age, long birth interval, and vaccination coverage are higher for female children as compared to male children. On the other hand, the effects of (larger) household size, residence in Punjab and Sindh are higher for male children. Thus, we can say that higher age of mother (at the birth of the child), long birth interval, and full vaccination coverage have more favourable effect for the girl child.

Appendix B summarizes the results for smooth effects of period (baseline hazard), Asset Index (ai), (Mother's) health seeking behaviour (hsb) index and birth order. The baseline hazard is given by the graph for the variable period. This variable is the extended form of the variable age in the augmented dataset so that, for example, if a child is aged 13 months (either current age, or the age at death), then the index child will have 13 values (from 1 to 13). This variable was fitted non-parametrically. The graphs for the variable period for all children as well as separated by gender (figures B1.1 and B1.2) show heaping at various ages, most notably at 12,18, 24 and 36 showing high mortality at these ages. The effect for female children is relatively smoother than that for all children and male children. Overall, the mortality decreases up to around 32 months and then onwards, there is a consistent increase. The graphs for the Asset Index indicate that there is an overall decline in the curve suggesting that higher socio-economic status contributes to lower mortality. We can also observe that the decline is steadier in case of female children, perhaps, indicating a more positive effect on the mortality of female children. The mother's Health Seeking Behaviour (HSB) index represents the overall behaviour of the mother regarding the health needs of her children. The graphs of the nonparametric 
effect of this index on the mortality of children (figures B1.1 and B1.2) exhibit that the effect of health seeking behaviour of mother on overall mortality and female mortality follows somewhat "U-shape" pattern. Mortality declines steeply until around value 0.5 of the index and then it begins to increase rapidly afterwards. However, for male children, there is a steady decline of mortality which somewhat stabilizes after value 0.5 of the index. This may indicate that the positive health seeking behaviour of the mother has a more profound effect on the mortality reduction of her male children. Son preference may be one of the possible explanations for such tendency on part of the mother.

From the plots for the non linear effect of birth order on the mortality of children (figure B1.1) as well as female and male children (figure B1.2), it is clear that its effect is almost identical for all children as well as male and female children where it almost steadily increases until birth order 10 and then there is a steep decline. So we may say that the mortality increases with higher birth order. However, after a threshold of 10 or more births, the mortality starts declining. This decline in mortality after a higher birth order of 10 is consistent with the earlier result of the effect of larger household size on the mortality of children. We observed that larger household size is conducive for the survival of children keeping in view the fact that in a joint family setting (a common feature of a typical Pakistani household), the children get more care from the elder members of the household (such as grand-parents). We may also interpret that a child having a higher birth order may have less survival advantage due to competition among the siblings. However, a larger household size consisting of extended members of the family may have a positive effect on the mortality of children due to additional care given to such children by elder members of the household.

\subsubsection{Results: fixed and smooth effects for children 1-3 years of age}

Tables A4 through A6 in Appendix A contain the results for the fixed effects in the models for overall, female and male children (aged 1-3 years) respectively.

Table A4 indicates a positive sign for the variable gender which shows excess female mortality as compared to male children. The result is, however, statistically insignificant. The table also indicates that higher age of the mother, long birth interval ( $>24$ months) and full vaccination coverage significantly reduce mortality. Moreover, larger household 
size contributes to reduction of mortality. The mortality of children is higher in all three regions (Punjab, Sindh and Baluchistan) as compared to N.W.F.P. (the reference region). Mortality is significantly lower in rural areas as compared to urban areas. Further, we see that secondary or higher education of mother significantly reduces mortality of children. We observe, once more, that the threshold education level of mother is necessary for the positive effect on mortality.

Using this fact that the sign of the variable gender is positive (indicating excess mortality for the female children as compared to the male children) we further look at the marginal effects of the other covariates by considering the results from fixed effects from models for female and male children separately in the tables A5 and A6 respectively. From the tables, it is clear that higher age of mother, a large preceding birth interval ( $>24$ months) and full vaccination coverage are conducive for the survival of the children. We observe that large birth interval and being fully vaccinated significantly contribute to survival of children whereas higher age of the mother significantly reduces male child mortality but not that of female child. Mortality is higher in all the three regions (as compared to N.W.F.P.). Further we observe that female mortality is significantly higher in Punjab and Baluchistan. The mortality of both male and female children is lower in rural areas as compared to urban areas. One of the important results is that mother's education of secondary or higher level has a significantly positive effect on the mortality of female children. We observe that while mother's education will have a positive effect on the survival of the girl child if she is educated at secondary or higher level (perhaps giving her more say in household decision making process), the education of mother has a positive effect on mortality of male child even when the mother is having at least primary education (the effect is, though, statistically insignificant). This indicates that even a nominally educated mother (at the primary level) will have more positive attitude towards the health needs of her male child. This, again, indicates that under limited financial resources, the mother would be more inclined towards fulfilling the health needs of her male child as compared to female child due to strong cultural phenomenon of son preference. Moreover, comparing the marginal effects of variables for male and female children, we observe that the effects of long birth interval and vaccinations are higher for male children as compared to female children whereas the effect of mother's higher age 
(at the birth of her child) is almost similar for both male and female children. On the other hand, the effects of higher mortality in Punjab, Sindh and Baluchistan are higher for female children as compared to male children.

The smooth effects are given in Appendix B (figures B1.3 and B1.4). The graphs for the baseline hazard (represented by the variable period) exhibit identical pattern to those obtained for children aged 0-3 years, with heaping, notably, at ages 12, 18, 24 and 36 indicating high mortality at these ages. The graphs for the smooth effect of asset index for all children (figure B1.3) and for female and male children (figure B1.4) indicate that the pattern is almost identical for all children and female children, that is, there is a steady decline which indicates that higher values of the index (representing higher socioeconomic status) have a positive effect on the mortality of all children as well as female children. However, for male children, the curve behaves roughly like "U-shaped", which might indicate that although higher socio-economic status reduces mortality but it has no permanent decreasing effect on the mortality of male children. We may conclude that a higher socio-economic status (higher income) of the household may be more beneficial for the female child. The graphs of the nonparametric effect of hsb index on the mortality of children (figures B1.3 and B1.4) exhibit that, on the whole, positive health seeking behaviour of the mother leads to the reduction of mortality. For the male children, the graph shows that the mortality remains higher and relatively constant for lower (negative) values of the index and then sharply declines afterwards. The graphs for all children and female children are almost identical showing a steep decline of mortality with growing values of the index. However, after a value of 1.5 of the index, the curve unexpectedly shows an upward direction. From the plots for the non linear effect of birth order on the mortality of children as well as female and male children (figures B1.3 and B1.4), it is clear that its effect is almost identical for all children and male children where it almost steadily increases and begins to decline after a birth order of around 12 . This shows that the higher the birth order, the higher is the mortality. For female children, the mortality steadily increases up until birth order 3 and then behaves almost linearly (remains constant and high). We may interpret this as telling the point that lower birth order is more conducive for the female children (aged 1-3 years). 


\subsubsection{Results: fixed and smooth effects for Infants}

Appendix A also provides results for the fixed effects of models for infants (table A7) as well as for male and female infants (tables A8 and A9 respectively). From table A7, it is clear that male infants have a higher rate of mortality than female infants. This result is in line with the standard literature (Arnold, 1992; Berger et.al., 2002; Chidambaram et.al., 1985; Dancer et.al., 2007; D'Souza and Chen, 1980; Fuse and Crenshaw, 2006; Waldron, 1998). The fact that male infants are biologically weak indicates that they are more at risk of death as compared to female infants. Further, male babies are usually heavier as compared to female infants and this could be another possible reason for their higher mortality as a result of pregnancy or birth complications. Results for all infants, as well as by gender, indicate that higher age of mother, long birth interval, full vaccination coverage (according to number of vaccinations by particular age in months), and larger household size significantly reduce the risk of mortality. Mortality for infants is higher in the regions Punjab and Sindh whereas it is lower in Baluchistan (as compared to N.W.F.P.). In case of Punjab, this higher mortality is significant. As discussed earlier, the lower mortality in Baluchistan may be due to under-coverage of death reporting. For female infants, the mortality is higher (but insignificant) in the three regions whereas region-wise mortality patterns for male infants are the same as those for all infants. As before, rural mortality is lower than urban mortality for all infants as well as for female and male infants. As regards education of the mother, we see that mother's education has even (an unexpectedly) negative effect on the mortality of all infants and male infants, whereas for female infants the mother's education contributes to the reduction of mortality if mother has at least primary education. However, we observe that the effect of mother's education is statistically insignificant. This may be understandable keeping in view the fact that at such early age, the education of mother may not be the dominant factor in mortality reduction, or perhaps its effect is adjusted in the health seeking behaviour index for the mother.

The smooth effects are given in the Appendix B (figures B1.5 and B1.6). The graph for smooth effect of all the infants (figure B1.5) is relatively smoother than that for children aged 1-3 years. It shows a steady decline until age 12 months with heaping at ages 4,8 and 11 months. Almost similar patterns are exhibited by the graphs for male and female 
children (figure B1.6) with a relatively smoother effect for male infants as compared to female infants.

The graph for the smooth effect of asset index for all infants (figure B1.5) exhibits somewhat linear pattern with sharp decline for higher values (around 1.5) of the index. This indicates decreasing mortality with higher values (higher socio-economic status). The corresponding graphs for female and male children (figure B1.6) indicate a non linear pattern. The pattern is almost identical for both male and female infants with a rapid decline for female infants for higher (positive) values of the index. This may be an indication of the fact that better socio-economic status of the household may contribute more to the welfare (mortality reduction) of the female infant.

The graphs of the nonparametric effect of hsb index (figures B1.5 and B1.6) exhibit that overall positive health seeking behaviour of the mother leads to the reduction of mortality. However, we observe that the mortality reduction is much faster for male infants, which may indicate an effort on part of the mother to care more for the health of her male infant in the presence of limited financial backup. For all infants and female infants, the curve almost behaves like a U-shape, declining pattern up until 0.5 and then a steady increase.

The birth order pattern is almost identical for all infants and male infants (figures B1.5 and B1.6). The mortality increases until birth order of around 10 and afterwards there is a steady decline of the mortality. In case of female infants, we observe that there is a consistent increase until birth order of around 12 and then the graph declines rapidly. This leads to interpretation that mortality for all infants (as well as male and female infants) increases with increase in birth order and that the mortality will be lower only if the birth order is 10 or more.

\subsection{Conclusions}

In this paper, our aim was to determine gender differences in mortality in Pakistan. Using the data from the 1990-91 Pakistan Demographic and Health Survey (PDHS), we created a new dataset for children containing survival information of children and associated socio-economic and demographic information of parents. The data were analyzed for 
children (under 3 as well as 1-3 years old) and for infants using Bayesian structured hazard regression model. The freeware software BayesX was used for the model fitting. We found the gender differentials in mortality in mother's education and her health seeking behaviour, Socio-economic status of the household and birth order. We can broadly conclude that for male children and infants, higher age of the mother, long birth interval, vaccination coverage, mother's education (preferably at the level of secondary or higher), lower birth order, larger household size, and positive health seeking behaviour of the mother play an important role in reducing the mortality. On the other hand, important factors for reduced mortality for female children as well as female infants are higher age of the mother (at the birth of her child), long birth interval, full vaccination coverage, mother's education (at least at the level of secondary), lower birth order (up to 3), larger household size and higher socio-economic status of the household. Important outcomes are that the mother's education at the level of secondary or higher has a significant effect on the reduction of mortality for female children in the age range 1-3 years. Further, we conclude that higher socio-economic status of the household is conducive to the survival of the female child whereas positive health seeking behaviour of the mother contributes more to the survival of the male child.

Overall, no strong gender differentials in mortality were found. Most of the results are similar for male and female children as well as children. There can be possible issues with the quality of the data, particularly in respect of reporting of deaths. We know that Pakistan at the moment does not have a proper vital registration system (of births, deaths etc.) and, thus, any survey collecting information on these vital events may possibly suffer from under-reporting bias. In the current survey (PDHS 1990-91), we observe only 526 deaths which may possibly be an underestimate of the actual number of deaths occurred in the 5 years preceding the survey.

In the light of the above conclusions, we would recommend that effort be made for providing better access to education and health facilities for parents and raising the overall economic uplift of the household so that the gender gap in mortality is bridged. 


\subsection{References}

Abeykoon, A.T.P.L. (1995). Sex Preference in South Asia: Sri Lanka an Outlier. AsiaPacific Population Journal. 10 (3): 5-16.

Adebayo, S.M., Fahrmeir, L. (2005). Analysing child mortality in Nigeria with geoadditive discrete-time survival models. Statistics in Medicine. 24:709-728.

Ali, S. M. (1989). Does Son Preference Matter? Journal of Biosocial Science, 21(4). Arnold, F. (1992). Sex Preference and Its demographic and Health Implications. International Family Planning Perspectives. 18 (3): 93-101.

Bairagi, R. (1994). Excess female child mortality: its levels, trends and differentials in rural Bangladesh. Paper presented at International Symposium on Issues related to Sex Preference for Children in Rapidly Changing Demographic Dynamics in Asia, Seoul, Republic of Korea.

Bawah, A. and Zuberi, T. (2004). Socioeconomic Status and Child Mortality: An Illustration Using Housing and Household Characteristics from African Census Data. Paper presented at the Annual Meeting of the Population Association of America. Boston, April 1-3.

Berger, U., Fahrmeir L, Klasen S. (2002). Dynamic modelling of child mortality in developing countries: application for Zambia. SFB 386 Discussion Paper 299, University of Munich, Germany.

Booysen, van der Berg, Burger, von Maltitz, and du Rand (2005). Using an Asset Index to Assess Trends in Poverty in Seven Sub-Saharan African countries. Paper presented at conference on Multidimensional Poverty hosted by the International Poverty Centre of the United Nations Development Programme (UNDP) 29-31 August, Brasilia, Brazil

Brezger, A., Kneib, T., Lang, S. (2003). BayesX-Software for Bayesian Inference Based on Markov Chain Monte Carlo simulation Technique. Available under http://www.stat.uni-muenchen.de/ lang/BayesX

Cain, M. (1984). Women's Status and Fertility in Developing Countries: Son Preference and Economic Security, Population and Development Series No. 7, (Washington, D.C.: World Bank). 
Chidambaram, V.C., McDonals, J.W., Bracher, M.D. (1985). Infant and Child Mortality in the Developing World: Information from the World Fertility Survey. International Family Planning Perspectives. 11 (1): 17-25.

Coale, A. (1991). Excess Female Mortality and the Balance of the Sexes. Population and Development Review. 17: 517-523

Dancer, D., Rammohan, A., Smith, M.D. (2007). Infant Mortality and Child Nutrition in Bangladesh: Modelling Sample selection Using Copulas. The Royal Statistical Society Conference, York, UK.

Doctor, H.V. (2004). "The Effect of Living Standards on Childhood Mortality in Malawi." African Population Studies 19(2 Suppl A): 241-263

D'Souza, S. and Chen L.C. (1980). Sex Differentials in Mortality in Rural Bangladesh. Population and Development Review. 6 (2): 257-270.

Ehrlich, I and Lui, F.T. (1991). Intergenerational Trade, Longevity, and Economic Growth. Journal of Political Economy. 99 (5): 1029-1059.

Ehrlich, I and Lui, F.T. (1997). The Problem of Population and Growth: A Review of Literature from Malthus to Contemporary Models of Endogenous Population and Endogenous Growth. Journal of Economic Dynamics and Control. 21 (1): 205-242.

Ehrlich, I and Lui, F.T. (1998). Social Security, the Family and Economic Growth. Economic Inquiry. 36 (3): 390-409.

Feeney, G. and Alam, I. (2003). Fertility, population growth, and accuracy of census enumeration in Pakistan: 1961-1998. Ch. 4 in Population of Pakistan: An Analysis of 1998 Population and Housing Census, A.R. Kemal, Mohammad Irfan, and Naushin Mahmood, eds. Islamabad: Pakistan Institute of Development Economics.

Filmer, D., L. H. Prichett, L.H. (2001). Estimating Wealth Effects without Expenditure Data - Or Tears: An Application to Educational Enrollments in States of India. Demography 38(1):115-133

Fahrmeir L., Lang. S. (2001). Bayesian inference for generalized additive mixed models based on Markov random field priors. Applied Statistics, 50, 2: 201-220.

Fahrmeir, L., Lang, S. (2001). Bayesian semiparametric regression analysis of multicategorical time-space data. Annals of the Institute of Statistical Mathematics, 53, 10-30. 
Fuse, K. and Crenshaw, E.M. (2006). Gender Imbalance in Infant Mortality: A crossnational study of social structure and female infanticide. Social Science and Medicine. $62,360-374$.

Gangadharan, L., Maitra, P. (2000). Does Child Mortality reflect Gender Bias? Evidence from Pakistan. Indian Economic Review, 35, No. 2: 113-131.

Hausfater, G. and Hrdy, S.B. (1984). Infanticide: Comparatively and Evolutionary Perspectives. New York: Aladin.

Harttgen, K. and M. Misselhorn (2006). A Multilevel Approach to Explain Child Mortality and Undernutrition in South Asia and Sub-Saharan Africa. Mimeographed, University of Göttingen, Germany.

Johansson, S. and Nygren, O. (1991). The Missing Girls of China: A New Demographic Account. Population and Development Review. 17: 35-51.

Karim, M.S. (1994). Sex preference in Pakistan. Paper presented at the International Symposium on Issues Related to Sex Preference for Children in the Rapidly Changing Demographic Dynamics in Asia, Seoul, Republic of Korea.

Khan, M.A. and Sirageldin, I. (1977). Son preference and the demand for additional children in Pakistan. Demography, 14(4).

Klasen, S. (1994). Missing Women Reconsidered. World Development. 22: 1061-71.

Klasen, S., Wink, C. (2003). Missing Women: revisiting the debate. Feminist Econ 9: 263-300.

Klasen, S. (2003). Sex selection. In Demeny, P. und G. McNicoll (eds.) Encyclopedia of Population, Vol II: 878-881. New York: Macmillan Reference USA.

Kolenikov, S., and Angeles, G. (2004). The Use of Discrete Data in Principal Component Analysis: Theory, Simulations, and Applications to Socioeconomic Indices. Working Paper of MEASURE/Evaluation project, No. WP-04-85, Carolina Population Center, University of North Carolina.

Lang, S., Brezger, A., (2004). Bayesian P-Splines. Journal of Computational and Graphical Statistics. 13:183-212.

Nugent, J.B. (1985). The Old-Age Security Motive for Fertility. Population and Development Review. 11 (1): 75-97. 
Nugent, J.B. and Anker, R. (1990). Old-Age Support and Fertility. World Employment Programme Research Working Paper 172. International Labour Organisation, Geneva.

Sahn, D.E. and Stifel, D.C. (2000). Poverty Comparisons Over Time and across Countries in Africa. World Development. 28 (12): 2123-2155.

Sahn, D.E. and Stifel, D.C. (2003). Exploring Alternative Measures of Welfare in the Absence of Expenditure Data. Review of Income and Wealth 49(4): 463-489.

Sen, Amartya (1990). More than 100 Million Women are Missing. The New York Review of Books, December 20, 1990.

Schultz, T.P. (1997). Demand for Children in Low Income Countries. In: Rosenzweig, M.R. and Stark, O. (Ed). Handbook of Population and Family Economics. Vol. 1A: 349430. Elsevier Science B.V., Amsterdam.

World Bank (2008). http://go.worldbank.org/QTEHWN5Q70 


\subsection{Appendix A: Tables of fixed effects}

Table A 1 Fixed effects for Children aged 0-3 years

\begin{tabular}{|l|l|l|l|l|}
\hline Variable & Mean & SD & \multicolumn{2}{|c|}{ lo\% credible interval } \\
\hline const & & & -3.341 & -2.767 \\
gender & -3.070 & 0.218 & -0.091 & 0.009 \\
m_age & -0.040 & 0.039 & -0.022 & -0.011 \\
long_bi & -0.017 & 0.004 & -0.551 & -0.437 \\
full_vacc & -0.492 & 0.045 & -0.904 & -0.733 \\
hhmember & -0.821 & 0.069 & -0.026 & -0.014 \\
prim_m & -0.020 & 0.005 & -0.057 & 0.110 \\
Second_m & 0.027 & 0.065 & -0.126 & 0.079 \\
punjab & -0.023 & 0.079 & 0.075 & 0.206 \\
sindh & 0.141 & 0.052 & -0.048 & 0.097 \\
baluchis & 0.026 & 0.056 & -0.072 & 0.086 \\
residenc & 0.007 & 0.061 & -0.122 & 0.007 \\
\hline
\end{tabular}

Table A 2 Fixed effects for Female Children aged 0-3 years

\begin{tabular}{|l|l|l|l|l|}
\hline Variable & Mean & SD & \multicolumn{2}{|c|}{ lo\% credible interval } \\
\hline const & & & -3.219 & -2.202 \\
m_age & -2.697 & 0.381 & -0.024 & -0.006 \\
long_bi & -0.014 & 0.007 & -0.536 & -0.376 \\
full_vacc & -0.457 & 0.061 & -0.810 & -0.581 \\
hhmember & -0.691 & 0.092 & -0.030 & -0.011 \\
prim_m & -0.020 & 0.008 & -0.097 & 0.179 \\
second_m & 0.039 & 0.106 & -0.278 & 0.009 \\
punjab & -0.137 & 0.110 & -0.013 & 0.201 \\
sindh & 0.095 & 0.081 & -0.082 & 0.123 \\
baluchis & 0.018 & 0.080 & -0.194 & 0.060 \\
residenc & -0.065 & 0.098 & -0.146 & 0.053 \\
\hline
\end{tabular}

Table A 3 Fixed effects for Male Children aged 0-3 years

\begin{tabular}{|l|l|l|l|l|}
\hline Variable & Mean & SD & \multicolumn{2}{|c|}{ lo\% credible interval } \\
\hline const & & & -3.021 & -2.097 \\
m_age & -2.528 & 0.352 & -0.027 & -0.010 \\
long_bi & -0.019 & 0.006 & -0.583 & -0.428 \\
full_vacc & -0.507 & 0.060 & -1.212 & -0.895 \\
hhmember & -1.054 & 0.138 & -0.027 & -0.009 \\
prim_m & -0.018 & 0.007 & -0.122 & 0.123 \\
second_m & -0.002 & 0.097 & -0.070 & 0.241 \\
punjab & 0.084 & 0.118 & 0.095 & 0.292 \\
sindh & 0.194 & 0.075 & -0.067 & 0.138 \\
baluchis & 0.034 & 0.082 & -0.051 & 0.187 \\
residenc & 0.066 & 0.090 & -0.142 & 0.040 \\
\hline
\end{tabular}


Table A 4 Fixed effects for Children aged 1-3 years

\begin{tabular}{|l|l|l|l|l|}
\hline Variable & Mean & SD & \multicolumn{2}{|c|}{ lo\% credible interval } \\
\hline const & -4.126 & 0.402 & -4.681 & -3.629 \\
gender & 0.011 & 0.095 & -0.106 & 0.143 \\
m_age & -0.019 & 0.011 & -0.032 & -0.004 \\
long_bi & -0.478 & 0.116 & -0.626 & -0.323 \\
full_vacc & -0.649 & 0.153 & -0.852 & -0.447 \\
hhmember & -0.004 & 0.011 & -0.019 & 0.011 \\
prim_m & 0.168 & 0.164 & -0.050 & 0.374 \\
second_m & -0.429 & 0.343 & -0.950 & -0.054 \\
punjab & 0.206 & 0.135 & 0.045 & 0.369 \\
sindh & 0.064 & 0.144 & -0.116 & 0.251 \\
baluchis & 0.202 & 0.158 & 0.005 & 0.389 \\
residenc & -0.128 & 0.112 & -0.275 & 0.027 \\
\hline
\end{tabular}

Table A 5 Fixed effects for Female Children aged 1-3 years

\begin{tabular}{|l|l|l|l|l|}
\hline Variable & Mean & SD & \multicolumn{2}{|c|}{ lo\% credible interval } \\
\hline const & & & -3.876 \\
m_age & -4.764 & 0.661 & -5.637 & -0.045 \\
long_bi & -0.022 & 0.017 & -0.775 & -0.378 \\
full_vacc & -0.568 & 0.155 & -1.254 & -0.571 \\
hhmember & -0.891 & 0.259 & -0.018 & 0.024 \\
prim_m & 0.004 & 0.016 & -0.106 & 0.568 \\
second_m & 0.240 & 0.266 & -1.330 & -0.002 \\
punjab & -0.625 & 0.491 & 0.089 & 0.552 \\
sindh & 0.319 & 0.182 & -0.127 & 0.431 \\
baluchis & 0.162 & 0.218 & 0.012 & 0.555 \\
residenc & 0.286 & 0.215 & -0.456 & 0.099 \\
\hline
\end{tabular}

Table A 6 Fixed effects for Male Children aged 1-3 years

\begin{tabular}{|l|l|l|l|l|}
\hline Variable & Mean & SD & \multicolumn{2}{|c|}{ lower credible interval } \\
\hline const & & & -4.123 \\
m_age & -4.976 & 0.655 & -5.885 & -0.0002 \\
long_bi & -0.021 & 0.016 & -0.042 & -0.323 \\
full_vacc & -0.511 & 0.153 & -0.706 & -0.325 \\
hhmember & -0.540 & 0.181 & -0.758 & 0.008 \\
prim_m & -0.015 & 0.017 & -0.037 & 0.098 \\
second_m & -0.211 & 0.266 & -0.587 & 0.145 \\
punjab & -0.523 & 0.539 & -1.347 & 0.509 \\
sindh & 0.230 & 0.217 & -0.025 & 0.332 \\
baluchis & 0.049 & 0.224 & -0.227 & 0.438 \\
residenc & 0.134 & 0.224 & -0.156 & 0.074 \\
\hline
\end{tabular}


Table A 7 Fixed effects for Infants (aged under 1 year)

\begin{tabular}{|l|l|l|l|l|}
\hline Variable & Mean & SD & \multicolumn{2}{|c|}{ lo\% credible interval } \\
\hline const & & & -2.018 & -1.306 \\
m_age & -1.628 & 0.294 & -0.104 & 0.010 \\
gender & -0.048 & 0.044 & -0.023 & -0.010 \\
long_bi & -0.017 & 0.005 & -0.551 & -0.430 \\
full_vacc & -0.491 & 0.048 & -1.008 & -0.806 \\
hhmember & -0.904 & 0.079 & -0.031 & -0.017 \\
prim_m & -0.024 & 0.005 & -0.086 & 0.107 \\
second_m & 0.011 & 0.078 & -0.098 & 0.109 \\
punjab & 0.004 & 0.079 & 0.052 & 0.206 \\
sindh & 0.129 & 0.061 & -0.060 & 0.104 \\
baluchis & 0.026 & 0.062 & -0.145 & 0.057 \\
residenc & -0.041 & 0.081 & -0.124 & 0.023 \\
\hline
\end{tabular}

Table A 8 Fixed effects for Female Infants

\begin{tabular}{|l|l|l|l|l|}
\hline Variable & Mean & SD & \multicolumn{2}{|c|}{ lo\% credible interval } \\
\hline const & & & -1.960 & -1.278 \\
m_age & -1.623 & 0.275 & -0.021 & -0.003 \\
long_bi & -0.012 & 0.007 & -0.547 & -0.364 \\
full_vacc & -0.455 & 0.071 & -0.804 & -0.535 \\
hhmember & -0.666 & 0.104 & -0.038 & -0.018 \\
prim_m & -0.028 & 0.008 & -0.143 & 0.122 \\
second_m & -0.012 & 0.106 & -0.277 & 0.035 \\
punjab & -0.116 & 0.121 & -0.041 & 0.177 \\
sindh & 0.070 & 0.085 & -0.099 & 0.117 \\
baluchis & 0.009 & 0.086 & -0.276 & 0.011 \\
residenc & -0.129 & 0.113 & -0.147 & 0.070 \\
\hline
\end{tabular}

Table A 9 Fixed effects for Male Infants

\begin{tabular}{|l|l|l|l|l|}
\hline Variable & Mean & SD & \multicolumn{2}{|c|}{ lo\% credible interval } \\
\hline const & & & -1.914 & -1.243 \\
m_age & -1.577 & 0.268 & -0.029 & -0.012 \\
long_bi & -0.021 & 0.007 & -0.608 & -0.419 \\
full_vacc & -0.510 & 0.074 & -1.349 & -1.010 \\
hhmember & -1.179 & 0.136 & -0.030 & -0.010 \\
prim_m & -0.020 & 0.008 & -0.114 & 0.151 \\
second_m & 0.020 & 0.102 & -0.041 & 0.287 \\
punjab & 0.126 & 0.128 & 0.067 & 0.304 \\
sindh & 0.189 & 0.092 & -0.057 & 0.176 \\
baluchis & 0.059 & 0.090 & -0.087 & 0.187 \\
residenc & 0.050 & 0.108 & -0.129 & 0.070 \\
\hline
\end{tabular}




\subsection{Appendix B: Smooth effects of non-parametric functions}

Effect of period (baseline hazard)

(Children aged 0-3 years)

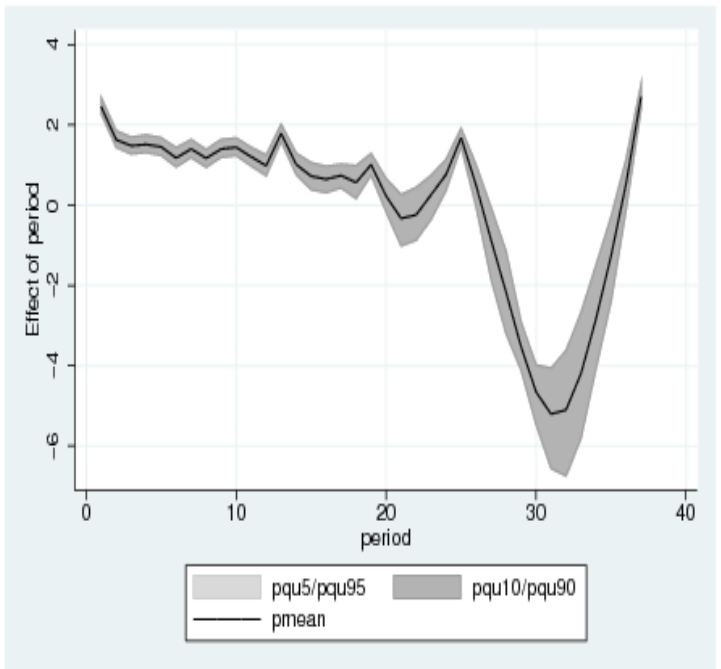

Effect of Asset Index

(Children aged 0-3 years)

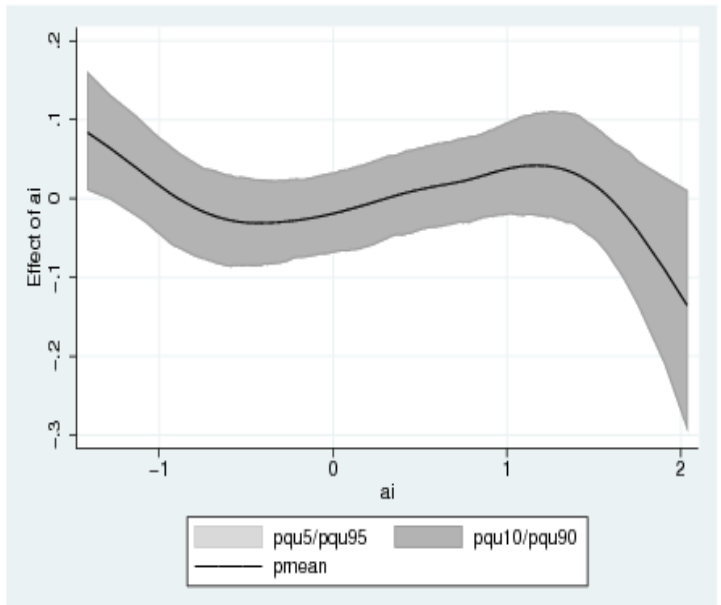

Figure B1. 1 Smooth effects for children aged $0-3$ years
Effect of Mother's hsb index

(Children aged 0-3 years)

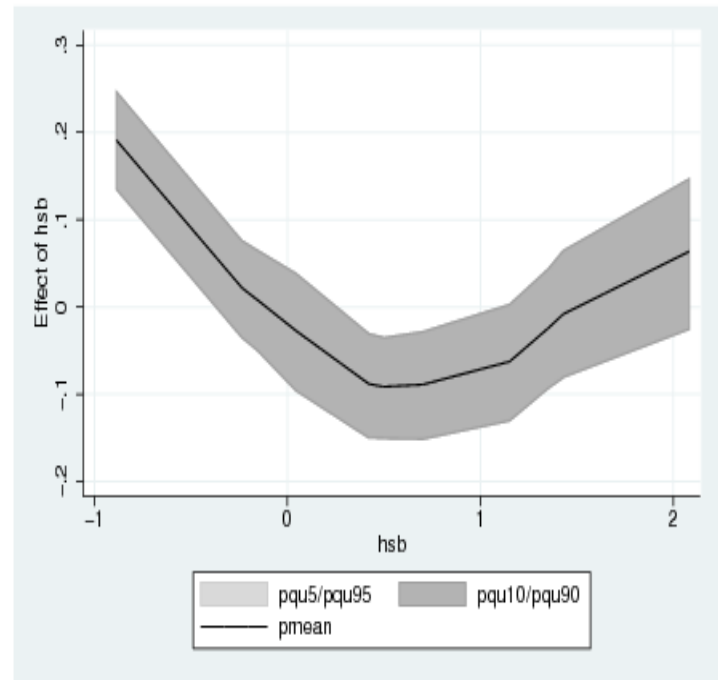

Effect of Birth Order

(Children aged 0-3 years)

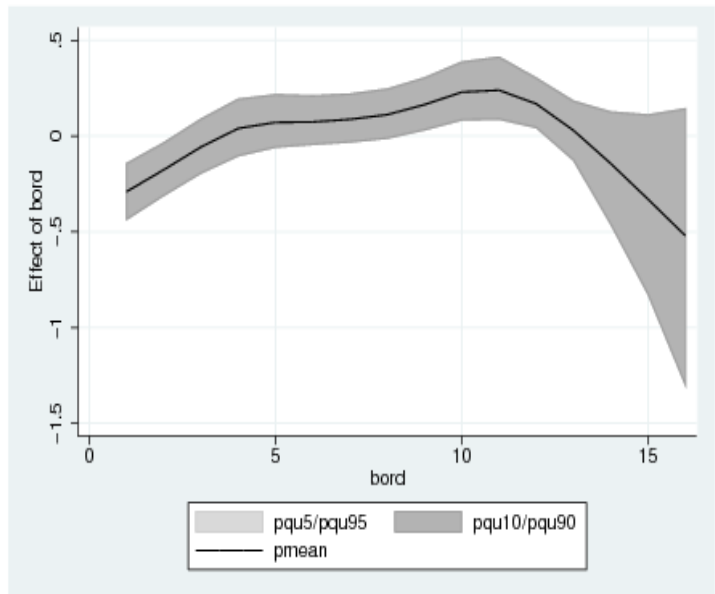


Effect of period (baseline hazard)

(Female children aged 0-3 years)

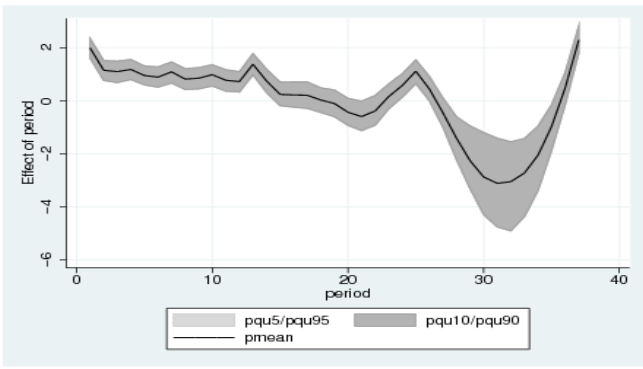

Effect of Asset Index

(Female children aged 0-3 years)

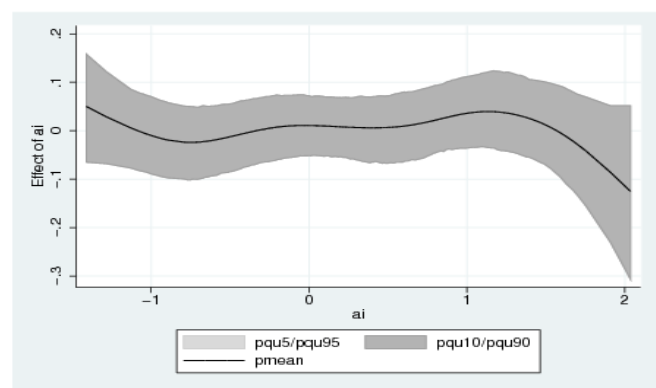

Effect of Mother's hsb index

(Female children aged 0-3 years)

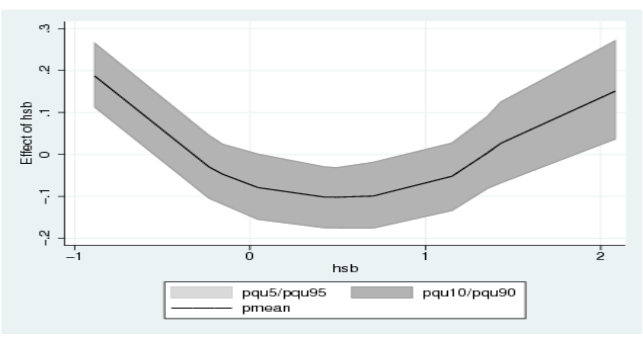

Effect of birth order

(Female children aged 0-3 years)

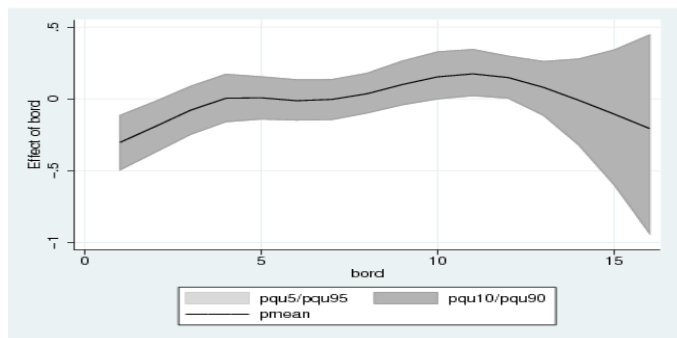

Figure B1. 2 Smooth effects for children aged $0-3$ years (by gender)
Effect of period (baseline hazard)

(Male children aged 0-3 years)

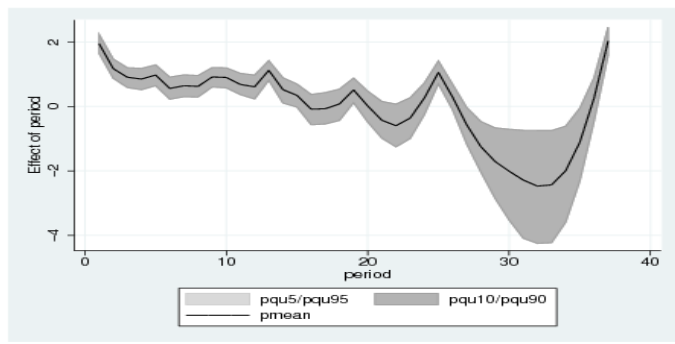

Effect of Asset Index

(Male children aged 0-3 years)

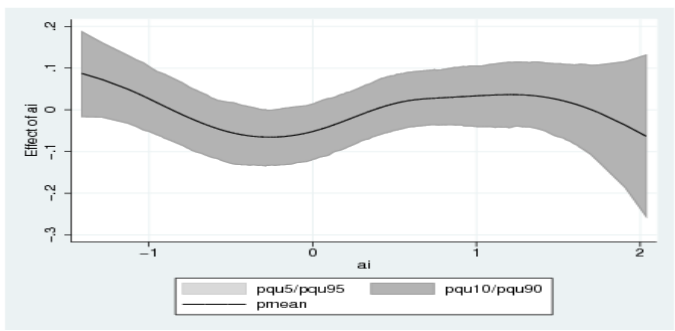

Effect of Mother's hsb index

(Male children aged 0-3 years)

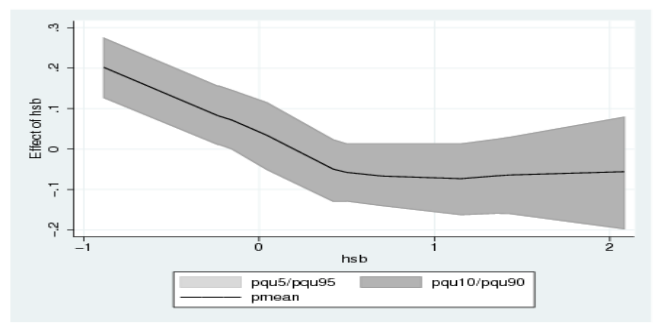

Effect of birth order

(Male children aged 0-3 years)

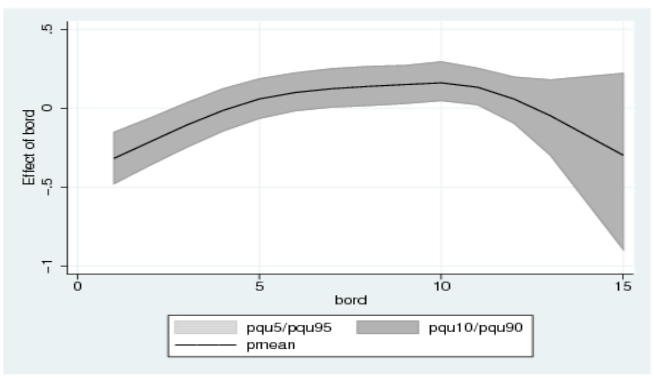


Effect of period (baseline hazard)

(Children aged 1-3 years)

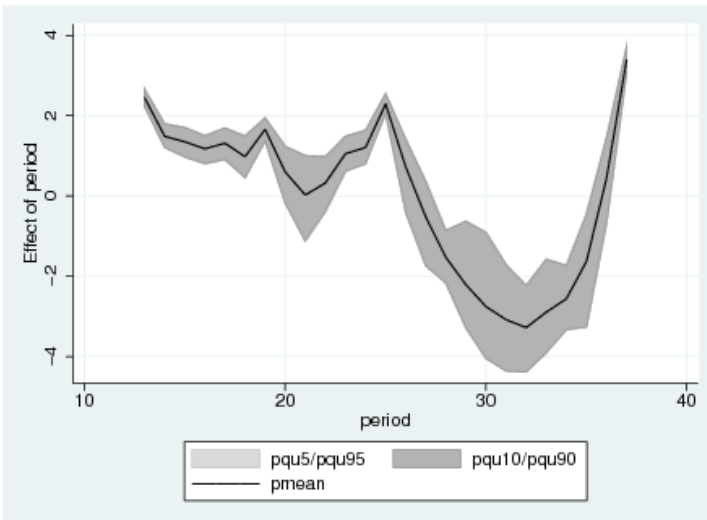

Effect of Asset Index

(Children aged 1-3 years)

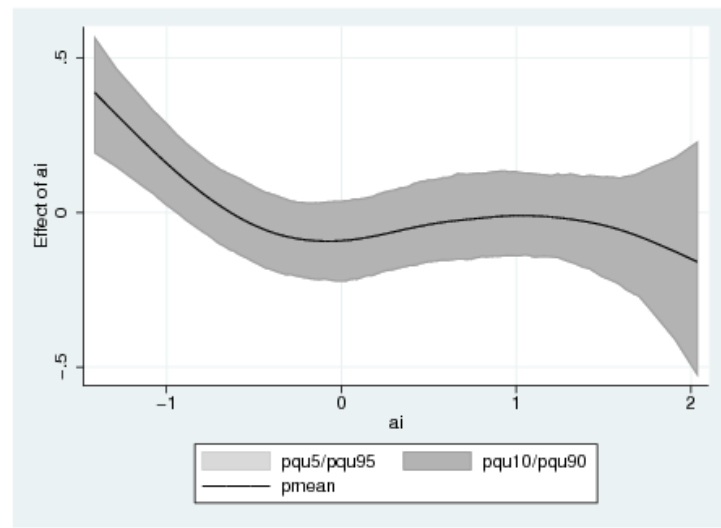

Effect of Mother's hsb index

(Children aged 1-3 years)

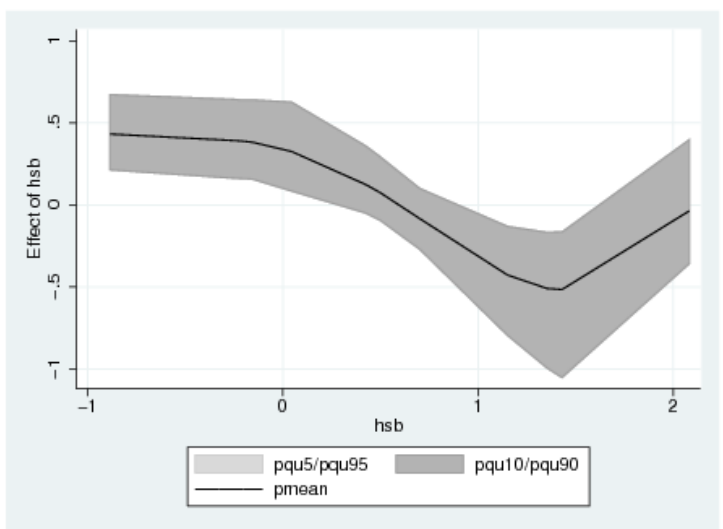

\section{Effect of Birth Order}

(Children aged 1-3 years)

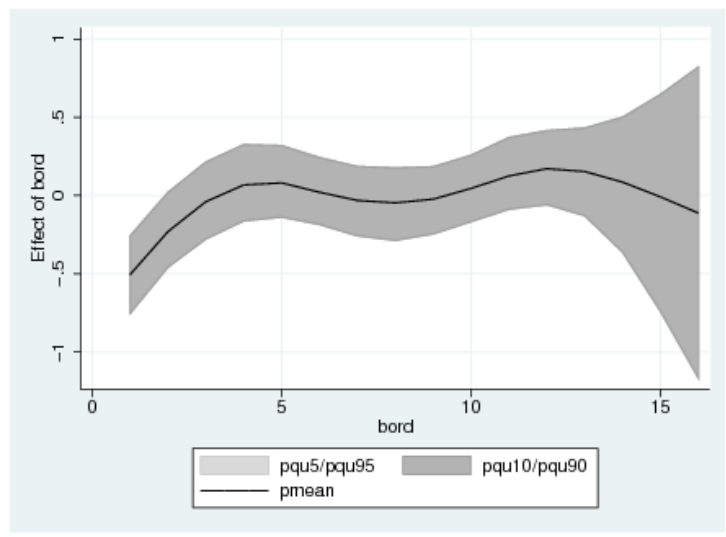

Figure B1. 3 Smooth effects for children aged $1-3$ years 
Effect of period (baseline hazard)

(Female children aged 1-3 years)

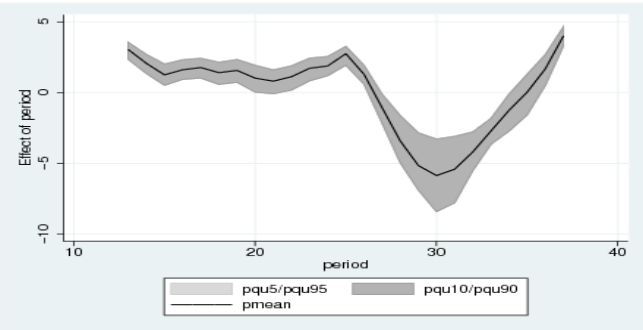

Effect of Asset Index

(Female children aged 1-3 years)

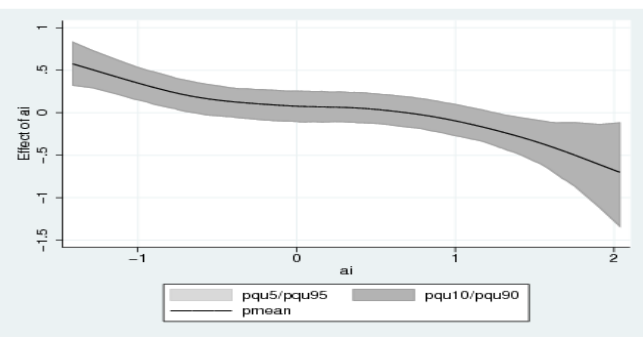

Effect of Mother's hsb index

(Female children aged 1-3 years)

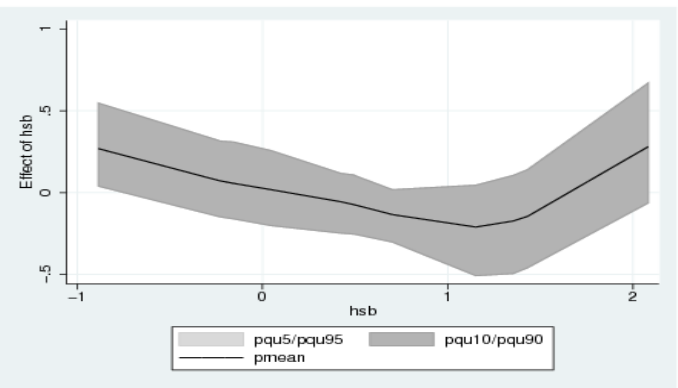

Effect of birth order

(Female children aged 1-3 years)

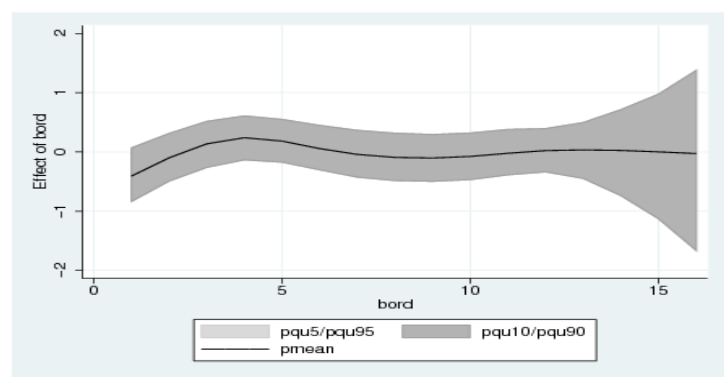

Figure B1. 4 smooth effects for children aged 1-3 years (by gender)
Effect of period (baseline hazard)

(Male children aged 1-3 years)

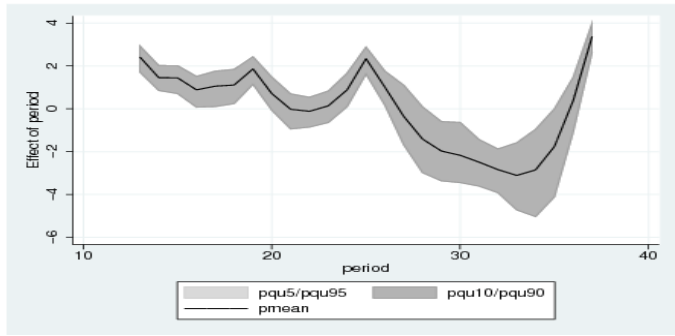

Effect of Asset Index

(Male children aged 1-3 years)

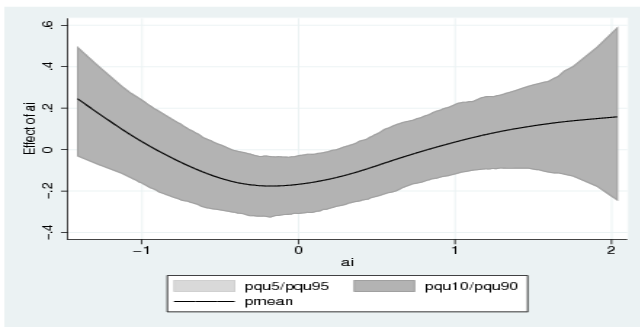

Effect of Mother's hsb index

(Male children aged 1-3 years)

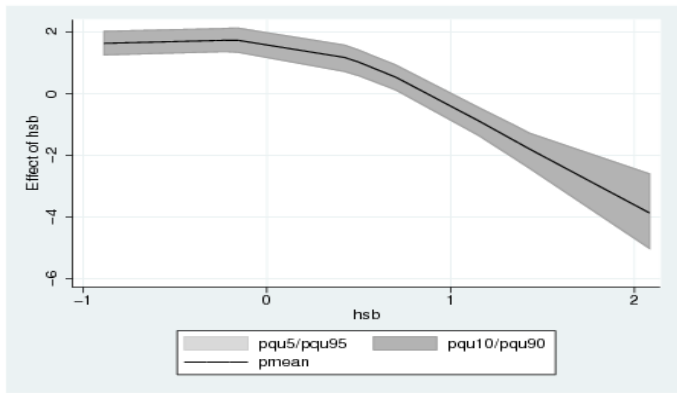

Effect of birth order

(Male children aged 1-3 years)

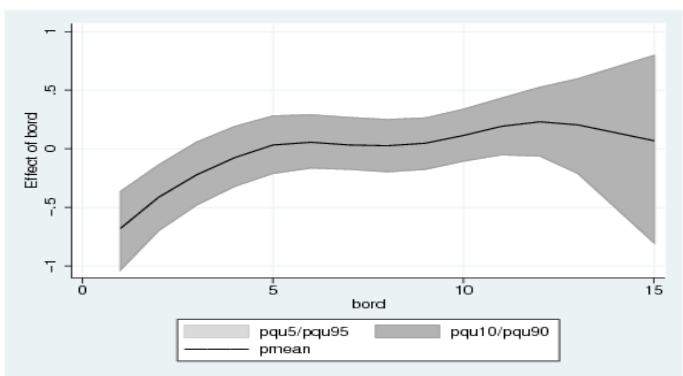


Effect of period (baseline hazard)

(Infants)

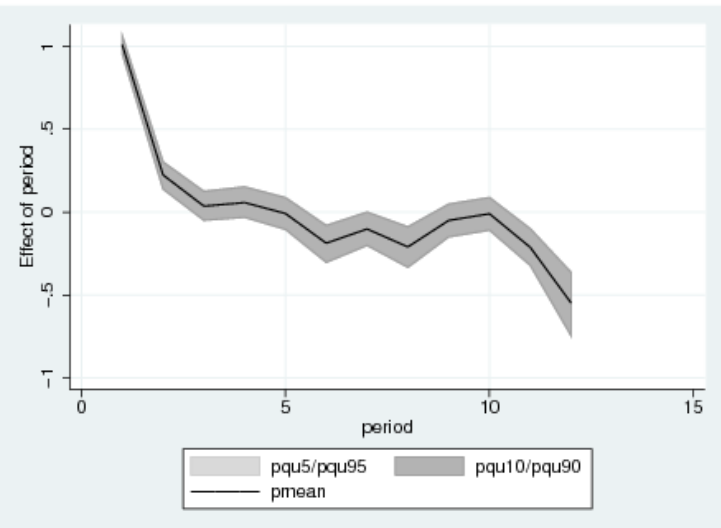

Effect of Asset Index

(Infants)

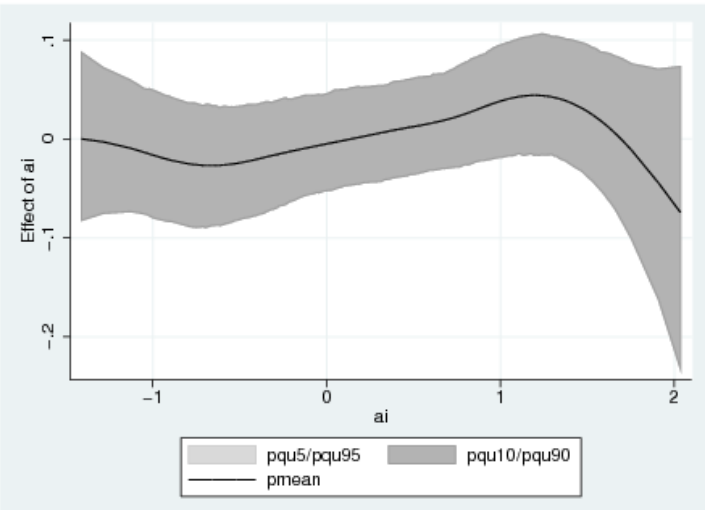

Effect of Mother's hsb Index

(Infants)

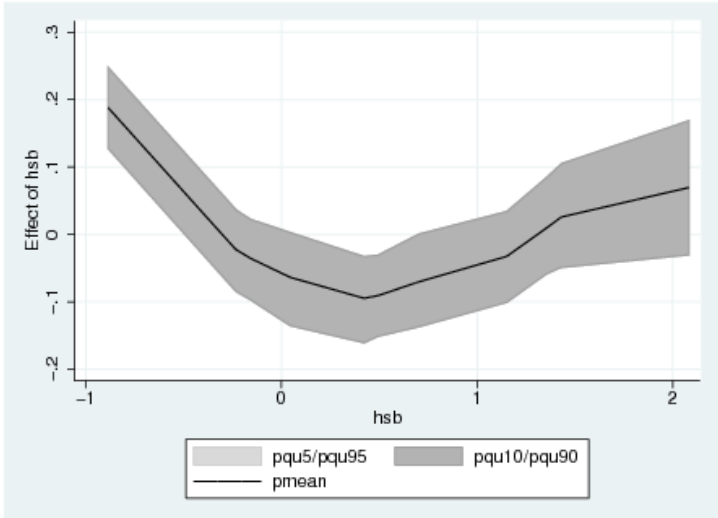

Effect of birth order

(Infants)

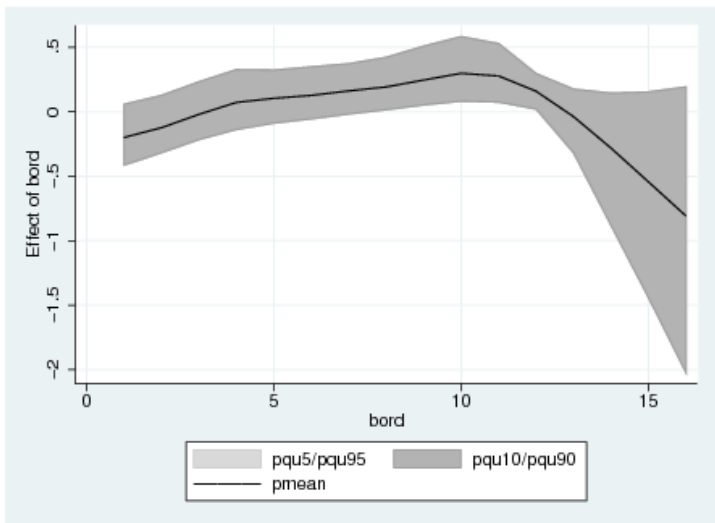

Figure B1. 5 Smooth effects for Infants 
Effect of period (baseline hazard)

(Female Infants)

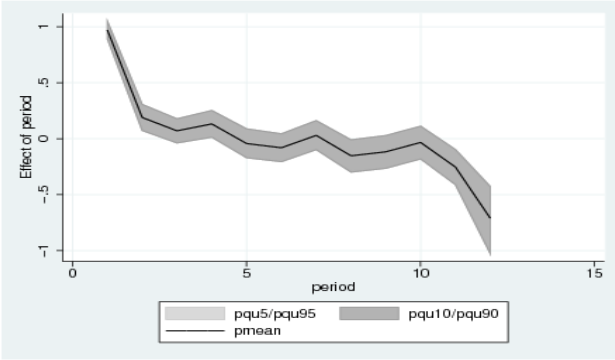

Effect of Asset Index

(Female Infants)

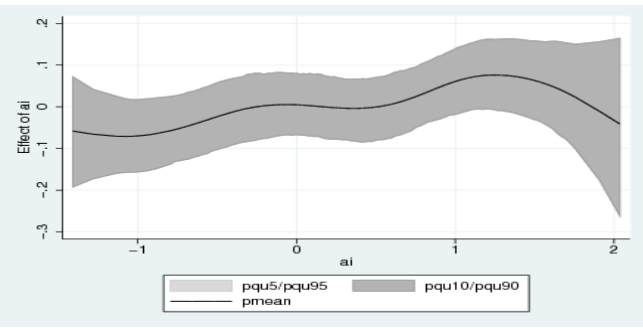

Effect of Mother's hsb index

(Female Infants)

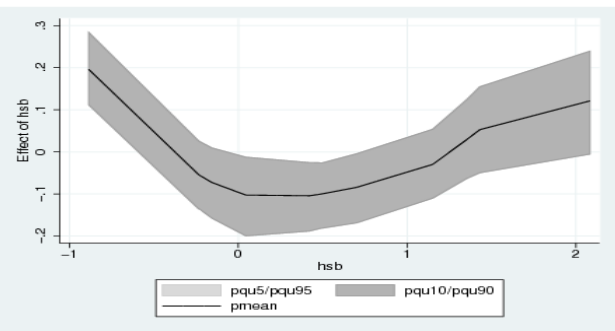

Effect of birth order

(Female Infants)

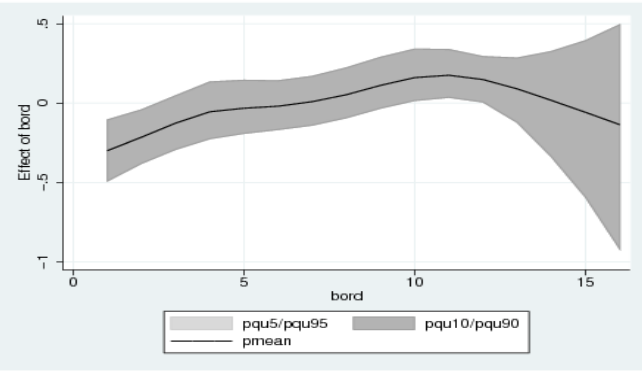

Figure B1. 6 Smooth Effects for Infants (by gender)
Effect of period (baseline hazard)

(Male Infants)

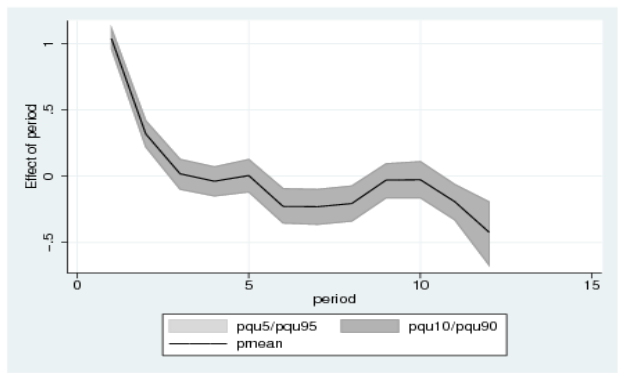

Effect of Asset Index

(Male Infants)

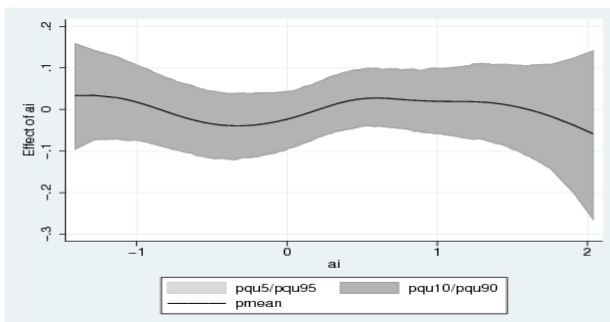

Effect of Mother's hsb index

(Male Infants)

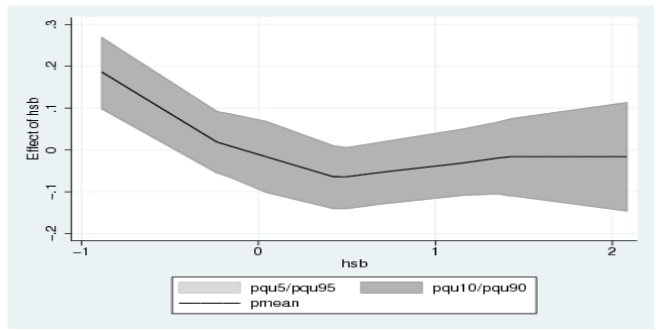

Effect of birth order

(Male Infants)

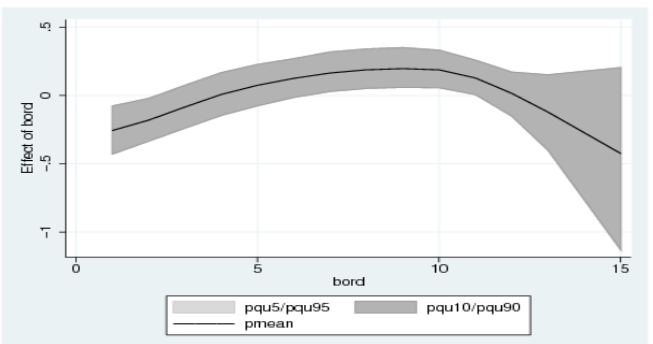




\title{
Essay 2
}

\section{Gender Bias in Mortality in Pakistan: Trends and Determinants 1990-2000}

\begin{abstract}
In this paper, we study the patterns of mortality differentials for male and female children over a period of time. Data from two surveys (10 years apart) have been analyzed which indicate that although the mortality rate has come down in the 10 year period, but most of the patterns of gender differentials almost remain the same. Notable departures being the higher age of mother associated with higher mortality, and the low mortality in urban areas as compared to the rural areas. Another strong indication is the significant positive effect of mother's education on the mortality of children, in particular the female child.
\end{abstract}




\subsection{Introduction}

"We cannot waste our precious children. Not another one, not another day" -Nelson Mandela and Graca Machel

Infant and child mortality are the two important health indicators used in the development literature. In fact, reducing child mortality by two thirds by the year 2015 is one of the targets in the Millennium Development Goals (MDGs). For a less developed country to progress it needs healthy children. Implementing efforts to decrease infant and child mortality is the only way to ensure a healthy population and prosperous future (UNAUSA, 2007). South Asia is a region which has one of the highest rates of infant and child mortality. One striking feature of mortality in South Asian context is the gender bias in mortality which has recently attracted much attention. (Das Gupta 1987; Kishor 1993 and 1995; Klasen and Wink 2003). Consequently, the term "missing women" was coined by Sen (1990) and further elaborated by researchers like Coal (1991), Klasen (1994) and Klasen and Wink (2002). The term "missing women" refers to the additional number of women who would have been alive today in the absence of any gender discrimination against the girl child. There is, however, consistent reduction in the relative number of missing women in China and South Asia (although the number has increased in absolute terms). The reason for the decline in percentage numbers is mainly due to declining sex ratios in most of the South Asian countries. According to Klasen and Wink (2002), considerable reductions in sex ratios have been observed, during the period 1981-1998, in South Asia (with Nepal having more drastic decline, and India having modest decline) and West Asia whereas China, South Korea and Sub-Saharan Africa have witnessed a slight increase in the sex ratios. In case of Pakistan, the (latest) census of 1998 shows the sex ratio to be 1.08 indicating a significant decline from that of 1981 (having sex ratio of 1.10) and 1972 (where sex ratio stood at 1.14). The declining sex ratio has contributed to a decline in the percentage of missing women in Pakistan from $10.23 \%$ (1981 census) to $7.8 \%$ (1998 census). This improvement may be due to improved enumeration of females on one hand, and improved education, employment, opportunities, and rising urbanization on the other hand. However, this improvement in the sex ratios has not fully translated into elimination of gender bias against the females 
as gender discrimination manifests itself in the form of higher post-noenatal and child mortality for females and low access to health care for female children (Klasen and Wink, 2002).

Gender bias in mortality is now well documented, particularly, for China and India (For India: Griffiths, Matthews, \& Hinde, 2000; Kishor, 1993; Murthi, Guio, \& Dre`ze, 1995; For China: Arnold \& Liu, 1986; Coale, 1991; Coale \& Banister, 1994; Johansson \& Nygren, 1991; Li \& Cooney, 1993). In case of China, the official one-child policy is one of the main driving forces behind parents' discriminatory preference for sons over daughters, whereas in India, deep religious, cultural as well as financial factors are responsible for discrimination against the girl child. Pakistan stands out in the South Asia as a country with worst performer in infant and child mortality (see evidence in Table 2.1 below). We see that Pakistan, with an infant mortality rate of 81 and under five mortality of 103 (both figures are per 1000 live births), stands out as a country with highest levels of infant and under five child mortality. Although the levels of infant and child mortality have declined in the recent years (in Pakistan Demographic and Health Survey of 1990-91, these figures were 97 and 124 respectively), however, the improvement is incompatible with sustained higher economic growth rate (above 6\%) and better macro-economic indicators. Besides, Pakistan is considered to be one of the worst performers in the gender development index (Table 2.1 below). Clearly with a Gender Development Index (GDI) rank of 107, Pakistan is far behind in the areas of gender mainstreaming and women empowerment as compared to its other South Asian counterparts.

Table 2. 1 Some regional Statistics

\begin{tabular}{|l|l|l|l|l|l|}
\hline & Bangladesh & India & Nepal & Pakistan & Sri Lanka \\
\hline $\begin{array}{l}\text { Under-5 mortality } \\
\text { rate,2003 }\end{array}$ & 69 & 87 & 82 & 103 & 15 \\
\hline $\begin{array}{l}\text { Infant mortality rate } \\
\text { (under 1),2003 }\end{array}$ & 46 & 63 & 61 & 81 & 13 \\
\hline HDI Rank, 2003 & 139 & 127 & 136 & 135 & 93 \\
\hline GDI Rank, 2003 & 105 & 98 & 106 & 107 & 66 \\
\hline
\end{tabular}

Source: HDR 2005 
This emphasizes the need to look at the gender dimension of child and infant mortality. A fairly large literature exists on the gender differences in infant and child mortality mostly based on the "son preference hypothesis" (Arnold et al. 2002; Arnold et al. 1998; Arnold 1992; Kishor 1993; Das Gupta 1987; Das Gupta and Mari Bhat 1997). In many countries in the South Asia, sons are considered to be a source of old age security and a means of better returns to investment whereas daughters are considered to be expensive (in areas where the dowry system is prevalent) and due to less economic independence of women, daughters are considered to be of less utility as compared to sons. In case of Pakistan, such literature is relatively small (Khan and Serageldin, 1977; Ali, 1989; Kiani 1992; Karim 1994; Gangadharan and Maitra 2000). These studies have looked into the underlying causes of son preference in Pakistan and its effect, if any, on the mortality differentials of children. Khan and Serageldin (1977) and Ali (1989) suggest that strong son preference may be due to the fact that sons are regarded as economic assets and oldage security. Data from Pakistan Demographic and Health Survey of 1990-91 shows that, of the women with no children, about one-third desired to have a son, while the preference for having a daughter was negligible (NIPS, 1992). Karim (1994), however, shows that the incidence of wider neglect of female children or preferential treatment for male children was not evident from the data. Gangadharan and Maitra (2000) infer that there is an excess female mortality in the children above one year of age, and they suggest that this might be due to preferential treatment of sons over daughters.

The emphasis in this paper is on the changing pattern of gender differentials in mortality over time. Our aim is to determine the nature, extent and determinants of gender differentials in mortality in Pakistan over a time period of ten years. The data from two surveys that are ten years apart have been considered and the determinants of gender differentials in mortality have been determined.

\subsection{Material and Methods}

Data from Pakistan Demographic and Health Survey (PDHS) 1990-91 and Pakistan Reproductive Health and Family Planning Survey (PRHFPS) 2000-01 have been utilized for the analysis and comparison. The PDHS is a nationally representative survey 
conducted by the Macro International in collaboration with USAID and Government of Pakistan and is part of the International DHS programme of the Macro International.

PRHFPS was conducted by the National Institute of Population Studies (NIPS) Islamabad. This survey interviewed 6857 households in a representative sample of the four provinces of Pakistan. In the selected household, 7411 ever-married women aged 1549 years were interviewed. The survey focused on the objectives of assessing reproductive health and family planning programme. PRHFPS provides status of socioeconomic, demographic reproductive health and family planning indicators.

\subsubsection{Descriptive Statistics}

Table 2.2 summarizes the levels of infant, child and under five mortality in Pakistan. These rates have been obtained from the life table analysis on the datasets for the two surveys. The rates reflect the mortality over the ten-year period before the respective survey.

Table 2. 2 Infant and Child Mortality based on the two selected surveys

\begin{tabular}{|c|c|c|c|c|c|c|}
\hline \multirow[t]{2}{*}{ (2) } & \multicolumn{3}{|c|}{ PDHS 1990-91 } & \multicolumn{3}{|c|}{ PRHFPS 2000-01 } \\
\hline & Male & Female & Both sexes & Male & Female & Both sexes \\
\hline Infant Mortality $\left({ }_{0} \mathrm{q}_{1}\right)$ & 102 & 86 & 94 & 99 & 71 & 85 \\
\hline Child Mortality $\left({ }_{1} \mathrm{q}_{4}\right)$ & 22 & 37 & 29 & 15 & 24 & 20 \\
\hline Under 5 Mortality $\left({ }_{0} \mathrm{q}_{5}\right)$ & 122 & 119 & 120 & 112 & 93 & 103 \\
\hline
\end{tabular}

The above table provides infant mortality, child mortality and under 5 mortality rates (per 1000) for male, female as well as all children for the two surveys. The table indicates the pattern and levels of mortality among children in Pakistan for the two surveys. We could immediately note two facts: First, there has been a small decline in mortality for children of both sexes; however, the mortality still remains very high. Second, in both surveys, the child mortality for girls $\left({ }_{1} \mathrm{q}_{4}\right)$ remains higher than that of boys, that is, in PDHS the female child mortality rate was 37 as compared to the male child mortality rate of 22 , whereas, in PRHFPS, the same comparison is 24 versus 15 . This may reflect the fact that after the infant stage, the mortality differences between female and male children may be indicative of the preferential treatment of son over daughters by the respective parents 
and may well indicate gender bias against the female child. The higher infant and under five mortality rates for male as compared to female children are consistent with the current literature.

Two data sets were constructed for this paper from the available data for the two surveys (PDHS 1990-91 and PRHFPS 2000-01). In the original PDHS data, only one death occurred beyond the age of three years, so we restricted the data to first 3 years (36 months of age) only. Similarly, in order to avoid an overlap with the PDHS data, we restricted the dataset from the PRHFPS to the years 1991 and above (so effectively all those cases where the births occurred before 1991 were dropped). Similarly, the analysis of the PRHFPS data was also restricted to first three years of life (36 months) so as to make the comparisons valid with those of the PDHS data. Further, as the PDHS does not include data on Islamabad (as a region) as is the case in the PRHFPS dataset, so we also dropped the observations on Islamabad so as to bring uniformity in the comparison of the two datasets.

The following table shows the variables selected for this study.

Table 2. 3 Categorical variables included in the analysis

\begin{tabular}{|c|c|c|c|c|c|c|}
\hline \multirow[t]{2}{*}{ Variable } & \multirow[t]{2}{*}{ Interpretation } & \multirow[t]{2}{*}{ Coding } & \multicolumn{2}{|l|}{ PDHS 1990-91 } & \multicolumn{2}{|l|}{ PRHFPS 2000-01 } \\
\hline & & & Female & Male & Female & Male \\
\hline GENDER & Sex of Child & $\begin{array}{l}0: \text { Male }\left(\mathrm{RC}^{*}\right) \\
1: \text { Female }\end{array}$ & $2086(48.8 \%)$ & $2191(51.2 \%)$ & $2202(48.4 \%)$ & $2344(51.6 \%)$ \\
\hline BORD1 & $\begin{array}{l}\text { Whether the child has } \\
\text { birth order } 1\end{array}$ & $\begin{array}{l}0: \text { No } \\
1: \text { Yes }\end{array}$ & $\begin{array}{r}1717(82.3 \%) \\
369(17.7 \%)\end{array}$ & $\begin{array}{r}1766(80.6 \%) \\
425(19.4 \%)\end{array}$ & $\begin{array}{r}1712(77.7 \%) \\
490(22.3 \%)\end{array}$ & $\begin{array}{r}1808(77.1 \%) \\
536(22.9 \%)\end{array}$ \\
\hline LONG_BI & Long Birth Interval & $\begin{array}{l}0: \leq 24 \text { months }(\mathrm{RC}) \\
1:>24 \text { months }\end{array}$ & $\begin{array}{r}945(45.3 \%) \\
1141(54.7 \%)\end{array}$ & $\begin{array}{l}1028(46.9 \%) \\
1163(53.1 \%)\end{array}$ & $\begin{array}{l}1118(50.8 \%) \\
1084(49.2 \%)\end{array}$ & $\begin{array}{l}1225(52.3 \%) \\
1119(47.7 \%)\end{array}$ \\
\hline FULL_VACC & Fully Vaccinated & $\begin{array}{l}0: \text { No }(\mathrm{RC}) \\
1: \text { Yes }\end{array}$ & $\begin{array}{r}1517(72.7 \%) \\
569(27.3 \%)\end{array}$ & $\begin{array}{r}5131(69.9 \%) \\
660(30.1 \%)\end{array}$ & $\begin{array}{r}1304(59.2 \%) \\
898(40.8 \%)\end{array}$ & $\begin{array}{r}1359(58.0 \%) \\
985(42.0 \%)\end{array}$ \\
\hline REGION & Province of residence & $\begin{array}{l}\text { 1: Punjab } \\
\text { 2: Sindh } \\
\text { 3: NWFP (RC) } \\
\text { 4: Baluchistan }\end{array}$ & $\begin{array}{l}699(33.5 \%) \\
557(26.7 \%) \\
548(26.3 \%) \\
282(13.5 \%)\end{array}$ & $\begin{array}{l}805(36.7 \%) \\
561(25.6 \%) \\
541(24.7 \%) \\
284(13.0 \%)\end{array}$ & $\begin{array}{l}979(44.4 \%) \\
623(28.3 \%) \\
418(19.0 \%) \\
182(8.3 \%)\end{array}$ & $\begin{array}{r}1032(44.0 \%) \\
674(28.8 \%) \\
420(17.9 \%) \\
218(9.3 \%)\end{array}$ \\
\hline RESIDENCE & $\begin{array}{l}\text { Type of place of } \\
\text { residence }\end{array}$ & $\begin{array}{l}\text { 0: Urban (RC) } \\
\text { 1: Rural }\end{array}$ & $\begin{array}{l}1074(51.5 \%) \\
1012(48.5 \%)\end{array}$ & $\begin{array}{l}1103(50.3 \%) \\
1088(49.7 \%)\end{array}$ & $\begin{array}{c}832(37.8 \%) \\
1370(62.2 \%)\end{array}$ & $\begin{array}{r}850(36.3 \%) \\
1494(63.7 \%)\end{array}$ \\
\hline $\begin{array}{l}\text { PRIM_M/SEC } \\
\text { OND_M }\end{array}$ & $\begin{array}{l}\text { Primary/Secondary } \\
\text { Education of mother }\end{array}$ & $\begin{array}{l}\text { 0: No education (RC) } \\
\text { 1:Primary/ Secondary }\end{array}$ & $\begin{array}{l}1561(74.8 \%) \\
211 / 314 \\
(10.1 \% / 15.1 \%)\end{array}$ & $\begin{array}{l}1588(77.0 \%) \\
205 / 298 \\
(9.4 \% / 13.6 \%)\end{array}$ & $\begin{array}{l}16136(74.3 \%) \\
260 / 306 \\
(11.8 \% / 13.9 \%)\end{array}$ & $\begin{array}{l}1749(74.6 \%) \\
279 / 316 \\
(11.9 \% / 13.5 \%)\end{array}$ \\
\hline
\end{tabular}

* RC: Reference Category 
Table 2. 4 Continuous variables included in the analysis

\begin{tabular}{|c|c|c|c|c|c|c|c|c|c|}
\hline \multirow[t]{3}{*}{ Variable } & \multirow[t]{3}{*}{ Interpretation } & \multicolumn{4}{|c|}{ PDHS 1990-91 } & \multicolumn{4}{|c|}{ PRHFPS 2000-2001 } \\
\hline & & \multicolumn{2}{|c|}{ Female children } & \multicolumn{2}{|c|}{ Male Children } & \multicolumn{2}{|c|}{ Female children } & \multicolumn{2}{|c|}{ Male Children } \\
\hline & & Mean & SD* & Mean & SD* & Mean & $\mathrm{SD}^{*}$ & Mean & $\mathrm{SD}^{*}$ \\
\hline $\mathrm{CH} \_\mathrm{AGE} \dagger$ & Child's age (months) & 15.4 & 11.0 & 15.6 & 11.4 & 15.0 & 11.6 & 14.8 & 11.8 \\
\hline M_AGE $\ddagger$ & Mother's age (years) & 27.3 & 6.3 & 27.4 & 6.7 & 27.1 & 6.4 & 27.1 & 6.4 \\
\hline HHMEMBERS & Household size & 9.1 & 4.6 & 9.2 & 4.6 & 9.5 & 4.8 & 9.5 & 5.1 \\
\hline AI & Asset Index & 0.0188 & 1.02 & -0.0386 & 0.98 & -0.1453 & 0.89 & -0.1641 & 0.88 \\
\hline HSB & Health Seeking Behaviour & 0.0415 & 1.02 & 0.0142 & 1.01 & 0.024 & 1.0 & 0.0379 & 0.98 \\
\hline
\end{tabular}

*SD: Standard Deviation;

$\dagger$ Ch_Age indicates the current age of the child if the child is alive; and it indicates the age at death if the child is dead.

$\ddagger$ M_Age is the age of the mother at the birth of the index child

The variables AI and HSBI were constructed using factor analysis. For methodological details of the technique of factor analysis for constructing the asset index; see Sahn and Stifel $(2000,2003)$. The dummy variable FULL_VACC was constructed from the information available on the immunization of children (see last chapter).

\subsection{Empirical Framework}

Bayesian structured hazard model based on mixed model methodology (Kneib \& Fahrmeir, 2006) has been utilized in this study. The technique used here is a generalization of the Cox proportional hazard model. The only reason of switching from MCMC based methodology (used in Essay 1) was that each time the program in our software (BayesX) crashed when we were trying to get the MCMC based results for PRHFPS dataset. As the MCMC based method is computationally intensive, so the relatively larger sample size of the PRHFPS dataset may possibly be the reason for such a crash. Hence choice of the mixed model methodology was rather due to convenience in this particular situation. Following is a brief description of the model used in this essay:

\subsubsection{Structured Hazard Regression Model}

Consider right-censored survival data with observed lifetimes $t_{i}$ and censoring indicators $\delta_{\mathrm{i}}, \mathrm{i}=1,2, \ldots \ldots, \mathrm{n}$, and further additional variables $v_{\mathrm{i}}$. The most common type of statistical model for analyzing the effect of the covariates on the survival time is the Cox proportional hazard model defined by:

$$
\lambda(t ; v)=\lambda_{0}(t) \exp \left(v^{\prime} \gamma\right)
$$

Where $\gamma$ is a vector of regression coefficients, $\lambda_{0}(t)$ is the baseline hazard rate. In such setting the baseline hazard rate remains unspecified and the partial likelihood method is 
used to estimate the regression coefficients $\gamma$. However, the Cox model has certain limitations as in real situations we may be interested in estimating non-linear effects of some covariates as well as some of the variables may have spatial structure. Kneib and Fahrmeir (2006) have extended the Cox model to a more generalized structured hazard model using the Bayesian approach. In this approach, the Cox model has been extended as

$$
\lambda_{i}(t)=\lambda_{i}(t)=\lambda\left(t ; v_{i}\right)=\exp \left(\eta_{i}(t)\right)
$$

With additive predictor

$$
\eta_{i}(t)=f_{0}(t)+\sum_{j=1}^{J} f_{j}\left(x_{i j}\right)+v_{i}^{\prime} \gamma
$$

Where the vector $\gamma$ contains the usual linear effects, $f_{0}(t)=\log \left(\lambda_{0}(t)\right)$ is the log baseline hazard, and $f_{j}\left(x_{i j}\right)$ is the non-linear effect of a continuous covariate $x_{j}$.

\subsubsection{Prior Specifications}

In this modeling framework, we specify non-informative (flat) prior to $\gamma$, that is,

$$
\mathrm{p}(\gamma) \alpha \text { const. }
$$

Bayesian Penalised Splines (Lang \& Brezger, 2004) are used to estimate the baseline effect and non-parametric effects. In this approach, it is assumed that the unknown functions $\mathrm{f}_{\mathrm{j}}$ of covariate $\mathrm{x}_{\mathrm{j}}$ can be approximated by a polynomial spline of degree $l$ defined by a set of equally spaced knots

$$
\xi_{0}=x_{\min }<\xi_{1}<\ldots \ldots \ldots \ldots \ldots \xi_{k-1}<\xi_{k}=x_{\max } \quad \text { (omitting the subscript } \mathrm{j} \text { for convenience) }
$$

over the domain of $\mathrm{x}$.

The spline can be expressed as a linear combination of $\mathrm{M}=\mathrm{k}+1 \mathrm{~B}$-spline basis functions $\mathrm{B}_{\mathrm{m}}$, that is,

$$
f(x)=\sum_{m=1}^{M} \beta_{m} B_{m}(x)
$$

where $B_{m}$ is the $m$-th basis function. Here $\boldsymbol{\beta}=\left(\beta_{1}, \beta_{2}, \ldots \ldots \ldots \beta_{M}\right)^{\prime}$ corresponds to vector of regression coefficients

A moderate number of knots is selected (usually 20) so as to ensure flexibility, whereas the smoothness of the function is maintained by taking quadratic difference penalties for neighbouring coefficients in the sequence $\beta_{j}=\left(\beta_{j 1}, \beta_{j 2}, \ldots \ldots \ldots \ldots, \beta_{j d_{j}}\right)^{\prime}$. In the penalized 
likelihood setting, such difference penalty can be expressed as $\lambda_{j} \beta_{j}^{\prime} K_{j} \beta_{j}$ where $K_{j}=D^{\prime} D$ with a first or second-order difference matrix $\mathrm{D}$ and smoothing parameter $\lambda_{j}=\frac{1}{2 \tau_{j}{ }^{2}}$. In the Bayesian mixed model approach, the above mentioned difference penalty is equivalent to the prior $p\left(\beta_{j} / \tau_{j}{ }^{2}\right)$ defined by

$$
P\left(\beta j / \tau_{j}^{2}\right) \propto \exp \left(-\frac{1}{2 \tau_{j}^{2}} \beta_{j}^{\prime} K_{j} \beta_{j}\right)
$$

where $K_{j}$ acts as a penalty matrix with $\operatorname{rank}\left(K_{j}\right)=k_{j} \leq d_{j}=\operatorname{dim}\left(\beta_{j}\right)$, and $\tau_{j}^{2} \geq 0$ are interpreted as a variance or (inverse) smoothness parameter. These variances are treated as unknown fixed constants and are estimated through a marginal likelihood approach.

\subsubsection{Mixed Model based inference}

The inference in this approach is based on the penalized log-likelihood, that is,

$$
l_{p e n}(\gamma, \beta)=l(\gamma, \beta)-\sum_{j=1}^{p} \frac{1}{2 \tau_{j}^{2}} \beta_{j}^{\prime} K_{j} \beta_{j}
$$

In the Bayesian approach, above mentioned penalized log-likelihood is equivalent to the log-posterior and, therefore, maximizing the above with respect to the regression coefficients yields either penalized likelihood or posterior mode estimates. However, marginal likelihood estimates for the variance parameters $\tau_{j}^{2}$ cannot be derived from the above mentioned penalized log-likelihood because some of the random effects distributions are improper. Hence for the estimation of the structured hazard regression models, the general mixed model is reparametrized in a classical variance components model formulation so as to obtain uncorrelated random effects with proper prior priors, and then, using the Newton-Raphson/ Fisher scoring algorithm, the regression coefficients are iteratively updated given the current variance parameters. Similarly, the variance components are iteratively updated given current regression coefficients.

The variance parameter $\tau_{j}^{2}$ is equivalent to the inverse smoothing parameter in a frequentist approach and controls the trade off between flexibility and smoothness. In practice, weakly informative inverse Gamma hyperprior $\tau_{\mathrm{j}}{ }^{2} \sim \mathrm{IG}\left(\mathrm{aj}_{\mathrm{j}}, \mathrm{b}_{\mathrm{j}}\right)$ are assigned to $\tau_{\mathrm{j}}^{2}$, with $\mathrm{aj}_{\mathrm{j}}=\mathrm{b}_{\mathrm{j}}=0.001$ as a standard option. 
More methodological details of the above Bayesian mixed model can be found in Kneib and Fahrmeir (2006) and Lang and Brezger (2004).

The whole model methodology has been implemented in the software BayesX, a freeware software available at http://www.stat.uni-muenchen.de/ bayesx/bayesx.html .

\subsection{Results and Discussions}

The analyses were carried out using the freeware software BayesX. Analyses were done for infant and child mortality for each sex separately and for each of the two surveys (PDHS and PRHFPS).

The semiparametric predictor used in our analysis is of the form

$$
\begin{aligned}
\eta_{\text {it }}= & \mathrm{f}_{0}\left(\text { age } \_ \text {child } 1\right)+\mathrm{f}_{1}(\mathrm{ai})+\mathrm{f}_{2}(\mathrm{hsb})+\gamma_{1} \mathrm{~m} \_ \text {age }+\gamma_{2} \text { long_bi }+\gamma_{3} \text { bord } 1+\gamma_{4} \text { full_vacc } \\
& +\gamma_{5} \text { hhmember }+\gamma_{6} \text { prim_m } \mathrm{m}+\gamma_{7} \text { second_m }+\gamma_{8} \text { punjab }+\gamma_{9} \operatorname{sindh}+\gamma_{10} \text { baluchis } \\
& +\gamma_{11} \text { residenc }
\end{aligned}
$$

Here $\mathrm{f}_{0}\left(\right.$ age $\_$child 1$)$ represents the baseline hazard.

\subsubsection{Results: Fixed effects}

Tables 2.5 and 2.6 provide the posterior mode estimates, along with $90 \%$ confidence intervals, for our selected model for the DHS 1990-91 and the PRHFPS 2000-01 for both male and female children. In contrast to the MCMC-based methodology (used in Essay 1, which provides posterior means estimates), the mixed model based inference of the technique used in this essay provides posterior mode estimates. Further, we have selected the $90 \%$ credible interval here so as to get maximum coverage of our estimates.

There are some visible similarities as well as differences. Having a large (preceding) birth interval, being fully vaccinated and living in house with large number of household members are significantly conducive for the survival of both male and female children. The marginal effect of full vaccination coverage is stronger for male children as compared to female children; whereas the same can be said for the male children in case of marginal effects of larger birth interval and household size. We further observe that being a resident in Punjab and Sindh has a higher mortality contribution, particularly for male children. However, there are some notable differences, namely, in the DHS, we see that higher the age of the mother, lower is the mortality, whereas in PRHFPS, the higher the age of the mother, the higher is the mortality and the effect of this higher mortality is 
also significant for both male and female children. Further, looking at the size of the marginal effects, we observe that the risk due to higher age of mother (at the birth of her child) is higher for female children as compared to male children. One might argue that in the ten years time period from PDHS to PRHFPS, female education has spread, and as a result the more educated mothers are terminating their fertility quite earlier (late marriages in case of an educated female may also be one of the factor), so the remaining mothers are most probably less educated and having poor background. So the mortality of children belonging to poor, less educated mothers is high. Similarly, the mortality is significantly low for both male and female children if they happen to be first-born child in case of the PDHS dataset, but for the PRHFPS dataset, we have the opposite scenario, that is, first-born children are significantly more at risk of death as compared to those having higher birth order. The marginal effect of higher mortality is stronger for female children thereby suggesting that first-born female children are more at risk as compared to first-born male children. Further, in case of male child, the mortality is higher in rural areas for the PRHFPS. This may reflect in part better health coverage available in the urban areas as compared to the rural areas. Interestingly this improvement is not visible for the female child which may be a sign of gender discrimination in access to health on part of the parents. One striking aspect of the change in mortality patterns from PDHS to PRHFPS is the significantly positive effect of mother's education (particularly, secondary or higher level) on the mortality of children. This shows the effect of the growing and better education opportunity of females in the 10 years time period. We can further observe that mother's education has got a significantly positive effect on the mortality of both male and female children in the PRHFPS whereas in the PDHS the positive effect is only for the female children. This is again an indication of positive effect of the growing female education in the past ten years. Furthermore, in case of PRHFPS dataset, the marginal effect of mother's (secondary or higher level) education is stronger for the female children in comparison to that for male children. This further elaborates the point that mother's education has a particularly favourable effect on the mortality reduction for daughters. Another notable difference is the effect of being first born on the mortality of the children. Whereas in PDHS, the effect is significantly lower, the same in the PRHFPS is lower but not significant. We can also observe that the mortality in Baluchistan is 
significantly lower for female children in Baluchistan in case of PRHFPS. Since Baluchistan is the most economically backward region of Pakistan with less adequate health facilities, this result seems a bit strange. However, one reason may be the undercoverage of female children in Baluchistan.

Another interesting result is the opposite signs for the variable "residence" for female and male children. Although the mortality is lower in rural areas in the PDHS, we observe that for the PRHFPS dataset, female (children) mortality is lower in rural areas whereas male (children) mortality is lower in urban areas.

Table 2. 5 Fixed effects for Female and Male Children (under 3) from PDHS

\begin{tabular}{|c|c|c|c|c|c|c|}
\hline \multirow[t]{3}{*}{ Variable } & \multicolumn{3}{|c|}{ Female Children } & \multicolumn{3}{|c|}{ Male Children } \\
\hline & \multicolumn{3}{|c|}{$90 \%$ Conf. Interval } & \multicolumn{3}{|c|}{$90 \%$ Conf. Interval } \\
\hline & Post. Mode & Lower & Tpper & Post. Mode & Lower & Upper \\
\hline const & -7.598 & -9.232 & -5.965 & -5.170 & -5.781 & -4.559 \\
\hline age mab & -0.006 & -0.025 & 0.014 & -0.017 & -0.034 & 0.0004 \\
\hline long bi & $-1.109 * * *$ & -1.355 & -0.863 & $-1.160 * * *$ & -1.399 & -0.921 \\
\hline bord 1 & $-0.423 * *$ & -0.728 & -0.118 & $-0.421 * *$ & -0.689 & -0.152 \\
\hline full vacc & $-1.748 * * *$ & -2.156 & -1.341 & $-2.681 * * *$ & -3.244 & -2.118 \\
\hline hhmembers & $-0.054 * * *$ & -0.082 & -0.026 & $-0.032 * * *$ & -0.058 & -0.007 \\
\hline prim_m & 0.051 & -0.313 & 0.414 & -0.039 & -0.409 & 0.332 \\
\hline second $\mathrm{m}$ & $-0.471 *$ & -0.910 & -0.033 & 0.216 & -0.192 & 0.625 \\
\hline Punjab & 0.166 & -0.125 & 0.458 & $0.410 * *$ & 0.124 & 0.696 \\
\hline Sindh & 0.068 & -0.235 & 0.371 & 0.090 & -0.230 & 0.411 \\
\hline Baloch & -0.079 & -0.467 & 0.310 & 0.101 & -0.257 & 0.459 \\
\hline residence & -0.107 & -0.392 & 0.178 & -0.139 & -0.399 & 0.121 \\
\hline
\end{tabular}

Table 2. 6 Fixed effects for Female and Male children (under 3) from PRHFPS

\begin{tabular}{|c|c|c|c|c|c|c|}
\hline \multirow[t]{3}{*}{ Variable } & \multicolumn{3}{|c|}{ Female Children } & \multicolumn{3}{|c|}{ Male Chldren } \\
\hline & \multicolumn{3}{|c|}{$90 \%$ Conf. Interval } & \multicolumn{3}{|c|}{$90 \%$ Conf. Interval } \\
\hline & Post. Mode & Lower & Upper & Post. Mode & Lower & Upper \\
\hline const & -6.351 & -6.980 & -5.721 & -6.261 & -6.951 & -5.570 \\
\hline age mab & $0.052 * * *$ & 0.038 & 0.066 & $0.026 * * *$ & 0.013 & 0.038 \\
\hline long_bi & $-0.591 * * *$ & -0.810 & -0.372 & $-0.435 * * *$ & -0.633 & -0.238 \\
\hline bord 1 & $0.748 * * *$ & 0.518 & 0.977 & $0.673 * * *$ & 0.479 & 0.866 \\
\hline full_vacc & $-1.026 * * *$ & -1.240 & -0.812 & $-1.451 * * *$ & -1.658 & -1.245 \\
\hline hhmembers & $-0.060 * * *$ & -0.083 & -0.038 & $-0.100 * * *$ & -0.121 & -0.079 \\
\hline prim_m & -0.270 & -0.595 & 0.055 & $-0.304 *$ & -0.573 & -0.035 \\
\hline second_m & $-0.739 * * *$ & -1.195 & -0.283 & $-0.928 * * *$ & -1.297 & -0.559 \\
\hline Punjab & 0.142 & -0.092 & 0.378 & $0.353 * *$ & 0.122 & 0.583 \\
\hline Sindh & -0.077 & -0.334 & 0.181 & 0.168 & -0.082 & 0.418 \\
\hline Baloch & $-1.029 * * *$ & -1.546 & -0.512 & -0.114 & -0.452 & 0.224 \\
\hline residence & -0.006 & -0.230 & 0.217 & 0.085 & -0.121 & 0.291 \\
\hline
\end{tabular}

Tables 2.7 and 2.8 provide the comparative results for the mortality differences of male and female children aged 1 year and above (restricted to first three years of life). More or less similar patterns in mortality exist as was the case for the overall children with few exceptions. The effects of long birth interval as well as vaccination coverage are no more significant in the PRHFPS (interestingly, the sign reverses for female children). In contrast to the PDHS (where even larger household size is detrimental to the survival of 
female child), we see that the larger household size has a significantly positive effect for both male and female children in the PRHFPS. As before, mother's education has a positive effect on the mortality reduction, however, in the PRHFPS dataset, we observe that this effect is significantly positive for female children if the mother has secondary or higher education. Mortality for female children is lower in the PRHFPS as compared to other regions. This may be partly due to undercoverage of female children in Baluchistan, the point elaborated earlier. However, in contrast to the results for all children, we observe that for the children aged one and over, the mortality is lower for rural areas for both male and female children in the two surveys.

Table 2. 7 Fixed effects for Female and Male Children (over 1 and under 3) from PDHS

\begin{tabular}{|c|c|c|c|c|c|c|}
\hline \multirow[t]{3}{*}{ Variable } & \multicolumn{3}{|c|}{ Female Children (1+) } & \multicolumn{3}{|c|}{ Male Children $(1+)$} \\
\hline & \multicolumn{3}{|c|}{$90 \%$ Conf. Interval } & \multicolumn{3}{|c|}{$90 \%$ Conf. Interval } \\
\hline & Post. Mode & Lower & Tpper & Post. Mode & Lower & Upper \\
\hline const & -6.574 & -8.736 & -4.412 & -9.266 & -12.15 & -6.380 \\
\hline age_mab & -0.053 & -0.108 & 0.002 & -0.026 & -0.073 & 0.021 \\
\hline long_bi & $-1.212 * * *$ & -1.852 & -0.572 & $-1.218 * * *$ & -1.831 & -0.605 \\
\hline bord 1 & $-1.172 * *$ & -2.080 & -0.263 & $-1.763 * * *$ & -2.842 & -0.685 \\
\hline full_vacc & $-1.623 * * *$ & -2.645 & -0.602 & $-1.352 * *$ & -2.249 & -0.455 \\
\hline hhmembers & 0.017 & -0.047 & 0.081 & -0.015 & -0.082 & 0.052 \\
\hline prim_m & 0.624 & -0.287 & 1.536 & -0.079 & -1.143 & 0.982 \\
\hline second_m & -0.823 & -2.625 & 0.978 & -0.904 & -2.699 & 0.891 \\
\hline Punjab & 0.610 & -0.285 & 1.506 & 0.433 & -0.387 & 1.254 \\
\hline Sindh & 0.477 & -0.459 & 1.412 & 0.028 & -0.927 & 0.982 \\
\hline Baloch & 0.846 & -0.130 & 1.822 & 0.292 & -0.664 & 1.248 \\
\hline residence & -0.135 & -0.908 & 0.639 & -0.471 & -1.205 & 0.263 \\
\hline
\end{tabular}

Table 2. 8 Fixed effects for Female and Male children (over 1 and under 3) from PRHFPS

\begin{tabular}{|c|c|c|c|c|c|c|}
\hline \multirow[t]{3}{*}{ Variable } & \multicolumn{3}{|c|}{ Female Children $(1+)$} & \multicolumn{3}{|c|}{ Male Chldren (1+) } \\
\hline & \multicolumn{3}{|c|}{$90 \%$ Conf. Interval } & \multicolumn{3}{|c|}{$90 \%$ Conf. Interval } \\
\hline & Post. Mode & Lower & pper & Post. Mode & Lower & Upper \\
\hline const & -13.015 & -16.323 & -9.707 & -10.998 & -13.978 & -8.018 \\
\hline age_mab & $0.091 * * *$ & 0.057 & 0.125 & $0.059 * * *$ & 0.023 & 0.096 \\
\hline long_bi & -0.259 & -0.794 & 0.276 & -0.176 & -0.802 & 0.450 \\
\hline bord1 & 1.082 & 0.469 & 1.695 & 1.083 & 0.440 & 1.726 \\
\hline full_vacc & 0.315 & -0.137 & 0.768 & -0.332 & -0.836 & 0.173 \\
\hline hhmembers & $-0.103 * * *$ & -0.166 & -0.040 & -0.154 & -0.232 & -0.076 \\
\hline prim_m & -594.747 & $-4.670 e+128$ & $4.670 \mathrm{e}+128$ & -0.948 & -1.958 & 0.062 \\
\hline second_m & $-1.385 *$ & -2.581 & -0.189 & -1.160 & -2.544 & 0.223 \\
\hline Punjab & -0.242 & -0.817 & 0.332 & 0.189 & -0.442 & 0.820 \\
\hline Sindh & 0.238 & -0.371 & 0.848 & 0.028 & -0.695 & 0.752 \\
\hline Baloch & -1.565 & -3.285 & 0.154 & -1.014 & -2.312 & 0.285 \\
\hline residence & -0.098 & -0.632 & 0.435 & -0.210 & -0.850 & 0.431 \\
\hline
\end{tabular}

Tables 2.9 and 2.10 give comparative results for male and female infants in the two surveys. Like the earlier results for children, the higher age of the mother contributes to significantly higher mortality for both male and female children in case of PRHFPS dataset in contrast to that for PDHS dataset. Long birth interval, being fully vaccinated, having larger household size are all conducive for the survival of infants (in both 
surveys). Whereas mortality is lower for the first-born male and female infants for the PDHS, the opposite is true for the PRHFPS. That is, being first-born is associated with significantly higher mortality for both male and female infants in case of the PRHFPS dataset. Mother's education (primary and above) contributes to the reduction in mortality (exceptions being the male infants in DHS and female infants in the PRHFPS). As for regional patterns of mortality, we observe that the mortality is higher in Punjab (significantly for male infants) and Sindh. Except for male infants in the PDHS dataset, the mortality for both male and female infants is lower in Baluchistan in both surveys. There may be some possible interpretation of such big differences in regional patterns of mortality. As Punjab is the most economically prosperous and developed region, it seems very strange that this region has much higher mortality patterns than the rest of the regions. Similarly, lower mortality in the two less developed regions, namely N.W.F.P. and Baluchistan, are also apparently unexpected. One may argue that perhaps the data accuracy (in as far as the reporting of the child's death by his/ her mother is concerned) is more accurate in Punjab. Further, there may be a possible under-reporting of deaths (particularly those of girls in N.W.F.P. and Baluchistan). The particular culture (mostly conservative) of the two regions of N.W.F.P. and Baluchistan usually prohibits to report information on the female member of the household and this may possibly lead to the under-reporting. Another fact is that the four regions of Pakistan are broadly inhabited by the four major ethnic groups (namely, Punjabi, Sindhi, Pashtun and Baluchi). Thus genetic factors may also be playing the role. This fact is, however, not been explored in this work.

Further, we observe the change in the patterns of mortality in the rural and urban areas. In the DHS, both male and female infants have a lower mortality in rural areas whereas in the PRHFPS, we see that the mortality for infants is lower in urban areas. This may perhaps reflect the availability of and access to better maternity services in urban areas in comparison to rural area. 
Table 2.9 Fixed effects for Female and Male Infants from PDHS

\begin{tabular}{|c|c|c|c|c|c|c|}
\hline \multirow[t]{3}{*}{ Variable } & \multicolumn{3}{|c|}{ Female Infants } & \multicolumn{3}{|c|}{ Male Infants } \\
\hline & \multicolumn{3}{|c|}{$90 \%$ Conf. Interval } & \multicolumn{3}{|c|}{$90 \%$ Conf. Interval } \\
\hline & Post. Mode & Lower & pper & Post. Mode & Lower & Upper \\
\hline const & -3.851 & -4.562 & -3.140 & -3.819 & -4.480 & -3.157 \\
\hline age_mab & 0.003 & -0.019 & 0.024 & -0.016 & -0.034 & 0.003 \\
\hline long_bi & $-1.076 * * *$ & -1.348 & -0.805 & $-1.157 * * *$ & -1.417 & -0.897 \\
\hline bord 1 & -0.294 & -0.626 & 0.037 & $-0.304 *$ & -0.584 & -0.023 \\
\hline full_vacc & $-1.754 * * *$ & -2.206 & -1.303 & $-3.109 * * *$ & -3.858 & -2.361 \\
\hline hhmembers & $-0.070 * * *$ & -0.103 & -0.038 & $-0.036 * *$ & -0.063 & -0.008 \\
\hline prim_m & -0.035 & -0.441 & 0.371 & -0.018 & -0.414 & 0.378 \\
\hline second $\mathrm{m}$ & $-0.464 *$ & -0.927 & -0.0005 & 0.305 & -0.122 & 0.732 \\
\hline Punjab & 0.107 & -0.208 & 0.422 & 0.386 & 0.080 & 0.691 \\
\hline Sindh & 0.031 & -0.295 & 0.357 & 0.100 & -0.241 & 0.442 \\
\hline Baloch & -0.283 & -0.730 & 0.163 & 0.074 & -0.315 & 0.463 \\
\hline residence & -0.112 & -0.423 & 0.199 & -0.099 & -0.378 & 0.179 \\
\hline
\end{tabular}

Table 2. 10 Fixed effects for Female and Male Infants from PRHFPS

\begin{tabular}{|c|c|c|c|c|c|c|}
\hline \multirow[t]{3}{*}{ Variable } & \multicolumn{3}{|c|}{ Female Infants } & \multicolumn{3}{|c|}{ Male Infants } \\
\hline & \multicolumn{3}{|c|}{$90 \%$ Conf. Interval } & \multicolumn{3}{|c|}{$90 \%$ Conf. Interval } \\
\hline & Post. Mode & Lower & Upper & Post. Mode & Lower & Upper \\
\hline const & -5.038 & -5.657 & -4.419 & -3.905 & -4.517 & -3.294 \\
\hline age_mab & $0.040 * * * *$ & 0.025 & 0.055 & $0.021 * *$ & 0.007 & 0.035 \\
\hline long_bi & $-0.629 * * *$ & -0.855 & -0.402 & $-0.477 * * *$ & -0.685 & -0.268 \\
\hline bord 1 & $0.569 * * *$ & 0.332 & 0.807 & $0.615 * * *$ & 0.412 & 0.818 \\
\hline full_vacc & $-1.312 * * *$ & -1.555 & -1.069 & $-1.649 * * *$ & -1.882 & -1.416 \\
\hline hhmembers & $-0.054 * * *$ & -0.077 & -0.031 & $-0.093 * * *$ & -0.115 & -0.072 \\
\hline prim_m & 0.013 & -0.292 & 0.318 & -0.236 & -0.515 & 0.043 \\
\hline second_m & -0.472 & -0.920 & -0.023 & $-0.890 * * *$ & -1.273 & -0.507 \\
\hline Punjab & 0.233 & -0.018 & 0.483 & 0.382 & 0.134 & 0.630 \\
\hline Sindh & -0.117 & -0.395 & 0.161 & 0.193 & -0.074 & 0.460 \\
\hline Baloch & -0.971 & -1.513 & -0.429 & -0.014 & -0.366 & 0.339 \\
\hline residence & 0.042 & -0.193 & 0.277 & 0.105 & -0.111 & 0.320 \\
\hline
\end{tabular}

\subsubsection{Results: Smooth (non-parametric) effects}

Appendices A-D provide results of the smooth effects in our model for both male and female children (and infants) for the PDHS and the PRHFPS. For the male and female children (Appendix A, figure 2.1), we observe that asset index has an overall decreasing pattern (more visible in case of female children) in both DHS and PRHFPS, however, the (mother's) health seeking behaviour (hsb) index has a clear positive effect for male children in the PDHS. In all other cases, the effect has not a unique pattern. We can say that better socio-economic conditions (captured by the asset index) has a favourable effect on the mortality of children, especially for the female children whereas in one particular case (male children in the PDHS); we can conclude that positive health seeking behaviour of the mother contributes to reduced mortality. The positive health seeking behaviour of mother's in case of male children may be due to various reasons. One may argue that, during pregnancy, male children are more heavier, and thus more vulnerable 
as compared to female children, and thus the mother would be more likely to have frequent antenatal visits, tetanus injection, be assisted at birth by some trained health assistant and perhaps would like the delivery to take place in a hospital. As the health seeking behaviour index captures the mother's pre-delivery health behaviour, so in the absence of, and access to, a sex determining technology (Ultrasound), one cannot assume that the gender bias my be playing any effective role in such situation.

Figure 2.2 (Appendix B) provides the nonparametric (smooth) effects of the asset index (ai) and the (mother's) health seeking behaviour (hsb) index for male and female children above one year of age in the two surveys PDHS and PRHFPS. As before, we can see that the there is a clear declining pattern of asset index for female children in comparison to male children, whereas the effect of (mother's) health seeking behaviour index is visibly declining for male children in both PDHS and PRHFPS. Hence we can say, as before, that female children comparatively fare well in well-off household whereas mother's health seeking behaviour is mainly positive in case of male children.

Figure 2.3 (Appendix C) provides the results for the nonparametric (smooth) effects of our model for the male and female infants for both PDHS and PRHFPS. We observe that the only clearly visible effect is the declining pattern of Asset Index for both male and female infants for the PRHFPS dataset. In case of PDHS, we observe that the (mother's) health seeking behaviour has a slightly decreasing pattern for male infants. We can conclude that better economic conditions of the household do play a favourable role on the reduced mortality of infants and this fact is more clearly visible in case of PRHFPS dataset.

Figure 2.4 (Appendix D) provides results for the baseline effect of our model for male and female children as well as infants for the two surveys. We observe that the effects are mostly uneven decreasing functions thereby indicating some sort of age heaping at certain ages like 6, 12, 24, and 36 months. The exceptions are the effects for infants where (except that for male infants in the PRHFPS) the effects are linear and smoothly declining. These effects are apparently unexpected. However, we can interpret these as a constantly declining baseline effect over the whole time axis (that is, from birth to first birthday). 


\subsection{Conclusions}

Present study was carried out to examine the change in patterns of gender differentials in mortality in Pakistan over a period of ten years. Datasets from two standard surveys, namely PDHS 1990-91 and PRHFPS 2000-01, were analyzed using Bayesian structured hazard regression (based on mixed model methodology). Models were fitted for infant, child and overall mortality and for each sex separately, using the freeware software BayesX. Results indicate that although the mortality levels have dropped in the ten year period, the overall pattern of gender differentials remains almost unchanged. Notable exceptions being the higher mortality associated with higher age of the mother and low mortality in urban areas for the data in the PRHFPPS 200-01 as compared to that of PDHS 1990-91. Further, we note that mother's education now has a more significant impact on the mortality reduction of her children and this effect is more dominant for the girl child. This perhaps indicate that with the passage of time, improved access to education by the mother has brought significant improvement in the mortality of children, in particular, the girl child.

\subsection{References}

Ali, S.M (1989). Does Son Preference Matter? Journal of Biosocial Science, 21(4), 399408.

Arnold, F.(1992). Sex preference and its demographic and health implications, International Family Planning Perspective 18(3): 93-101.

Arnold, F. (2001). Son preference in south Asia, Pp: 281-299 in Z.A. Sathar and J.F. Phillips (eds.), Fertility Transition in South Asia. Oxford: Oxford University Press.

Arnold, F., M.K. Choe, and T.K. Roy. (1998). Son preference, the family-building process and child mortality in India, Population Studies 52: 301-315.

Arnold, F., S. Kishor, and T.K. Roy. (2002). Sex-selective abortions in India, Population and Development Review 28(4): 1-28.

Arnold, F., \& Liu, Z. (1986). Sex preference, fertility, and family planning in China. Population and Development Review, 12, 221-246. 
Brezger, A., Kneib, T., Lang, S. (2003). BayesX—Software for Bayesian Inference Based on Mixed Model Methodology. Available under http://www.stat.unimuenchen.de/ lang/BayesX.

Coale, A. J. (1991). Excess female mortality and the balance of the sexes in the population: An estimate of the number of missing females. Population and Development Review, 17, 517-523.

Coale, A. J., \& Banister, J. (1994). Decades of missing females in China. Demography, $31,459-479$.

Das Gupta, M. (1987). Selective discrimination against female children in rural Punjab, India, Population and Development Review 13(1): 77-100.

Desai, S., Rastogi, S. and Vanneman, R. (2005). Gender Differences in Child Survival in India: What Do We Know? Paper presented in the International Population Conference at the International Union for the Scientific Study of Population, France, 18-23 July, http://www.iussp.princeton.edu/download.aspx .

Das Gupta, M. and Bhat, P.N.M. (1997). Fertility decline and increased manifestation of sex bias in India, Population Studies 51(3): 307-315.

D’Souza, S. and Chen, L.C. (1980). Sex differentials in mortality in rural Bangladesh, Population and Development Review 6(2): 257-270.

Gangadharan, L., Maitra, P. (2000). Does Child Mortality reflect Gender Bias? Evidence from Pakistan. Indian Economic Review, 35, No. 2: 113-131

Griffiths, P., Matthews, Z., \& Hinde, A. (2000). Understanding the sex ratio in India: A simulation approach. Demography, 37, 477-488.

Hill, K. and Upchurch, D.M. (1995). Gender differences in child health: Evidence from the Demographic and Health Surveys, Population and Development Review, 21(1): 127151.

Johansson, S., and Nygren, O. (1991). The missing girls of China: A new demographic account. Population and Development Review, 17, 35-51.

Karim, M. S. (1994). Sex preference in Pakistan. Paper presented at the International Symposium on Issues Related to Sex Preference for Children in the Rapidly Changing Demographic Dynamics in Asia, Seoul, and Republic of Korea. 
Khan, M.A. and Sirageldin, I. (1977). Son Preference and the Demand for Additional Children in Pakistan, Demography, 14(4), 481 - 495.

Kiani, M. F. K. (1992). Differentials in Child Mortality and Health Care in Pakistan, Pakistan Development Review, 31(4: Part II), 1051-58.

Kishor, S. (1993). May god give sons to all: Gender and child mortality in India, American Sociological Review 58(2): 247-265.

Kishor, S. (1995). Gender Differentials in Child Mortality: A Review of the Evidence, Pp. 19-54 in Women's Health in India: Risk and Vulnerability, edited by M. Das Gupta, L.C. Chen, and T.N. Krishnan. Bombay: Oxford University Press.

Klasen, S. (1994). Missing Women Reconsidered. World Development. 22: 1061-71.

Klasen, S. and Wink, C. (2003). Missing women: revisiting the debate. Feminist Econ 9: 263-300.

Klasen, S. and Wink, C. (2002), A Turning Point in Gender Bias in Mortality? An Update on the Number of Missing Women, Population and Development Review, 28, 285-312.

Kneib, T and Fahrmeir, L. (2006). A mixed Model Approach for Geoadditive Hazard Regression. Scandinavian J.Stat., 34, 207-228.

Li, J., \& Cooney, R. S. (1993). Son preference and the one child policy in China: 19791988. Population Research and Policy Review, 12, 277-296.

Murthi, M., Guio, A., and Dreze, J. 1995. Mortality, fertility and gender bias in India: A

District-level analysis, Population and Development Review 21(4): 745-781.

Sahn, D.E. and Stifel, D.C. (2000). Poverty Comparisons Over Time and across Countries in Africa. World Development. 28 (12): 2123-2155.

Sahn, D.E. and Stifel, D.C. (2003). Exploring Alternative Measures of Welfare in the Absence of Expenditure Data. Review of Income and Wealth 49(4): 463-489.

Sen, A. (1990), "More Than 100 Million Women Are Missing", The New York Review, December $20^{\text {th }} 1990$.

UNAUSA (2007), http://www.unausa.org/site/pp.asp?c=fvKRI8MPJpF\&b=474169 (website accessed on 20 Nov 2007) 


\subsection{Appendix A}

Female Children (DHS)

Effect of ai

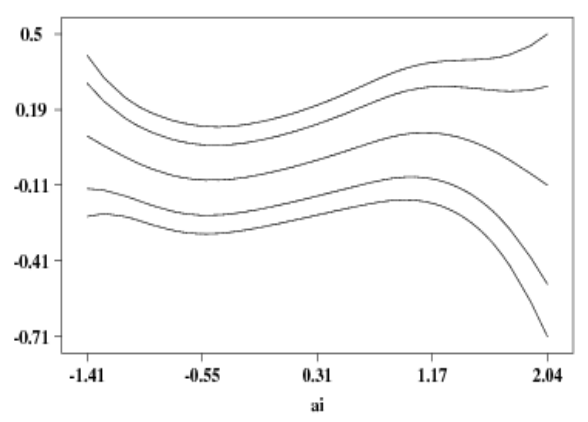

Effect of hsb

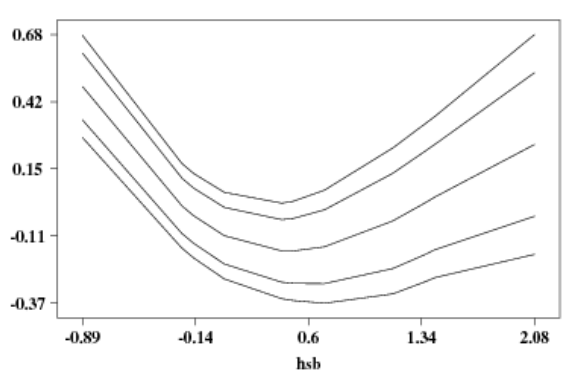

Male Children (DHS)

Effect of ai
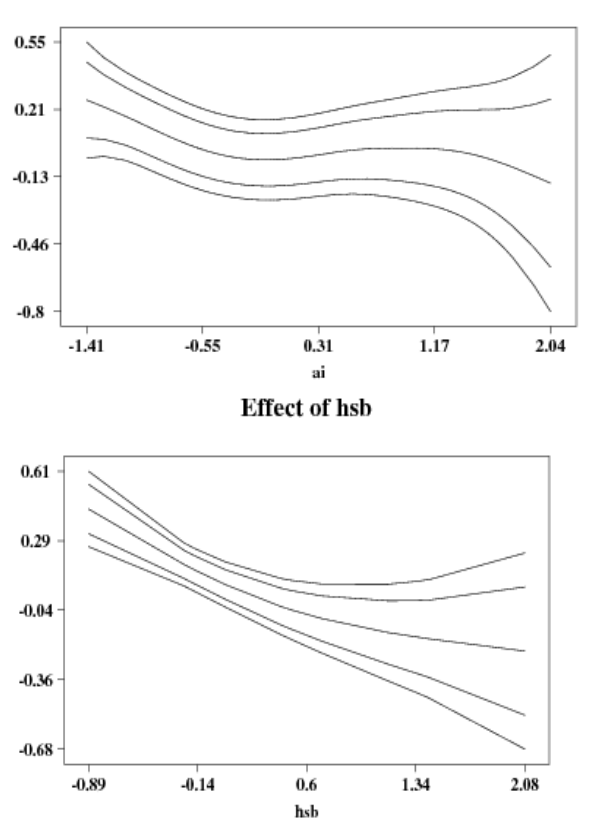

Figure B2. 1 Smooth effects (all children)

\section{Female Children (PRHFPS)}

Effect of ai

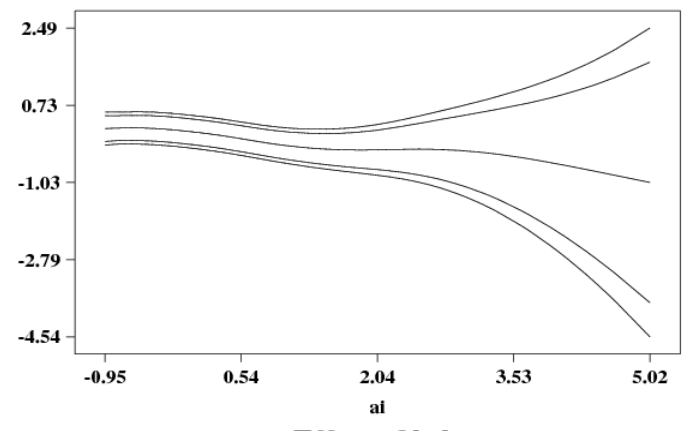

Effect of hsb

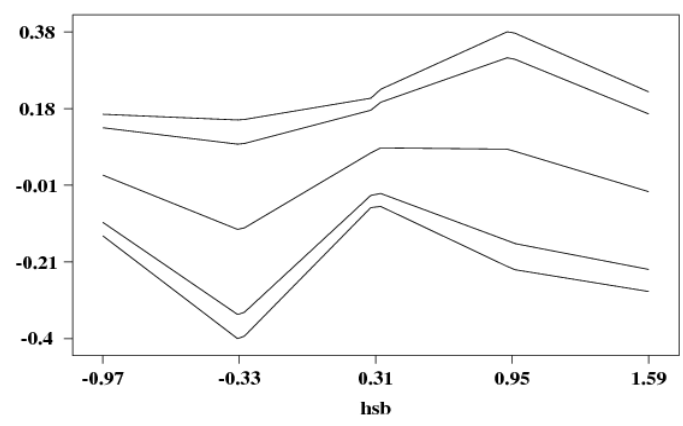

\section{Male Children (PRHFPS)}
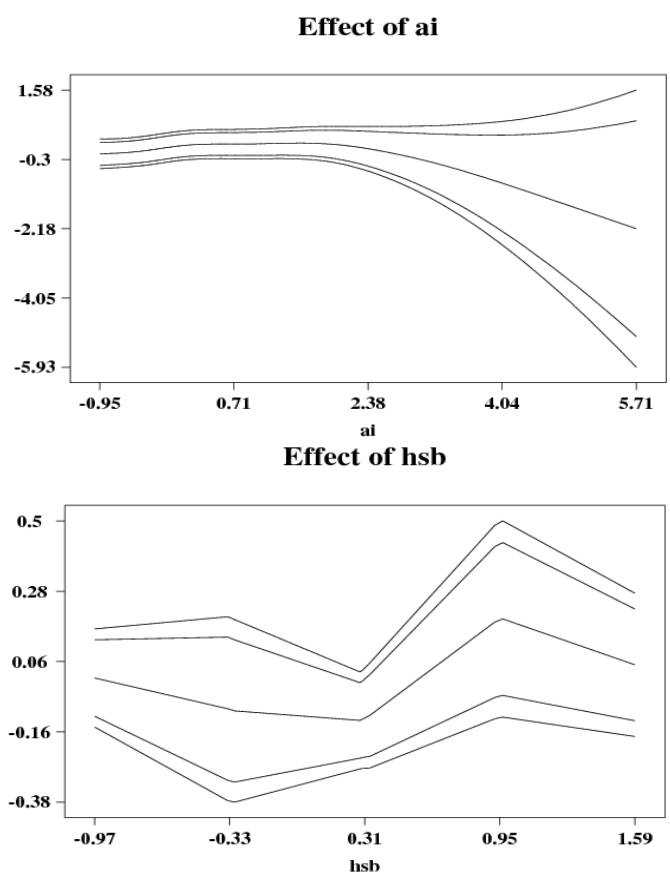


\subsection{Appendix B}

Female children 1+ (DHS)

Effect of ai

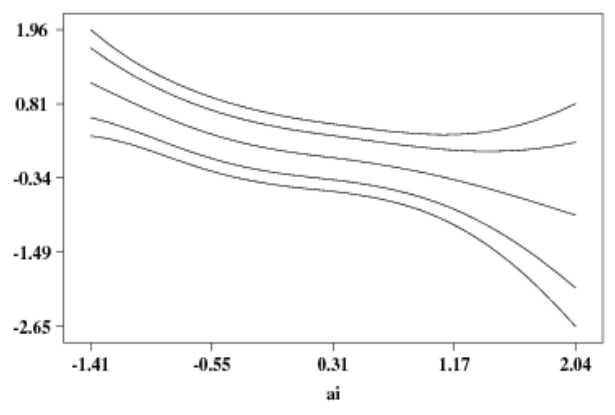

Effect of hsb

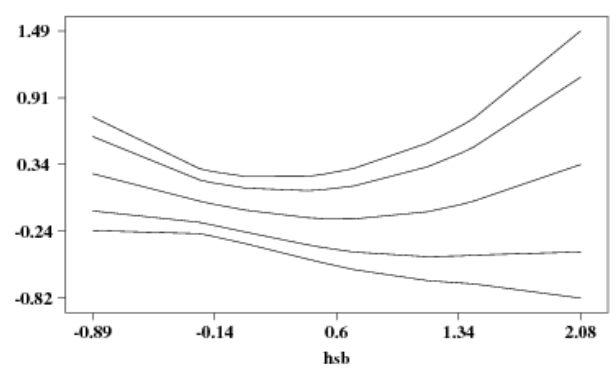

Male Children 1+ (DHS)

Effect of ai

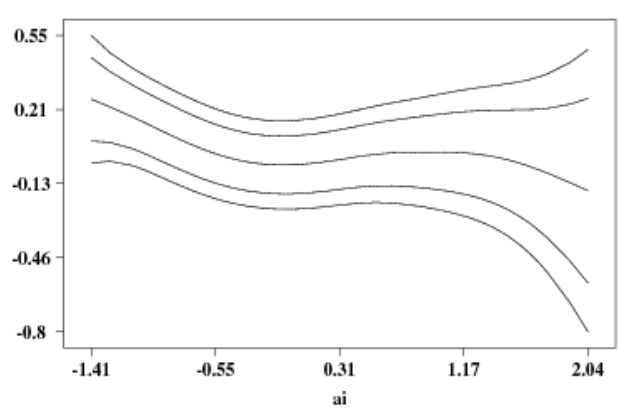

Effect of hsb

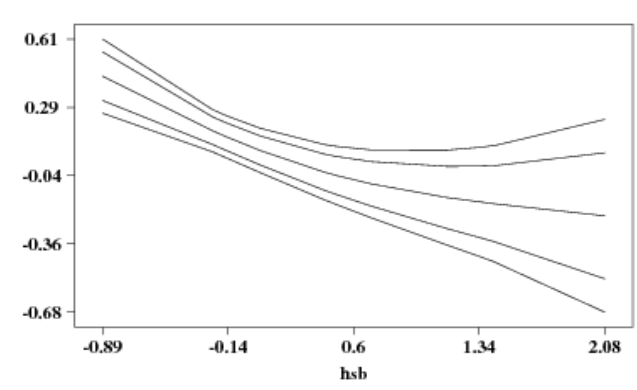

Figure B2. 2 Smooth effects (children 1+)
Female Children 1+ (PRHFPS)

Effect of ai

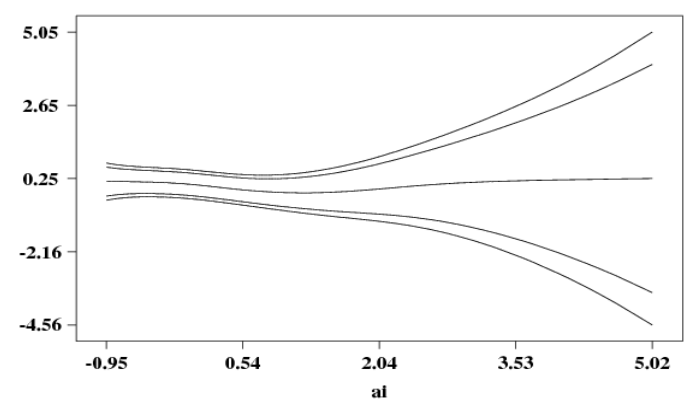

Effect of hsb

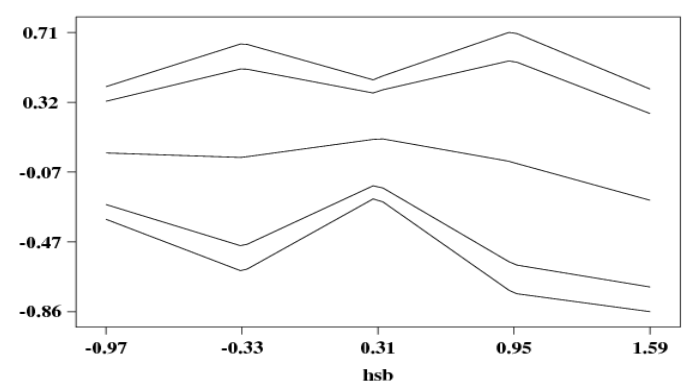

Male Children 1+ (PRHFPS)

Effect of ai

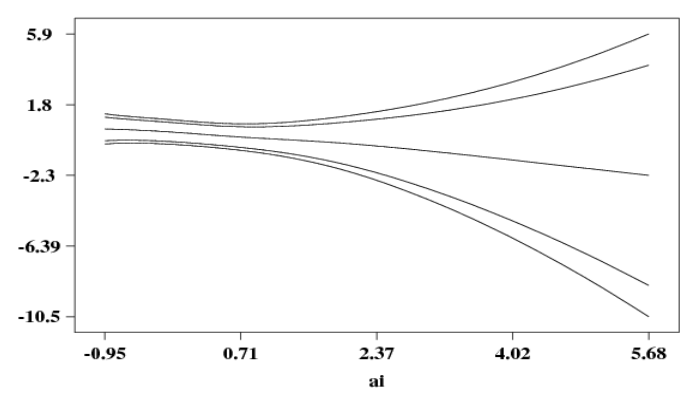

Effect of hsb

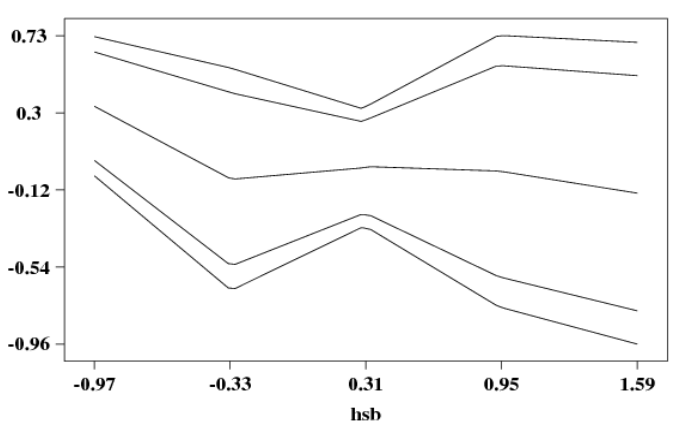




\subsection{Appendix C}

Female Infants (DHS)

Effect of ai
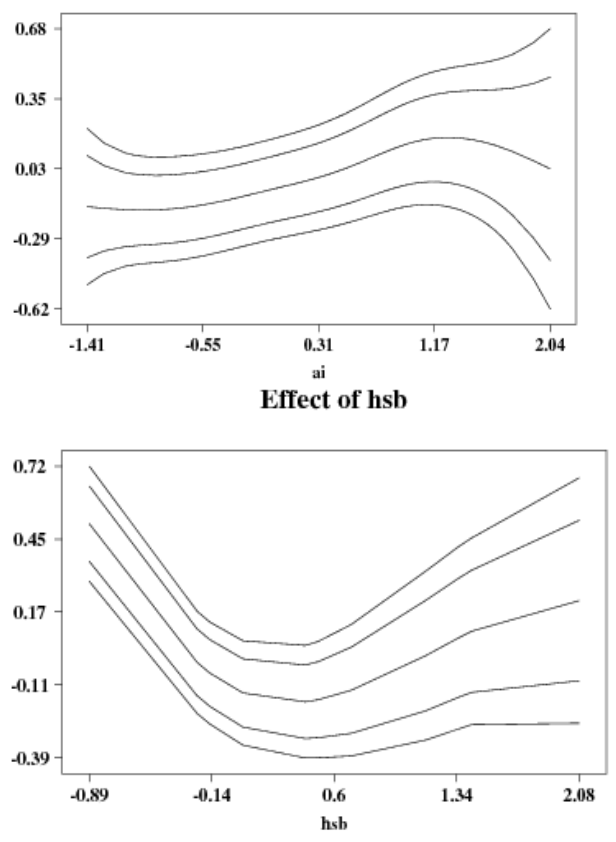

Male Infants (DHS)

Effect of ai

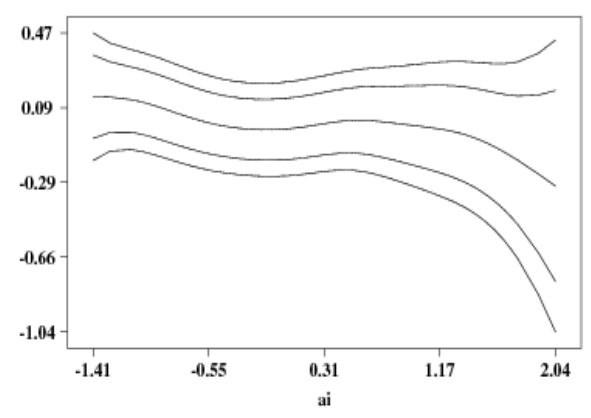

Effect of hsb

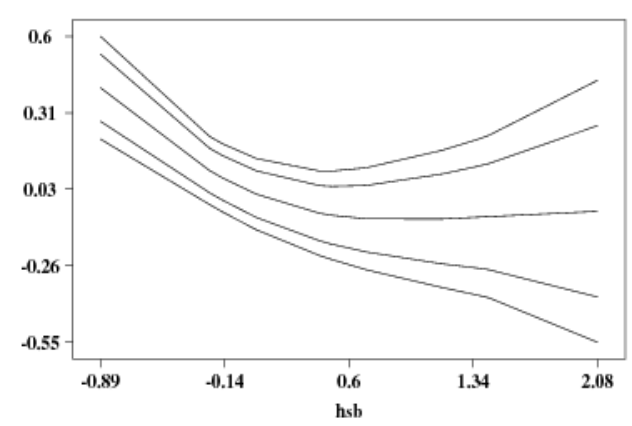

Figure B2. 3 smooth effects (Infants)
Female Infants (PRHFPS)

Effect of ai
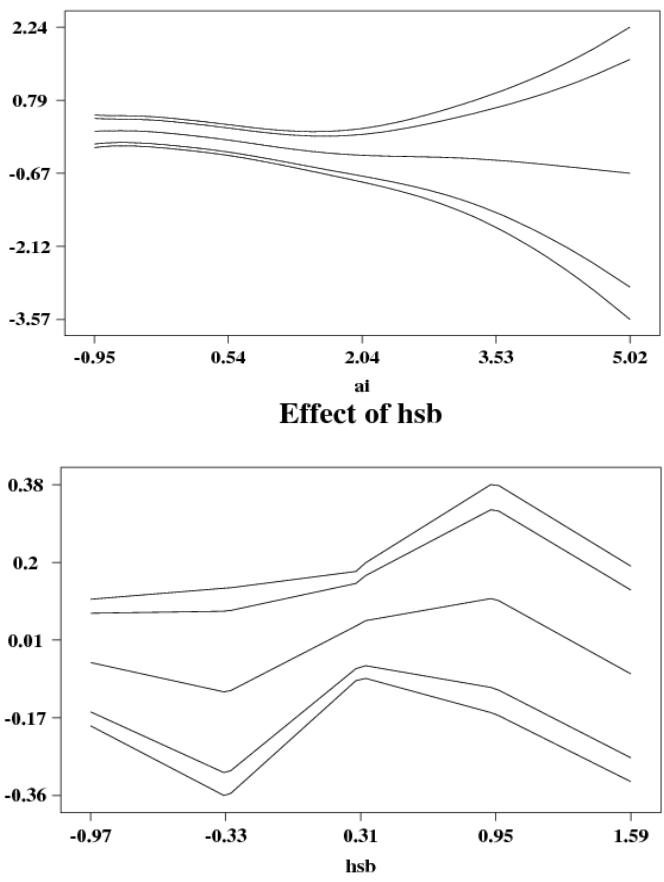

Male Infants (PRHFPS)

Effect of ai

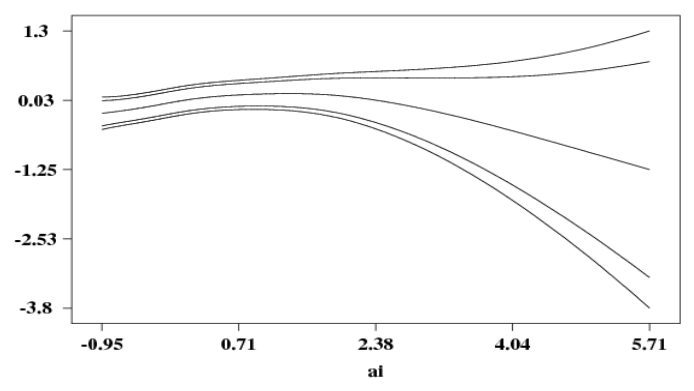

Effect of hsb

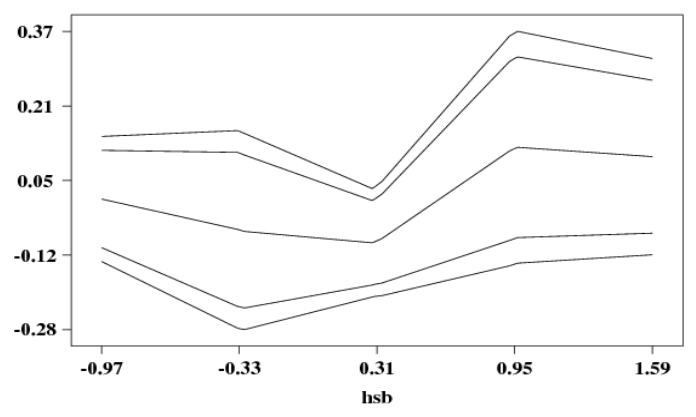




\subsection{Appendix D}

\section{Female Children (DHS)}

Effect of length_ch

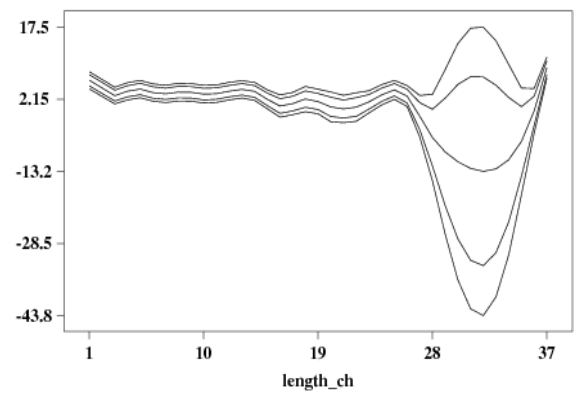

Male Children (DHS)

Effect of length_ch

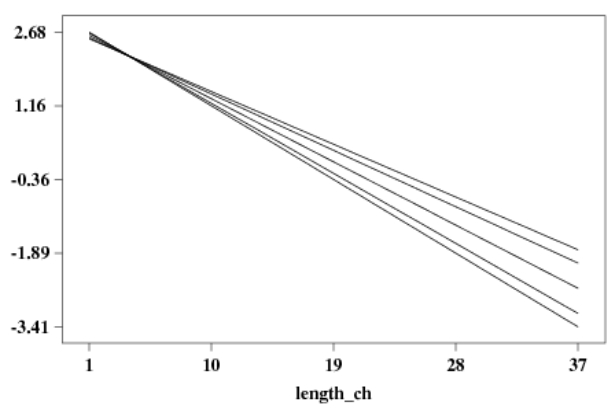

Female Children 1+ (DHS)

Effect of length_ch

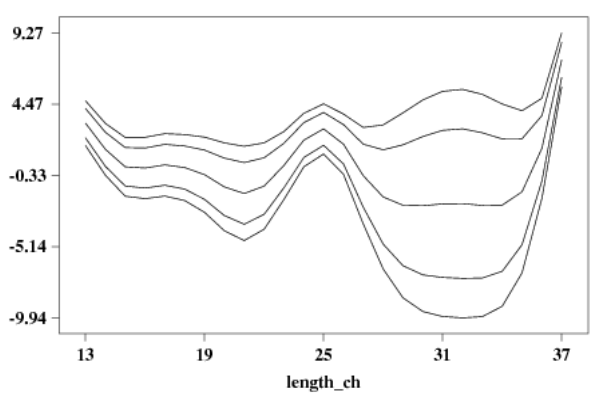

Male Children 1+ (DHS)

Effect of length_ch

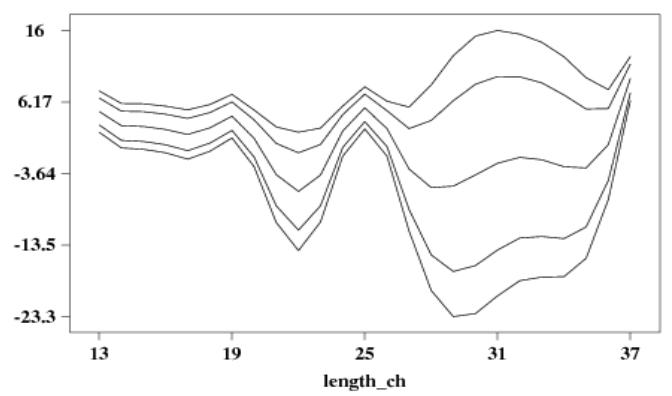

Figure B2. 4 Baseline effects
Female Children (PRHFPS)

Effect of age_child1

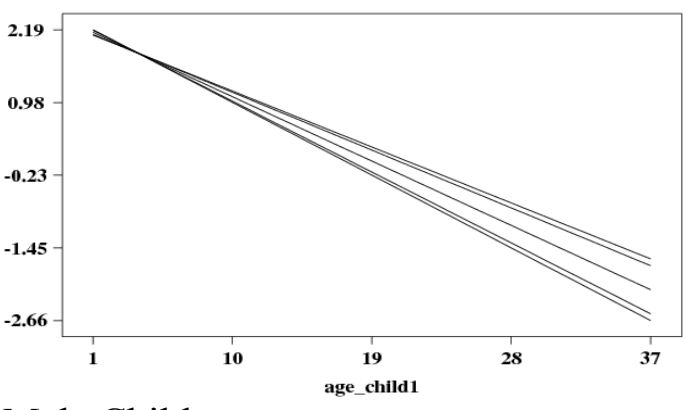

Male Children (PRHFPS)

Effect of age_child1

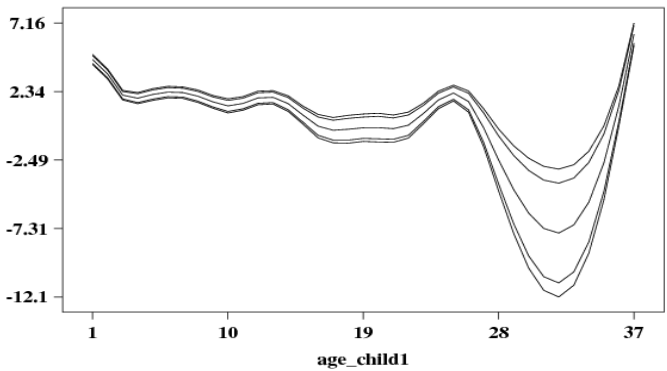

Female Children 1+ (PRHFPS)

Effect of age_child1

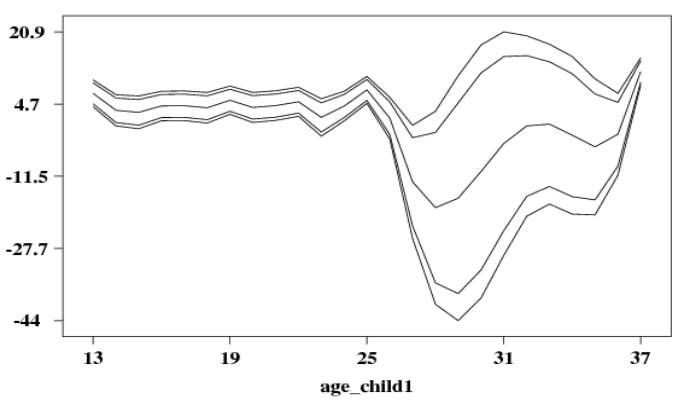

Male Children 1+ (PRHFPS)

Effect of age_child1

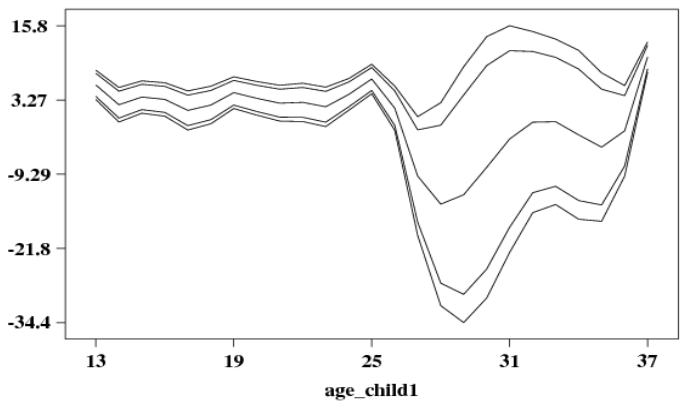




\section{Appendix D (Continued):}

Female Infants (DHS)

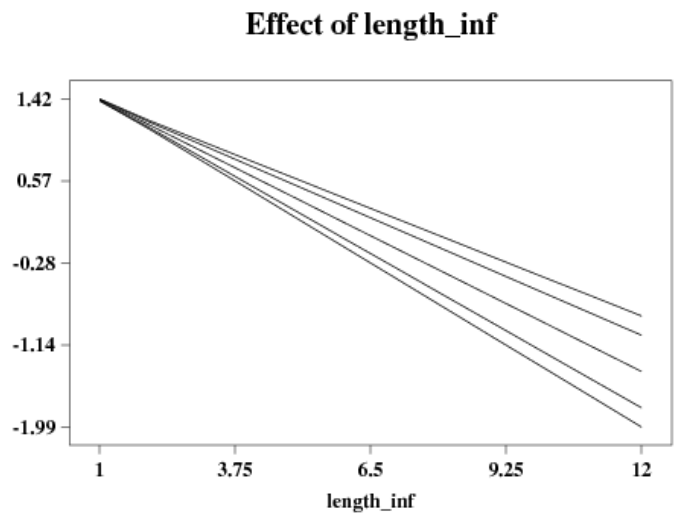

Male Infants (DHS)

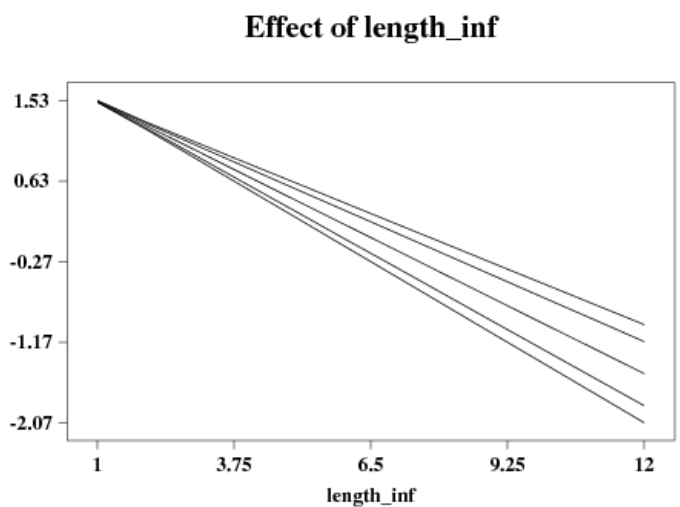

Female Infants (PRHFPS)

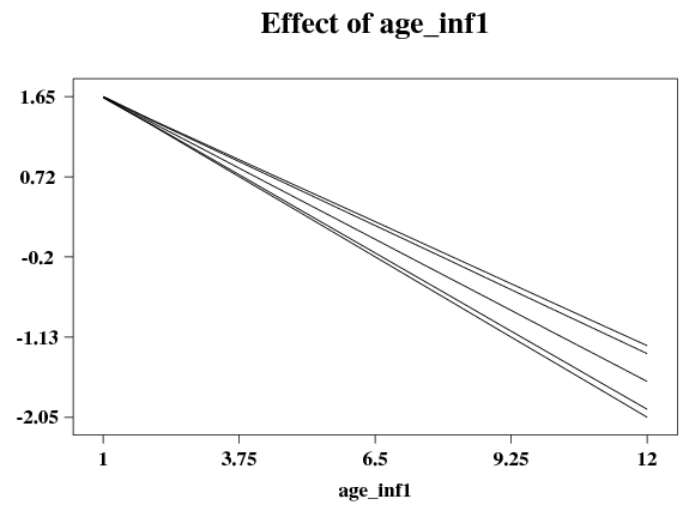

Male Infants (PRHFPS)

Effect of age_inf1

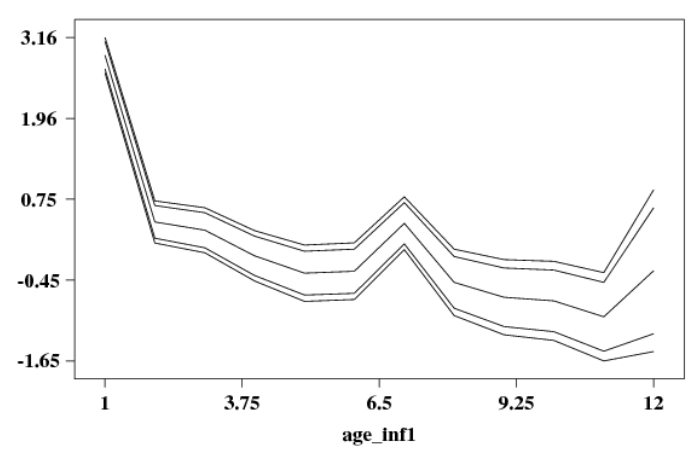




\title{
Essay 3
}

\section{Determinants of Undernutrition in Pakistan: An Investigation into Gender Differentials}

\begin{abstract}
Undernutrition among children is one of the world's leading public health problems and is a major cause of illness and death among children. Using the data from the PDHS 1990-91 for Pakistan, this article studies the prevalence and determinants of undernutrition in Pakistan and tries to determine gender-specific differentials of undernutrition using the Bayesian Structured Additive Regression Model. Results indicate that education of mother, long birth interval, and full vaccination coverage, better economic conditions of the household and positive health seeking behaviour of the mother plays an important role for better nourishment of the children, most of them having stronger effect for the girl child. Splitting the data into two age groups indicated that there is an excess female undernutrition in the age group above two years. We suspect that this might reflect gender bias against female children in access to nutrition.
\end{abstract}




\subsection{Introduction}

Good nutrition is one of the basic requirements for good health and is crucial for the attainment of the first goal of the Millennium Development Goals (MDG). However, progress on the MDGs over the last few years indicate that the world is not on track to halve the proportion of underweight children by 2015 - a key indicator set in the MDG 1 of fight against poverty and hunger. UNICEF's May 2006 Progress for Children reports that 27 per cent of children under five in the developing world are underweight. Some 5.6 million under-fives die of causes related to undernutrition each year

Undernutrition may be defined as insufficient intake of energy and nutrients to meet an individual's needs to maintain good health. Additionally, it may indicate insufficient absorption of nutrients due to ill health. The term "malnutrition" is sometimes also used synonymously for undernutrition. However, strictly speaking, malnutrition includes both undernutrition as well as over-nutrition. Overnutrition simply refers to excess intake of macronutrients and micronutrients (Maleta 2006). In the developing world, it is the undernutrition which is of greater concern because it is alleged to be one of the leading causes of morbidity in children and contributes to more than half of child deaths (HKI 2001). Nutritional deprivation in early life can have long lasting effects on growth, educational attainment and productivity. Usually, the undernutrition in children (under age five) is used as a measure for determining the extent of this particular public health problem in a population (WHO, 1995; Kandala et. al., 2002).

\subsubsection{Causes of undernutrition}

A framework for the causes of undernutrition has been proposed by the UNICEF (1998). The framework is sometimes also called the food-care-health conceptual framework. According to the framework given in figure 3.1, the causes for the undernutrition can be classified into immediate, underlying and basic causes. The immediate causes are inadequate dietary intake and disease. Inadequate dietary intake may increase the susceptibility to and severity of infection; conversely, many infectious diseases reduce dietary intake and nutrient utilization through loss of appetite and reduced absorption. The immediate causes in turn are caused by a complex and seemingly endless number of 
underlying causes. These underlying causes can, however, be classified broadly into three groups. These are household food insecurity, inadequate maternal and child care, and poor health services in an unhealthy environment. These underlying causes are in turn determined by various groups of basic causes related to the amount, control, and use of various resources. Resources mainly consist of human resources (people, their knowledge, skills, and time); economic resources (assets, land, income); and organizational resources (formal and non-formal institutions, extended families, and child-care organizations). The role of education is crucial in determining how these resources are utilized to secure food, health and care for children.

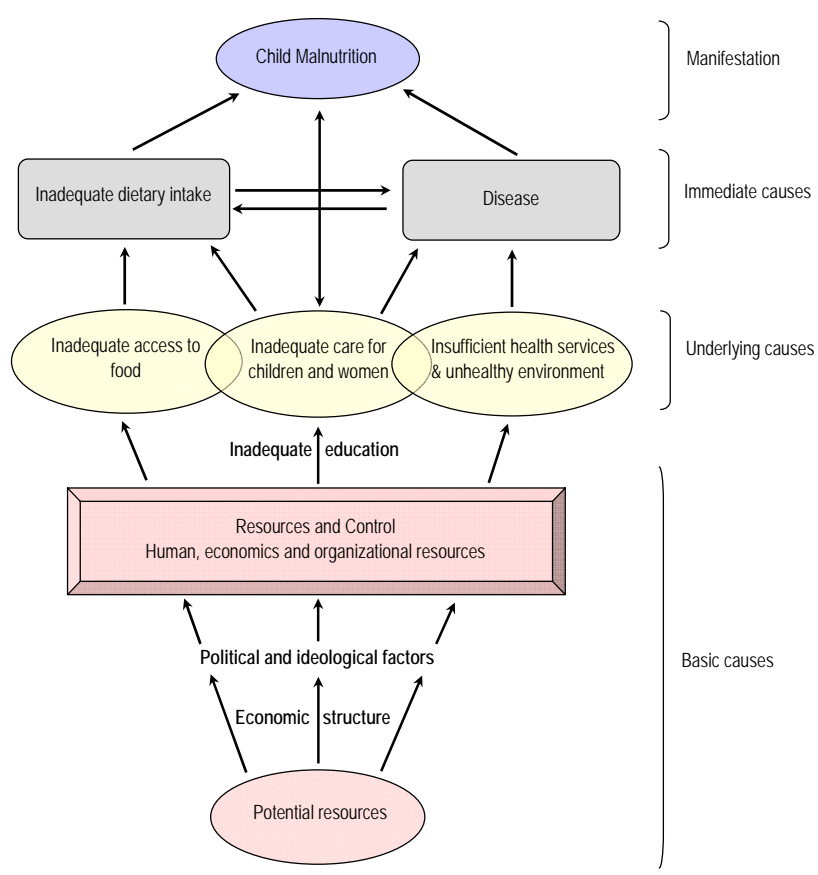

Figure 3. 1 UNICEF Conceptual Framework for causes of malnutrition (1998)

\subsubsection{Measures of Undernutrition}

The nutritional status for children is usually determined by considering the anthropometric status of the child (such as height, weight and age) and comparing it with a reference standard. Common measures are the indices representing height-for-age (stunting), weight-for-height (wasting), and weight-for-age (underweight). Stunting represents long term nutritional deficiency and, therefore, reflects past nutritional status or chronic undernutrition. Wasting, on the other hand, represents current nutritional status 
or acute undernutrition. Underweight does not distinguish between chronic and acute undernutrition because children may be underweight due to stunting and/or wasting (HKI 2001). Stunting, wasting and underweight for a child i are usually determined using a Zscore defined as

$$
\mathrm{Z}_{\mathrm{i}}=\frac{\mathrm{AI}_{\mathrm{i}}-\mathrm{MAI}}{\sigma}
$$

Where $\mathrm{AI}_{\mathrm{i}}$ stands for an anthropometric indicator (such as height, weight or age), MAI refers to median of a reference population and $\sigma$ refers to the standard deviation of the reference population. The reference population is usually taken as the NCHS-CDC Growth Standards recommended by the WHO (1983 and 1995). These growth standards were actually developed in the 1970's whereby data from two distinct datasets were combined. For children under two years, the data used was the longitudinal Fels Study 1929-74 (Ohio Fels Institute) collected on white bottle-fed middle-class children. For children above two years old, the data came from three cross-section surveys conducted in USA during the period 1960-75. Using such a reference population as standard has been a subject of criticism and many researchers have discussed the issue at length (e.g. Klasen, 2007). However, it has been concluded that the reference standard does not pose much a problem if one is to compare the nutritional status of children within a country at a particular point of time. A threshold is then decided to classify the children as undernourished or healthy. Usually, the percentage of children below minus two standard deviations ( $-2 \mathrm{SD})$ from the median of the reference population are classified as undernourished (depending on the choice of the indicator). For example, the percentage of children having z-score of height-for-age below -2 standard deviations of the reference standard would be declared as stunted. Children would be considered severely undernourished if the corresponding z-score falls below -3 standard deviation of the median of the reference population (Kandala et.al. 2002).

There exists abundant literature on the causes, prevalence and determinants of undernutrition (or malnutrition). Smith and Haddad (1999) and UNICEF (1998) provide a comprehensive coverage of various issues related with undernutrition in the context of developing countries. Most of the earlier studies investigate the role of undernutrition as a potential factor for high morbidity and mortality in the developing countries (Sommer 
and Loewenstein 1975; Chen et al. 1980; Vella et al. 1992a; Vella et al. 1992b; Singh 1989; Santhanakrishnan and Ramalingam 1987; Ruzicka and Kane 1985; Katz et al. 1989; Briend et al. 1988). The bulk of the literature also deals with the urban-rural disparity in child health outcomes mainly focusing on nutritional status of children. These studies suggest that, on the average, urban children are better nourished than rural children (von Braun et.al, 1993; Ruel et.al, 1998; Menon et.al, 2000; Sahn and Stifel, 2003; Smith et.al, 2005; Fotso, 2006; Fotso, 2007).

Recently studies using more advanced statistical methodology have been conducted (Kandala et.al. 2002, Belitz et.al. 2007) making use of the Bayesian geoadditive regression models with focus on Sub-Saharan Africa and India. Using the same techniques, Belitz et.al. (2007) specifically investigate the sex-specific determinants of undernutrition in India.

\subsubsection{Undernutrition in South Asia}

According to UNICEF (2006), more than half of the world's underweight children come from South Asia. Further, it is the only region where girls are more likely to be underweight than boys. In its annual report of 2006, the UNICEF estimates that 146 million children under five are underweight in the developing world and more than half of them live in South Asia. In fact, only three countries (India, Bangladesh and Pakistan) account for half the world's underweight children, despite the fact that these countries have just $29 \%$ of the developing world's under-five population. Other forms of undernutrition, such as stunting and wasting, are also persisting in South Asia. With a stunting rate of $44 \%$ and a wasting rate of $15 \%$ among the under five children, South Asia represents the region with much higher levels of undernutrition than all other regions such as Sub-Saharan Africa, Middle East/ North Africa, East Asia/ Pacific, Latin America/ Caribbean, and CEE/ CIS (see table 3.1). The phenomenon of gender discrimination may also be at work in many regions making undernutrition a much more complex issue. We see this fact in South Asia where girls are more likely to be underweight than boys (UNICEF, 2006). Another interesting result from Table 3.1 is the "South Asia/ Sub-Saharan Africa Enigma or puzzle" (Klasen 2000, Harttgen \& 
Misselhorn 2006). It is known that undernutrition is one of the major causes of child mortality. In fact, more than $50 \%$ of the child mortality is associated with undernutrition (Pelletier et.al., 1995). Considering the two regions of South Asia and Sub-Saharan Africa, we know that South Asian countries have the worst indicators of anthropometrics in the world (Klasen, 2000). In fact, more than half of the underweight children are just in three countries of South Asia, namely, India, Pakistan and Bangladesh (UNICEF, 2008). Similarly South Asian children have the highest incidence of low birth weight. However, in case of Sub-Saharan Africa, the rates of infant and under-five mortality are much higher than those in South Asia. The infant mortality rates in Sub-Saharan Africa are almost 30\% higher than those in South Asia. Similarly, the under-five mortality rates in Sub-Saharan Africa are more than $60 \%$ higher than those in South Asia (Klasen, 2000). This contradicting feature of mortality/ undernutrition reversals in the two regions is sometimes also called South Asia/ Sub-Saharan Africa Enigma of anthropometric failure and mortality reversals (Harttgen \& Misselhorn, 2006). Klasen (2000) suggests that the unusually high rate of undernutrition in South Asia may partly be due to the US-based reference standard. He further argues that the higher rates of mortality in Sub-Saharan Africa may be attributed to very high fertility, higher and rising prevalence of HIV/ AIDS, and a possible multiplicative interaction of various risk factors.

Table 3. 1 Under five mortality and levels of undernutrition in selected regions

\begin{tabular}{|l|c|c|c|c|}
\hline \multirow{2}{*}{ Region } & U5 Mortality & \multicolumn{3}{|c|}{ \% of under-fives suffering from: } \\
& $(2004)$ & Underweight $\quad$ Stunting & Wasting \\
\hline South Asia & 92 & 46 & 44 & 15 \\
Sub-Saharan Africa & 171 & 28 & 38 & 9 \\
Middle East/ North Africa & 56 & 17 & 23 & 8 \\
East Asia/ Pacific & 36 & 15 & 19 & ---- \\
Latin America/ Caribbean & 31 & 7 & 16 & 2 \\
CEE*/CIS* & 38 & 5 & 14 & 3 \\
\hline
\end{tabular}

Source: UNICEF (2006), ${ }^{*}$ CEE: Central and Eastern Europe, ${ }^{* *}$ CIS: Commonwealth of Independent States 


\subsubsection{Scenario for Pakistan}

Malnutrition is one of the major public health problems in Pakistan. Gender norms as well as lower social status of women and girls are mainly responsible for disproportionately higher rates of malnutrition among women and girls. In contrast to international mortality statistics, female mortality is $12 \%$ higher, as compared to male, between the ages of 1 and 4 years (ADB, 2007).

Pakistan is one of the three South Asian countries (the others being India and Bangladesh) which has a much higher number of underweight children. Table 3.2 indicates that although Pakistan has comparatively low undernutrition rates as compared to its South Asian neighbours, it still has the highest under-five mortality rate.

Table 3. 2 Under five mortality and rates of undernutrition in South Asia

\begin{tabular}{|c|c|c|c|c|}
\hline \multirow[t]{2}{*}{ Country } & \multirow{2}{*}{$\begin{array}{l}\text { U5 Mortality } \\
\text { (2004) }\end{array}$} & \multicolumn{3}{|c|}{$\%$ of under-fives suffering from: } \\
\hline & & Underweight & Stunting & Wasting \\
\hline Pakistan & 101 & 38 & 37 & 13 \\
\hline India & 85 & 47 & 46 & 16 \\
\hline Bangladesh & 77 & 48 & 43 & 13 \\
\hline Nepal & 76 & 48 & 51 & 10 \\
\hline Bhutan & 80 & 19 & 40 & 3 \\
\hline Sri Lanka & 14 & 29 & 14 & 14 \\
\hline
\end{tabular}

Source: UNICEF (2006)

The aim of the current study is to study the pattern and determinants of sex-specific undernutrition in Pakistani children aged under five years. The Objective is to determine the gender bias in the nutritional status of female children as compared to male children.

\subsection{Data and Methods}

We make use of the data set from Pakistan Demographic and Health Survey (PDHS) 1990-91. This is a representative survey covering all four provinces of Pakistan. The data set contains information on 6428 children born during the past five years preceding the survey. The information was provided by 6611 mothers who were asked about their birth histories and other personal, demographic, and socio-economic information of the 
household. For the current study, a new data set was constructed containing information on the nutritional status of the children who are still alive. Those cases for which the nutritional information was incomplete were dropped from the sample. The effective sample size for this study thus reduced to 4079 children. This may, however, leads to a sample selection bias as we restrict our discussion to only the living children. As undernutrition is one of the leading causes of child mortality so we can expect that most of the dead children were probably also undernourished. However, in the absence of any anthropometric information on those children, we are unable to consider that. Similarly, among the living children, we have left out those children from our sample for whom the anthropometric information was missing. This further increases our sample selection bias. Hence all the results on the remaining children need to be interpreted carefully as those will apply only on the remaining 4079 children. From the available information, some further new variables were constructed capturing the socio-economic status of the household, health seeking behaviour of the mother, and the immunization status of the index child. As the PDHS does not contain information on income, so a new variable, called Asset Index, was created using the information on the household assets (such as radio, TV, refrigerator, electricity, car etc.), quality of house (floor material, wall material), and basic hygienic facilities (like availability of toilet, source of drinking water). The technique of factor analysis was used to construct the asset index and was then used as a proxy for income of the household (Sahn and Stifel; 2000, 2003). Similarly, an index called Health Seeking Behaviour (HSB) of mother was constructed, using factor analysis, from information on antenatal visits, tetanus injection, place of delivery and assistance at birth. The binary variable for vaccination coverage was constructed from the information on immunization of the index child.

Tables 3.3 and 3.4 below contain information, respectively, on the continuous and categorical variables selected for the current study. 
Table 3. 3 Categorical variables selected for the study

\begin{tabular}{|c|c|c|c|c|}
\hline Predictor & Interpretation & Coding & Frequ & ency \\
\hline & & & Female children & Male Children \\
\hline GENDER & Sex of Child & $\begin{array}{l}0: \text { Male }\left(\mathrm{RC}^{* *}\right) \\
1: \text { Female }\end{array}$ & Female $=2030(49.8 \%)$ & Male $=2049(50.2 \%)$ \\
\hline TWIN & Whether child is twin & $\begin{array}{l}0: \text { No }(\mathrm{RC}) \\
1: \text { Yes }\end{array}$ & $\begin{array}{c}2000(98.5 \%) \\
30(1.5 \%)\end{array}$ & $\begin{array}{r}2018(98.5 \%) \\
31(1.5 \%)\end{array}$ \\
\hline BORD & Birth Order of the child & $\begin{array}{l}\text { 1: BORD1 (RC) } \\
\text { 2: BORD 2-3 } \\
\text { 3: BORD 4-6 } \\
\text { 4: BORD 7plus }\end{array}$ & $\begin{array}{l}341(16.8 \%) \\
615(30.3 \%) \\
713(35.1 \%) \\
361(17.8 \%)\end{array}$ & $\begin{array}{l}369(18.0 \%) \\
642(31.3 \%) \\
652(31.8 \%) \\
386(18.9 \%)\end{array}$ \\
\hline LONG_BI & Long Birth Interval & $\begin{array}{l}0: \leq 24 \text { months }(\mathrm{RC}) \\
1:>24 \text { months }\end{array}$ & $\begin{array}{r}955(47 \%) \\
1075(53 \%)\end{array}$ & $\begin{array}{r}975(47.6 \%) \\
1074(52.4 \%)\end{array}$ \\
\hline FULL_VACC & Fully Vaccinated & $\begin{array}{l}\text { 0: No (RC) } \\
\text { 1: Yes }\end{array}$ & $\begin{array}{r}1335(65.8 \%) \\
695(34.2 \%)\end{array}$ & $\begin{array}{r}1273(62.1 \%) \\
776(37.9 \%)\end{array}$ \\
\hline REGION & Province of residence & $\begin{array}{l}\text { 1: Punjab (RC) } \\
\text { 2: Sindh } \\
\text { 3: NWFP } \\
\text { 4: Baluchistan }\end{array}$ & $\begin{array}{l}692(34.1 \%) \\
599(29.5 \%) \\
533(26.3 \%) \\
206(10.1 \%)\end{array}$ & $\begin{array}{l}709(34.6 \%) \\
580(28.3 \%) \\
564(27.5 \%) \\
196(9.6 \%)\end{array}$ \\
\hline RESIDENC & Type of place of residence & $\begin{array}{l}\text { 0: Urban (RC) } \\
\text { 1: Rural }\end{array}$ & $\begin{array}{r}1115(54.9 \%) \\
915(45.1 \%)\end{array}$ & $\begin{array}{r}1075(52.5 \%) \\
974(47.5 \%)\end{array}$ \\
\hline PRIM_M/SECOND_M & $\begin{array}{l}\text { Primary/Secondary Education } \\
\text { level of mother }\end{array}$ & $\begin{array}{l}\text { 0: No education (RC) } \\
\text { 1:Primary/ Secondary }\end{array}$ & $\begin{array}{l}1487(73.3 \%) \\
220 / 323 \\
(10.8 \% / 15.9 \%)\end{array}$ & $\begin{array}{l}1530(74.7 \%) \\
220 / 299 \\
(10.7 \% / 14.6 \%)\end{array}$ \\
\hline
\end{tabular}

* RC: Reference Category

Table 3. 4 Continuous variables selected for the study

\begin{tabular}{|c|c|c|c|c|c|}
\hline \multirow[t]{2}{*}{ Variable } & \multirow{2}{*}{ Interpretation } & \multicolumn{2}{|c|}{ Female Children } & \multicolumn{2}{|c|}{ Male Children } \\
\hline & & Mean & SD* & Mean & SD* \\
\hline CH_AGE & $\begin{array}{l}\text { Child's Current age } \\
\text { (in months) }\end{array}$ & 28.03 & 17.35 & 28.03 & 17.08 \\
\hline M_AGE & $\begin{array}{l}\text { Mother's age in years } \\
\text { (at child's birth) }\end{array}$ & 27.27 & 6.33 & 27.47 & 6.58 \\
\hline AI & Asset Index & 0.1152 & 1.0189 & 0.0392 & 0.9915 \\
\hline HSBI & $\begin{array}{l}\text { (Mother's) Health Seeking } \\
\text { Behaviour }\end{array}$ & 0.0727 & 1.0321 & 0.0385 & 1.0171 \\
\hline HHMEMBER & Household Size & 9.43 & 4.92 & 9.41 & 4.69 \\
\hline
\end{tabular}

*Standard Deviation 
The variables AI and HSBI were constructed using factor analysis. For methodological details of the technique of factor analysis for constructing the asset index; see Sahn and Stifel $(2000,2003)$. The dummy variable FULL_VACC was constructed from the information available on the immunization of children (see Essay 1).

\subsubsection{Descriptive statistics}

Table 3.5 below gives the percentage of children (under five) that are stunted, wasted and underweight according to the PDHS 1990-91. The rates are also given sex-wise. Same information is given region-wise in Table 3.6 along with under-five mortality.

Table 3. 5 Rates of Undernutrition by Gender (PDHS 1990-91)

\begin{tabular}{|l|c|c|c|}
\hline & Stunting (\%) & Wasting (\%) & Underweight (\%) \\
\hline Male & 50.4 & 10.2 & 40.6 \\
Female & 48.7 & 8.2 & 39.8 \\
All & 49.7 & 9.2 & 40.2 \\
\hline
\end{tabular}

Source: www.measuredhs.com (official website of the DHS Programme)

Table 3. 6 Rates of Undernutrition by Region (PDHS 1990-91)

\begin{tabular}{|l|c|c|c|c|}
\hline Region & U5 Mortality & Stunting (\%) & Wasting (\%) & Underweight (\%) \\
\hline Punjab & 133 & 43.9 & 10.1 & 37.2 \\
Sindh & 106 & 53.5 & 8.8 & 47.6 \\
NWFP & 98 & 60.0 & 6.7 & 38.0 \\
Baluchistan & 101 & 70.8 & 6.0 & 56.4 \\
\hline
\end{tabular}

Source: www.measuredhs.com (official website of the DHS Programme)

Tables 3.5 and 3.6 indicate that stunting as well as underweight are more severe in Pakistan than wasting. More male children are under-nourished than female children. Further, children in the region of Punjab are better nourished as compared to other three regions. However, percentage of wasting is higher in Punjab relative to the other provinces. In contrast, the rates of under-five mortality (table 3.6) depict a puzzling situation. We observe that although Punjab has lower rates of undernutrition (stunting 
and underweight) as compared to other three regions it has the highest under-five mortality rate. In fact, the under-five mortality rate has almost reverse order for the four regions as compared to that of undernutrition. We are not sure whether it reflects the true picture or are there some data quality issues? As the DHS datasets are considered to be highly reliable and internationally comparable, one can only suspect a possible enigma on the style of one described earlier with reference to South Asia and Sub-Saharan Africa. Other reasons may be the accurate reporting of deaths in Punjab, or conversely, the under-reporting of deaths in other regions, specially, the N.W.F.P. and Baluchistan. We are, however, not clear on this aspect and the point needs to be investigated separately.

\subsubsection{Modelling}

We shall make use of the Bayesian structured additive regression model as suggested by Fahrmeir and Lang (2001), Brezger and Lang (2004), and Lang and Brezger (2006). The modeling approach is briefly described below:

Consider the triplet $\left(\mathrm{y}_{\mathrm{i}}, \mathrm{x}_{\mathrm{i}}, \mathrm{w}_{\mathrm{i}}\right), \mathrm{i}=1, \ldots . . \mathrm{n}$, where $\mathrm{y}_{\mathrm{i}}$ is the dependent variable (in our case, the Z-score for stunting for the children in our constructed dataset), $\mathrm{x}_{\mathrm{i}}$ and $\mathrm{w}_{\mathrm{i}}$ are the continuous and categorical (dummy) variables, respectively, to be used as predictors in our model. We assume that

$$
y_{i} \sim N\left(\eta_{i}, \sigma^{2}\right)
$$

That is, the response $y_{i}$ is independently and normally distributed. The traditional linear predictor used for studying the effect of the predictors on the response is of the form

$$
\eta_{i}=x_{i}^{\prime} \beta+w_{i}^{\prime} \gamma
$$

This can be generalized to a semi-parametric additive predictor as

$$
\eta_{i}=f_{1}\left(x_{i 1}\right)+f_{2}\left(x_{i 2}\right)+\ldots \ldots \ldots \ldots+f_{p}\left(x_{i p}\right)+w_{i}^{\prime} \gamma
$$

Where $f_{1}, f_{2}, \ldots \ldots, f_{p}$ are the nonlinear smooth effects of the continuous variables. 


\subsubsection{Specification of priors}

In the Bayesian framework, the unknown smooth functions $f_{j}$, parameters $\gamma$, and the variance parameter $\sigma^{2}$ are all considered as random, and therefore have to be assigned suitable priors. The usual approach is to assign diffuse priors (uninformative prior) to the parameters of the fixed effects, that is, $\gamma_{j} \propto$ constant $j=1, \ldots \ldots . . r$

The unknown (smooth) functions $f_{j}, j=1, \ldots \ldots p$, are estimated using the Bayesian $p$ spline basis approach (Lang \& Brezger 2004). In this approach, it is assumed that the unknown functions can be approximated by a polynomial spline of degree $l$ defined by a set of equally spaced knots

$\xi_{0}=x_{\min }<\xi_{1}<\ldots \ldots \ldots \ldots \ldots \xi_{k-1}<\xi_{k}=x_{\max } \quad$ (omitting the subscript $\mathrm{j}$ for convenience) over the domain of $\mathrm{x}$.

The spline can be expressed as a linear combination of $\mathrm{M}=\mathrm{k}+1$ B-spline basis functions, that is,

$$
f(x)=\sum_{m=1}^{M} \beta_{m} B_{m}(x)
$$

where $B_{m}$ is the $m$-th basis function.

Now, let $\mathrm{X}$ be the $\mathrm{n} \times \mathrm{M}$ design matrix with the $(\mathrm{i}, \mathrm{m})$ th element given by

$$
\mathrm{X}(\mathrm{i}, \mathrm{m})=\mathrm{B}_{\mathrm{m}}\left(\mathrm{x}_{\mathrm{i}}\right)
$$

Then the semiparametric predictor can be expressed in matrix notations as

$$
\eta=X_{1} \beta_{1}+X_{2} \beta_{2}+\ldots \ldots \ldots \ldots . .+X_{p} \beta_{p}+V \gamma
$$

Here $\beta_{j}(\mathrm{j}=1, \ldots \mathrm{p})$ are the unknown regression coefficients, whereas the matrix $\mathrm{V}$ corresponds to the design matrix for linear effects. Eilers and Marx (1996), in their frequentist setting, introduced difference penalties in the form of first and second order differences in order to overcome the difficulties involved with regression splines such as non-flexibility (for smaller number of knots) or over-fitting (for large number of knots).. Lang and Brezger (2004), in their Bayesian setting, proposed replacing differences with the stochastic analogues of first and second order random walks, given by 


$$
\begin{array}{lc}
\beta_{m}=\beta_{m-1}+u_{m} & (\text { First order random walk }) \\
\beta_{m}=2 \beta_{m-1}-\beta_{m-2}+u_{m} & (\text { Second order random walk })
\end{array} \quad \text { or }
$$

with Gaussian errors $u_{m} \sim N\left(0, \tau^{2}\right)$ and diffuse (uninformative) priors $\beta_{1} \propto$ constant or $\beta_{1}$ and $\beta_{2} \propto$ constant (for initial values). The variance parameter $\tau^{2}$ controls the amount of smoothness and is also referred to as the inverse smoothing parameter. The amount of smoothness is estimated by defining a hyperprior for the variance parameter $\tau^{2}$. A usual approach is to assign a conjugate prior for $\tau^{2}$ which is the inverse Gamma prior with hyperparameters a and $\mathrm{b}$, that is, $\tau^{2} \sim \operatorname{IG}(a, b)$. Common choices for $\mathrm{a}$ and $\mathrm{b}$ are $\mathrm{a}=1$ and $\mathrm{b}=0.005$ (or $\mathrm{b}=0.0005$ ). Alternatively, one may take $\mathrm{a}=\mathrm{b}=0.001$.

Brezger and Lang (2006) also suggest a general structure of the priors as

$$
\beta_{j} \mid \tau_{j}{ }^{2} \propto \frac{1}{\left(\tau_{j}{ }^{2}\right)^{r k\left(K_{j}\right) / 2}} \exp \left(-\frac{1}{2 \tau_{j}{ }^{2}} \beta_{j}^{\prime} K_{j} \beta_{j}\right)
$$

Where $\mathrm{K}_{\mathrm{j}}$ is a penalty matrix which depends on the prior assumptions regarding smoothness of $f_{j}$ and the type of covariate.

\subsubsection{Posterior inference}

The Bayesian inference, using the MCMC technique, is based on the posterior of the model. Let $\alpha$ be the vector of all unknown parameters, then the posterior is given by

$$
\begin{aligned}
p(\alpha \mid y) \propto & L\left(y, \beta_{1}, \tau_{1}, \beta_{2}, \tau_{2}, \ldots \ldots \ldots, \beta_{p}, \tau_{p}, \gamma\right) \prod_{j=1}^{p} p\left(\beta_{j} \mid \tau_{j}{ }^{2}\right) p\left(\tau_{j}{ }^{2}\right) \\
\propto & L\left(y, \beta_{1}, \tau_{1}, \beta_{2}, \tau_{2}, \ldots \ldots \ldots, \beta_{p}, \tau_{p}, \gamma\right) \\
& \prod_{j=1}^{p} \frac{1}{\left(\tau_{j}{ }^{2}\right)^{r k\left(K_{j}\right) / 2}} \exp \left(-\frac{1}{2 \tau_{j}{ }^{2}} \beta_{j}^{\prime} K_{j} \beta_{j}\right) \prod_{j=1}^{p}\left(\tau_{j}{ }^{2}\right)^{-a_{j}-1} \exp \left(-\frac{b_{j}}{\tau_{j}{ }^{2}}\right)
\end{aligned}
$$

This posterior is numerically intractable. To overcome this problem, Markov Chain Monte Carlo (MCMC) simulation technique is used to draw samples from the posterior. From these samples, quantities such as (posterior) mean, (posterior) standard deviation, and quantiles (which in turn, gives the associated credible 
interval) can be estimated. Methodological details of these issues can be found in Fahrmeir and Lang (2001), Brezger and Lang (2004), and Lang and Brezger (2006).

The whole methodology has been implemented in the freeware software BayesX (developed by Lang and Brezger) and is available from the website http://www.stat.uni-muenchen.de/ bayesx/bayesx.html

\subsection{Analysis}

The semiparametric predictor used in our analysis is of the form

$$
\begin{aligned}
\eta_{\mathrm{i}}= & \mathrm{f}_{0}\left(\mathrm{ch} \_ \text {age }\right)+\mathrm{f}_{1}\left(\mathrm{~m} \_ \text {age }\right)+\mathrm{f}_{2}(\mathrm{ai})+\mathrm{f}_{3}(\mathrm{hsb})+\gamma_{1} \text { gender }+\gamma_{2} \text { twin }+\gamma_{3} \text { bord2 } 33 \\
& +\gamma_{4} \text { bord4_6 }+\gamma_{5} \text { bord7plus }+\gamma_{6} \text { long_bi }+\gamma_{7} \text { full_vacc }+\gamma_{8} \text { hhmember }+\gamma_{9} \text { prim_m } \\
& +\gamma_{10} \text { second_m }+\gamma_{11} \text { c cworkin }+\gamma_{12} \operatorname{sindh}+\gamma_{13} \text { nwfp }+\gamma_{14} \text { baluchis }+\gamma_{15} \text { residenc }
\end{aligned}
$$

The dependent variable is the z-score for stunting. Results have been obtained for children under five years of age. Separate analyses were then carried out for the children in the two age groups $0-2$ years and above 2 years.

\subsubsection{Fixed (linear) effects}

Table A3.1 in appendix A gives results for the fixed effects for all children. The output gives posterior means along with their standard deviations and $80 \%$ credible intervals.

From the table, we can observe that having a long birth interval (more than 24 months) with the preceding child, being fully vaccinated, and having an educated mother (at least primary education) contributes to better nourishment. Out of these the effect of long birth interval, vaccination coverage, and mother having secondary or higher education is statistically significant. The table also shows that female children are slightly better nourished than male children although the effect is statistically insignificant. On the other hand, we observe that stunting is higher for twins, children of higher birth order (other than first born), larger households, mother being a working women, for all the three regions (as compared to the region of Punjab) and the rural areas. Keeping in view the fact that larger household are conducive for reduction in mortality (Essay 1), it is interesting to observe that larger household is not conducive for better nourishment of 
children. However, we may interpret that while larger households provide more care to children (mostly by elder memebers of the household in a joint or extended family setting), there seems to be a simultaneous competition for resources within the same larger household. This competition for limited resources may be responsible for worsening of nutritional status for the children of a larger household. Except for the negative effect of rural areas, the negative effects for the other factors are statistically significant.

Tables A3.2 and A3.3 in Appendix A provide results of our model for female and male children respectively. The two tables show mostly similar results along with some important differences with regard to the size of the individual effects. Both female and male children are (significantly) better nourished (less stunted) if the birth interval is large, and if they are fully vaccinated. However, we observe that the marginal effect of larger birth interval is stronger for female children whereas that of vaccination is stronger for male children. This may suggest that female children would comparatively be better nourished if the preceding birth interval is large (more than 24 months). On the other hand, male children would have better nutritional status, relative to female children, if they get fully vaccinated. Furthermore, the stunting also significantly decreases if the mother is educated. For both female and male children, the mother's education has a significantly positive effect on malnutrition if she is having secondary or higher education. As the marginal effect of secondary (or higher) education of mother is higher in case of female children, we may interpret this as indicating the fact that the education of mother has stronger (positive) effect on better nourishment of a girl child relative to the a male child. Further, we observe that the sign of the effect of mother having up to primary education is positive for female children, thereby indicating that even a minimum education (up to primary) of mother is associated with reductions in stunting for the female child. We further observe that being twin, having higher birth order (not being first born), living in a larger household, having a working-woman mother, and living in a region other than Punjab all lead to increased level of stunting. Looking at he marginal effects, we see that female twins fare worse relative to male twins whereas both female and male children are well nourished if they happen to be first-born. It is worth noting that having a working mother and living in a larger household have a (statistically) 
significantly adverse effect on the nutritional status of both male and female children. Moreover, relatively speaking, we observe that while mother being a working person has a more negative effect on the nutritional status of the daughters, the larger household size has more negative impact on the nutritional status of sons. This shows that in a larger household where there is a constant competition for resources, the sons are ralatively more disadvantaged as compared to daughters. This is contrast to the conclusions of Belitz et. al. (2007) wherein they observe that the daughter's nutritional status reacts more sensitively to competition of resources in a larger household. However, as we shall see in our later discussions, the observations of Belitz et.al. (2007) hold in our case when we consider the age range of more than 2 years for children. An interesting result is that for the residential area of the children. Regarding better nourishment, female children fare well in rural areas whereas male children are less stunted in urban areas. One reason may be better access to health facilities in urban areas and the fact that in case of bringing children to a health facility, parents are more likely to bring their sons rather than daughters, and the daughters may, on most occasions, get some sort of home treatment for the same illness.

As discussed earlier, the reference growth standards were constructed using two different populations. For children up to 24 months of age, the reference population was the white bottle-fed middle-class children in the USA; whereas for children above 24 months of age, the reference population came from three cross-section surveys conducted in the USA during the period 1960-75. It was, therefore, of interest to split our dataset in to two

parts: one for children in the age range 0-24 months, and other for those aged beyond 24 months. The aim was to study determinants of undernutrition (stunting) for children in these two age ranges and to determine the gender differentials of undernutrition in these age-groups.

\subsubsection{Fixed effects for children aged 0-2 years and above 2 years}

Tables A3.4 through A3.6 provide results for fixed effects for our fitted model for all children as well as female and male children in the age range 0-2 years (0-24 months). Given are the posterior means along with standard deviation and $80 \%$ credible interval. 
The results for all children (aged 0-2 years) given in table A3.4 are mostly identical to that for all children (under 5 years of age) provided in table A3.1. That is, girls are slightly better nourished than boys (although the size of the effect is now much larger as compared to that in table A3.1). So the gap in nutritional status of male and female children is now a bit higher. As before, we see that long birth interval and full vaccination coverage contributes to better nourishment, while being twin, having a higher birth order (not being first-born), living in larger households, having a working mother, and living in a region other than Punjab all contribute to less nourishment and we further see that most of these adverse effects are statistically significant. Furthermore, the marginal effects are now much stronger than those given in Table 3.1. The (statistically) significant positive effect of mother's education (at least secondary level) on the nutritional status of children is also quite clearly visible from the results in table A3.4.

Coming to the sex-specific differences in undernutrition (i.e. stunting), we compare the results given in tables A3.5 and A3.6. Except for the household size and residence, all other variables have similar effects for female and male children (aged 0-2 years). As before, we see that female children fare well in rural areas whereas male children are better nourished in urban areas. In fact, residence in rural areas has a significant positive effect for the nutritional status of female children. On the other hand, we see that male children are less stunted in urban areas. This may be partly due to better health facilities available in the urban centres and perhaps the parents may be more likely to bring their male child to a health facility as compared to a female child, thus contributing better health of male children. An interesting result is that of larger household size. In contrast to earlier results, we observe that larger household size is slightly conducive for female children in the age range of 0-2 years. This outcome is, however, statistically insignificant. There are important gender-specific differences in the two tables if we look at the size of individual effects. We observe that female children benefit more (with regards to their nourishment) if the birth interval is large and if they have full vaccination coverage (as compared to male children). Thus female children may be able to have better micronutrients available to them if the preceding birth interval is at least 24 months and are fully vaccinated. Further, we see that female children would be relatively better nourished (as compared to male children) if their birth order is not higher. Similarly, the 
significantly positive effect of mother's education (at least secondary level) is relatively stronger for female children than that for male children.

Tables A3.7 through A3.9 provide results for the fixed effects of our model for all children as well as female and male children aged more than 2 years (more than 24 months). One immediate result which might indicate the usefulness of splitting our data set into two parts comes in the form of reversal of sign for the variable gender given in table 3.7. This shows that for children above 2 years, female children are more stunted than male children. Although the result is statistically insignificant, it still can indicate that there might be some underlying gender discrimination. Table A3.7 further shows that full vaccination coverage and mother' education (at least primary) significantly contribute to lower levels of stunting. An unexpected outcome is that of long birth interval which has a negative sign. The result, though statistically insignificant, indicates poor nutritional status for children having large (preceding) birth interval. Perhaps longer birth interval may no more be an important indicator for the nutritional status for the children above two years. Other results are similar to the previous discussions. That is, higher birth order, larger household size, working mother, residence in the three regions other than Punjab, and living in rural area are less conducive to better nourishment. Discussing the results for female and male children separately (given in the tables A3.8 and A3.9 respectively), we observe some visible differences. Female twins are more stunted than male twins. In contrast to male children, female children may fare well (less stunted) even if their birth order is up to 6 . On the other hand, the female children would suffer more (less nourished) if the mother is a working woman. The regional patterns as well as effect of residential status are similar for male and female children in the age range above two years. Examining the marginal effects, we see that the effect of vaccination for male children is stronger as compared to female children; whereas mother's education has a stronger positive effect for female children. Furthermore, larger household size is relatively less conducive for female children. This outcome is in line with the observations by Belitz et.al. (2007). That is, daughters in the age range "more than 2 years" fare worse if they are living in a larger household in which there is a constant competition for the available scarce resources. 


\subsubsection{Smooth (non-linear) Effects}

The non-linear effect of continuous variables in our model, namely child's age (baseline effect), mother's age at the birth of her child, asset index and the health seeking behaviour index are given in Appendix B.

The non linear effects of our continuous variables for all children are given in figure B3.1. We observe that stunting increases with increasing age of the child where the deterioration of nutritional status is sharp up until about 20 months and then there is a steady and consistent, but in a zig-zag fashion, decline in nutritional status afterwards. As described by Belitz et.al. (2007), and also discussed in other studies such as Kandala et.al. (2001), Klasen and Moradi (2000), the sudden improvement at around 24 months of age does not reflect real improvement in the nutritional status. This simply reflects the fact that the reference population changes at 24 months of age and the children are now compared to the worse-nourished children (from the three cross-section surveys) as compared to the previously well-nourished reference population of bottle-fed white children. So the children continue to be undernourished and that was one of the reasons for WHO to try to formulate new reference standards in 2006. The other three non-linear effects show that children get better nourished with higher age (at birth) of mother, better socio-economic status of the household and positive health seeking behaviour of the mother.

Figures B3.2 and B3.3 provide, gender-wise, the non-linear effects of child's age, mother's age (at birth of the child), the asset index (proxy for socio-economic status of the household), and mother's health seeking behaviour. We observe that for both male and female children, the stunting increases with increasing age (of the child). This increase is very rapid up until age 20 months, and then there is a steady decline in nutritional status. Notable differences can be observed in the effect of other three variables. For male children, the effect of mother's age (at birth of the child) is almost linear and indicates that male children are better nourished if the age of the mother is higher. In case of female children, the effect is almost of the inverse-U type shape. This indicates that being a very young mother as well as very older one has a negative effect on the nutritional status of the female child. In other words, the female children are more 
stunted if the age of the mother at the birth of the female child is either very low (e.g. less than 20 years) or very high (e.g. more than 40). The effect of Asset index is almost linear in case of female children, and the curve increases with higher values of the index. Same is the case for male children, however, in that case the effect clearly shows non-linear pattern. This indicates that the size of the effect of asset index is larger for female children relative to the male children. We can say that both female and male children fare well in household with better economic conditions and this positive effect is more pronounced in case of female children. We also observe that the effect of health seeking behaviour of mother is conducive for better nourishment of both female and male children; however, one can observe that the effect has a slightly more positive trend for male children. This may be due to the fact that male children are more vulnerable to birth complications and infections, and so the mother may have more antenatal visits during the pregnancy of a male child, would have more likely given birth in a health facility (rather than at home), and would have been most likely assisted, during birth, by a trained health professional.

\subsubsection{Non-linear effects for children (0-2 years as well as above 2 years)}

Figures B3.4 through B3.9 provide non-linear effects for our model for children in the two age groups, namely, 0-2 years and above 2 years. The figures provide results for all children (in that age range) as well as gender-wise.

Regarding the effect of child's age (baseline effect in our model), we observe (from figures B3.4 through B3.6) that the effect is declining smoothly for children aged 0-2 years (0-24 months), thereby showing a smooth decline in the stunting levels. This is true for all children as well as for each sex separately. On the other hand, figures A3.6 through A3.9 indicate that an oscillatory effect for the child's age. This may be due to age heaping at particular ages as the mothers may report the ages of their older children in certain preferred digits. We see that the overall pattern of this effect is a declining one but not in a smooth fashion. The effect of mother's age (at the birth of her child) is nearly identical for all children as well as female and male children in the two age ranges (except the female children in the age range 0-2 years given in the Figure A3.5). That is, 
children have better nutritional status if the mother's age (at the birth of her child) is higher. For female children in the age-group 0-2 years (Figure A3.5), the effect is roughly inverted U-shape, thereby indicating the female children age 0-2 years would be better nourished if the mother (at the time of her daughter's birth) is neither too young nor too old. The remaining two effects, that is, Asset index and Health Seeking Bahaviour (HSB) index provides same information as discussed earlier in case of all children (under five years of age). That is, children in both age-groups (overall as well as gender-wise) are less stunted if they live in well-off households and having a mother with positive health seeking behaviour with regard to her children. However, as before, we observe that the effect of asset index is stronger (smooth linear) for female children, whereas that of the HSB is more pronounced for male children. This again signifies the fact that girls are less discriminated if the household has got better economic conditions.

\subsection{Conclusions}

The aim of the current study was to determine the factors affecting undernutrition in Pakistan. As an indicator of undernutrition, we used the anthropometric indicator of height for age popularly known as stunting. A particular focus of the study was on the gender-specific determinants of undernutrition. Using Bayesian structured additive regression model, we conclude that overall, children are more likely to be better nourished (less stunted) if the (preceding) birth interval is large (more than 24 months), the children are fully vaccinated, mother is educated and is of higher age, the household has better economic conditions and the mother has a positive health seeking behaviour. On the other hand, being twin, having higher birth order (not being first-born), residing in a household with larger size, having a working mother, not living in Punjab region and residing in rural area contributes to worsened nutritional status. Similarly we observed that higher age of the mother (at the birth of the child), better economic status of the household and positive health seeking behaviour of the mother has a positive effect on the nutritional status of the child. While analyzing the data for all children under the age of five years, we observed that there is no excess female undernutrition in Pakistan. In fact, female children are slightly better nourished as compared to male children. This is 
consistent with the standard literature. We then split the data into two parts: one for children aged 0-2 years, and the other consisting of children aged more than two years. Analyzing the data separately, we got the important result of reversal of sign for the variable gender. This indicated excess female undernutrition beyond two years of age. We suspect that it might reflect gender bias against female children in access to nutrition. Gender-wise analyses suggest that most of the conclusions for the overall analysis (all children) are also valid for the female and male children separately. However, there were visible differences in certain aspects. While mother's education is important for reduced stunting for both female and male children, we observed that for female children, even a minimum education of up to primary level can be significant for improved nourishment. Furthermore, the size of effects for female children is stronger relative to male children. Similarly, a non-working mother (house-wife) who is middle-aged (at the time of birth of the child), residence in rural area, and well-off household are conducive for the better nourishment of girl child, whereas higher age of the mother (at the birth of her child), living in urban areas, and positive health seeking behaviour of the mother are important factors for reduced stunting of the male child. We further observed that nutritional status of children in the region of Punjab is better than the rest of the Pakistan. Given the fact that the same PDHS dataset provides higher mortality levels in Punjab as compared to the rest of the three regions, one can consider it as an enigma or perhaps better and accurate data collection in Punjab. Klasen (2007), in fact, refers to such an enigma in a much broader regional perspective in which he discusses sub-Saharan Africa/ South Asia puzzle of higher mortality, but low malnutrition, in Sub-Saharan Africa as compared to low mortality, but higher rates of malnutrition in South Asia. This fact in case of the inter-provinces comparisons of Pakistan, however, needs to be elaborated further in future research studies.

Comparing the outcome of our study with those in the countries in the region we observe that most of our conclusions are in line with studies conducted on India (Belitz et.al. 2007; Mishra et.al. 1999), Sub-Saharan Africa (Klasen, 1996; Kandala et.al. 2001 \& 2002). Like Belitz et.al. (2007), we also observed that nutritional status of girl is more sensitive to competition for resources within the household (more specifically for female children aged more than 2 years), that is, female children are relatively more stunted as 
compared to male children if they are twins, have a short birth interval, if they live in a larger household, and have a higher birth order. Our study, however, differ from the above mentioned on some aspects. We observed that girls fare worse if their mother is a working person (that is, engaged in some earning activity). This may possibly reflect that a non-working mother may care their daughters well as compared to a working mother. Thus a non-working mother may contribute to the better nutritional status of her daughter. Unlike the previous studies, we have further split the sample of children (aged 0-5 years) into two groups, namely, 0-2 years and above 2 years. We were able to identify excess female stunting in children aged more than two years (which was though statistically insignificant). The other regional studies have also looked at the spatial structure of the levels of undernutrition and in case of India, for example, have come up with a North-South divide of the levels. In our case, we were unable to incorporate the spatial component in our model. As Pakistan has only four regions (provinces) so it does not make much sense to use spatial information for only four regions. Furthermore, the district level information was not available in our dataset. In future studies, it may be useful to study the extent and levels of undernutrition in Pakistan at the district level so as to get further insights on the spatial distribution of the phenomenon.

\subsection{References}

Belitz, C., Hübner, J., Klasen, S. and Lang, S. (2007). Determinants of the Socioeconomic and spatial pattern of undernutrition by sex in India: A geo-additive semiparametric regression approach. Working paper, Department of Statistics, University of Munich.

Brezger, A. and Lang, S. (2006). Generalized Structured Additive Regression based on Bayesian P-Splines. Computational Statistics and Data Analysis, 50, 967-991.

Briend, A., Wojtyniak, B. and Rowland, M.G.M.(1988). Breast feeding, nutritional status and child survival in rural Bangladesh. British Medical Journal, 296 (6626): 879-82.

Chen, L. C., A. K. M. A. Chowdhury, and S. L. Huffman. (1980). Anthropometric assessment of energy-protein malnutrition and subsequent risk of mortality among preschool aged children. American Journal of Clinical Nutrition 33(8): 1836-45. 
Fotso, J.C. (2006). Child health inequities in developing countries: differences across urban and rural areas. International Journal for Equity in Health, 5, 9.

Fotso, J.C. (2007). Urban-rural differentials in child malnutrition: Trends and socioeconomic correlates in sub-Saharan Africa. Health and Place, 13, 205-223.

Harttgen, K. and M. Misselhorn (2006). A multilevel approach to explain child mortality and undernutrition in South Asia and Sub-Saharan Africa. Mimeographed, University of Göttingen.

Helen Keller International, Bangladesh (2001). The Nutritional Surveillance Project in Bangladesh in 1999. Towards the Goals of the 1990 World Summit for Children. Dhaka, Bangladesh: Helen Keller International.

Fahrmeir, L. and Lang, S. (2001). Bayesian Inference for Generalized Additive Mixed Models Based on Markov Random Field Priors. Applied Statistics (JRSS C), 50, 201-220. Kandala, N.B., S. Lang, Klasen,S. and Fahrmeir, L. (2001). Semiparametric Analysis of the Socio-Demographic Determinants of Undernutrition in Two African Countries. Research in Official Statistics, EUROSTAT, Vol. 4 No.1:81-100

Kandala, N.-B., L. Fahrmeir, and S. Klasen (2002). Geo-additive models of Childhood Undernutrition in three Sub-Saharan African Countries. Sonderforschungsbereich 386: Discussion Paper no. 287., Deutsche Forschungsgemeinschaft.

Kandala, N. B., S. Lang, S. Klasen, and L. Fahrmeir (2001). Semiparametric Analysis of the Socio-Demographic and Spatial Determinants of Undernutrition in two African Countries. Sonderforschungsbereich 386: Discussion Paper no. 245., Deutsche Forschungsgemeinschaft.

Klasen, S. (1996). Nutrition, Health, and Mortality in Sub-Saharan Africa: Is there a Gender Bias? Journal of Development Studies 32: 913-932.

Klasen, S. (2000). Malnourished and low mortality in South Asia, better nourished and dying young in Africa: What can explain this puzzle? SFB 386 Discussion Paper No. 214. University of Munich.

Klasen, S. (2008). Poverty, undernutrition, and child mortality: Some inter-regional puzzles and their implications for research and policy. Journal of Economic Inequality, (1): 89-115. 
Klasen, S. and A. Moradi (2000). The Nutritional Status of Elites in India, Kenya and Zambia: An appropriate guide for developing reference standards for undernutrition? Sonderforschungsbereich 386: Discussion Paper no. 217., Deutsche Forschungsgemeinschaft.

Katz, J., K. P. West, Jr., I. Tarwotjo, and A. Sommer. 1989. The importance of age in evaluating anthropometric indices for predicting mortality. American Journal of Epidemiology 130(6): 1219-26.

Klasen, S. (1999). Malnourished and low mortality in South Asia, better nourished and dying young in Africa: What can explain this puzzle? SFB 386 Discussion Paper No. 214. University of Munich.

Maleta, K. (2006). "Epidemiology of Undernutrition in Malawi", chapter 8 in The Epidemiology of Malawi, edited by Eveline Geubbles and Cameron Bowie, available on http://www.medcol.mw/commhealth/publications/epi\%20book/Undernutrition $\% 20$ chapte r\%208.pdf .

Mishra, V., S. Lahiri, and N. Luther (1999). Child Nutrition in India. National family health survey subject reports number 14, International Institute for Population Sciences. Mumbai, India. East-West Center, Population and Health Studies, Honolulu, Hawaii, U.S.A.

Menon, P., Ruel, M., \& Morris, S. (2000). Socio-economic differentials in child stunting: Results from 11 DHS data sets. Food and Nutrition Bulletin, 21(3), 282-289.

Pelletier, D.L., E.A. Frongillo, Jr, D.G. Schroeder and J.P. Habicht (1995). The effects of mulnutrition on child mortality in developing countries, Bulleting of the World Health Organization 73 (4): 443-448.

Ruel, M., Garrett, J., Morris, S., Maxwell, D., Oshaug, O., Engle, P., Menon, P., Slack, A., \& Haddad, L. (1998). Urban challenges to food and nutrition security: A review of food security, health, and caregiving in the cities. Food Consumption and Nutrition Division Discussion Paper 51, International Food Policy Research Institute, Washington, DC.

Ruzicka, L. T. and P. Kane. 1985. Nutrition and child survival in south Asia. In K. Srinivasan and S. Mukerji, eds. Dynamics of population and family welfare, pp. 333-57. Bombay: Himalaya Publishing House. 
Sahn, D.E. and Stifel, D.C. (2000). Poverty Comparisons Over Time and across Countries in Africa. World Development. 28 (12): 2123-2155.

Sahn, D.E. and Stifel, D.C. (2003). Exploring Alternative Measures of Welfare in the Absence of Expenditure Data. Review of Income and Wealth 49(4): 463-489.

Sahn D.E., \& Stifel, D.C. (2003). Urban-rural inequality in living standards in Africa. Journal of African Economies, 12, 4, 564-597.

Santhanakrishnan, B. R. and R. Ramalingam. 1987. Risk factors of mortality in children with diarrhoeal disease in Madras, India. Journal of Diarrhoeal Disease Research 5(1): 36-9.

Singh, K. P. 1989. Green revolution and child survival in the state of Punjab. In International Population Conference, New Delhi: Proceedings, Vol. 1, pp. 379-88. Liege, Belgium: International Union for the Scientific Study of Population (IUSSP).

Smith, L., Ruel, M., \& Ndiaye, A. (2005). Why is child malnutrition lower in urban than in rural areas? Evidence from 36 developing countries. World Development, 33(8), 12851305.

Sommer, A. and M. S. Loewenstein. 1975. Nutritional status and mortality: A prospective validation of the QUAC stick. American Journal of Clinical Nutrition 28(3): 287-92.

Vella, V., A. Tomkins, A. Borghesi, G. B. Migliori, B. C. Adriko, and E. Crevatin. 1992a. Determinants of child nutrition and mortality in north-west Uganda. Bulletin of the World Health Organization 70(5): 637-43.

von Braun, J., McComb, J., Fred-Mensah, B., \& Pandya-Lorch, R. (1993). Urban food insecurity and malnutrition in developing countries: Trends, policies, and research implications. Washington, DC: International Food Policy Research Institute.

Vella, V., A. Tomkins, J. Nidku, and T. Marshall. 1992b. Determinants of child mortality in south-west Uganda. Journal of Biosocial Science 24(1): 103-12.

UNICEF (2006). UNICEF Annual Report 2006. New York: UNICEF. WHO (1983). Measuring Change in Nutritional Status. Geneva: WHO

WHO (1995). Physical Status: The Use and Interpretation of Anthropometry. WHO Technical Report Series No. 854. Geneva: WHO. 


\subsection{Appendix A}

Table A3. 1 Posterior means, S.D. and 80\% Credible Interval: All children

\begin{tabular}{|c|c|c|c|c|}
\hline \multirow[t]{2}{*}{ Variable } & \multirow[t]{2}{*}{ Mean } & \multirow[t]{2}{*}{ SD } & \multicolumn{2}{|c|}{$\underline{80 \%}$ credible interval } \\
\hline & & & lower & upper \\
\hline const & -1.561 & 0.112 & -1.6999 & -1.417 \\
\hline gender & 0.044 & 0.050 & -0.0216 & 0.108 \\
\hline twin & -0.649 & 0.198 & -0.901 & -0.396 \\
\hline bord2_3 & -0.080 & 0.083 & -0.188 & 0.020 \\
\hline bord4_6 & -0.251 & 0.091 & -0.367 & -0.136 \\
\hline bord7plus & -0.467 & 0.117 & -0.611 & -0.316 \\
\hline long_bi & 0.085 & 0.056 & 0.007 & 0.152 \\
\hline full_vacc & 0.222 & 0.051 & 0.155 & 0.287 \\
\hline hhmember & -0.0095 & 0.005 & -0.016 & -0.003 \\
\hline prim_m & 0.022 & 0.078 & -0.082 & 0.116 \\
\hline second_m & 0.529 & 0.084 & 0.424 & 0.635 \\
\hline c_workin & -0.139 & 0.072 & -0.233 & -0.050 \\
\hline sindh & -0.542 & 0.063 & -0.623 & -0.460 \\
\hline nwfp & -0.346 & 0.065 & -0.430 & -0.261 \\
\hline baluchis & -0.601 & 0.092 & -0.725 & -0.486 \\
\hline residenc & -0.030 & 0.066 & -0.114 & 0.0538 \\
\hline
\end{tabular}

Table A3. 2 Posterior means, S.D. and 80\% Credible Interval: Female children

\begin{tabular}{|l|l|l|l|c|}
\hline Variable & Mean & SD & \multicolumn{2}{c|}{ lower } \\
const & & & -1.883 & -1.470 \\
twin & -1.680 & 0.164 & -1.387 & -0.634 \\
bord2_3 & -1.018 & 0.294 & -0.204 & 0.106 \\
bord4_6 & -0.044 & 0.120 & -0.435 & -0.081 \\
bord7plus & -0.264 & 0.136 & -0.694 & -0.265 \\
long_bi & -0.479 & 0.168 & 0.010 & 0.222 \\
full_vacc & 0.117 & 0.083 & 0.088 & 0.283 \\
hhmember & 0.186 & 0.078 & -0.016 & 0.003 \\
prim_m & -0.006 & 0.008 & -0.098 & 0.196 \\
second_m & 0.046 & 0.116 & 0.440 & 0.744 \\
c_workin & 0.596 & 0.117 & -0.333 & -0.054 \\
sindh & -0.195 & 0.107 & -0.612 & -0.374 \\
nwfp & -0.493 & 0.094 & -0.512 & -0.259 \\
baluchis & -0.386 & 0.099 & -0.709 & -0.369 \\
residenc & -0.538 & 0.135 & -0.058 & 0.166 \\
\hline
\end{tabular}

Table A3. 3 Posterior means, S.D. and 80\% Credible Interval: Male children

\begin{tabular}{|c|c|c|c|c|}
\hline \multirow[t]{2}{*}{ Variable } & \multirow[t]{2}{*}{ Mean } & \multirow[t]{2}{*}{ SD } & \multicolumn{2}{|c|}{$\underline{\mathbf{8 0} \%}$ credible interval } \\
\hline & & & lower & upper \\
\hline const & -1.385 & 0.156 & -1.584 & -1.188 \\
\hline twin & -0.285 & 0.274 & -0.637 & 0.073 \\
\hline bord2_3 & -0.133 & 0.112 & -0.270 & 0.014 \\
\hline bord4_6 & -0.269 & 0.125 & -0.432 & -0.112 \\
\hline bord7plus & -0.504 & 0.157 & -0.697 & -0.312 \\
\hline long_bi & 0.093 & 0.078 & -0.005 & 0.192 \\
\hline full_vacc & 0.252 & 0.073 & 0.158 & 0.343 \\
\hline hhmēmber & -0.012 & 0.007 & -0.022 & -0.003 \\
\hline prim_m & -0.024 & 0.116 & -0.168 & 0.132 \\
\hline second_m & 0.452 & 0.125 & 0.285 & 0.603 \\
\hline c_workin & -0.095 & 0.100 & -0.221 & 0.033 \\
\hline sindh & -0.605 & 0.087 & -0.712 & -0.492 \\
\hline nwfp & -0.340 & 0.091 & -0.460 & -0.227 \\
\hline baluchis & -0.695 & 0.128 & -0.858 & -0.531 \\
\hline residenc & -0.117 & 0.084 & -0.224 & -0.017 \\
\hline
\end{tabular}


Table A3. 4 Posterior means, S.D. and 80\% Credible Interval: Children (0-2 years)

\begin{tabular}{|l|l|l|l|c|}
\hline Variable & Mean & SD & \multicolumn{2}{c|}{ lower } \\
\hline const & & & -1.442 & -1.042 \\
gender & -1.254 & 0.162 & 0.032 & 0.215 \\
twin & 0.121 & 0.071 & -1.844 & -1.136 \\
bord2_3 & -1.476 & 0.277 & -0.406 & -0.094 \\
bord4_6 & -0.247 & 0.125 & -0.560 & -0.197 \\
bord7plus & -0.378 & 0.142 & -0.857 & -0.435 \\
long_bi & -0.646 & 0.164 & 0.130 & 0.347 \\
full_vacc & 0.236 & 0.086 & 0.295 & 0.507 \\
hhmember & 0.397 & 0.085 & -0.014 & 0.006 \\
prim_m & -0.004 & 0.008 & -0.170 & 0.135 \\
second_m & -0.016 & 0.119 & 0.142 & 0.455 \\
c_workin & 0.299 & 0.124 & -0.289 & -0.005 \\
sindh & -0.141 & 0.110 & -0.558 & -0.325 \\
nwfp & -0.442 & 0.095 & -0.247 & 0.002 \\
baluchis & -0.124 & 0.095 & -0.652 & -0.285 \\
residenc & -0.467 & 0.146 & -0.089 & 0.140 \\
\hline
\end{tabular}

Table A3. 5 Posterior means, S.D. and 80\% Credible Interval: Female children (0-2 years)

\begin{tabular}{|l|l|l|l|l|}
\hline Variable & Mean & SD & \multicolumn{2}{c|}{ lower } \\
\hline const & & & -1.506 & -0.951 \\
twin & -1.234 & 0.216 & -2.029 & -1.115 \\
bord2_3 & -1.554 & 0.357 & -0.558 & -0.108 \\
bord4_6 & -0.338 & 0.174 & -0.895 & -0.393 \\
bord7plus & -0.654 & 0.192 & -1.099 & -0.529 \\
long_bi & -0.820 & 0.232 & 0.187 & 0.504 \\
full_vacc & 0.345 & 0.128 & 0.294 & 0.598 \\
hhmember & 0.446 & 0.122 & -0.010 & 0.018 \\
prim_m & 0.004 & 0.011 & -0.152 & 0.289 \\
second_m & 0.065 & 0.169 & 0.124 & 0.546 \\
c_workin & 0.335 & 0.161 & -0.258 & 0.145 \\
sindh & -0.058 & 0.155 & -0.627 & -0.288 \\
nwfp & -0.456 & 0.137 & -0.469 & -0.119 \\
baluchis & -0.295 & 0.139 & -0.962 & -0.456 \\
residenc & -0.705 & 0.202 & 0.034 & 0.365 \\
\hline
\end{tabular}

Table A3. 6 Posterior means, S.D. and 80\% Credible Interval: Male children (0-2 years)

\begin{tabular}{|c|c|c|c|c|}
\hline \multirow[t]{2}{*}{ Variable } & \multirow[t]{2}{*}{ Mean } & \multirow[t]{2}{*}{ SD } & \multicolumn{2}{|c|}{$\underline{80 \%}$ credible interval } \\
\hline & & & lower & upper \\
\hline const & -1.118 & 0.237 & -1.417 & -0.816 \\
\hline twin & -1.367 & 0.484 & -1.968 & -0.754 \\
\hline bord2 3 & -0.107 & 0.176 & -0.324 & 0.112 \\
\hline bord 46 & -0.023 & 0.199 & -0.275 & 0.226 \\
\hline bord7 $\overline{\text { plus }}$ & -0.431 & 0.239 & -0.744 & -0.122 \\
\hline long_bi & 0.163 & 0.121 & 0.001 & 0.321 \\
\hline full_vacc & 0.335 & 0.112 & 0.193 & 0.477 \\
\hline hhmember & -0.015 & 0.011 & -0.029 & 0.0002 \\
\hline prim_m & -0.131 & 0.176 & -0.360 & 0.097 \\
\hline second $\mathrm{m}$ & 0.268 & 0.191 & 0.024 & 0.515 \\
\hline c workin & -0.278 & 0.162 & -0.483 & -0.062 \\
\hline sindh & -0.488 & 0.133 & -0.659 & -0.318 \\
\hline nwfp & 0.023 & 0.129 & -0.135 & 0.190 \\
\hline baluchis & -0.234 & 0.197 & -0.498 & 0.011 \\
\hline residenc & -0.157 & 0.128 & -0.314 & 0.005 \\
\hline
\end{tabular}


Table A3. 7 Posterior means, S.D. and 80\% Credible Interval: Children (above 2 years)

\begin{tabular}{|c|c|c|c|c|}
\hline \multirow[t]{2}{*}{ Variable } & \multirow[t]{2}{*}{ Mean } & \multirow[t]{2}{*}{ SD } & \multicolumn{2}{|c|}{ 80\% credible interval } \\
\hline & & & lower & upper \\
\hline const & -1.810 & 0.152 & -1.997 & -1.620 \\
\hline gender & -0.002 & 0.065 & -0.085 & 0.079 \\
\hline twin & 0.048 & 0.267 & -0.297 & 0.409 \\
\hline bord2_3 & 0.035 & 0.109 & -0.109 & 0.175 \\
\hline bord4_6 & -0.161 & 0.125 & -0.321 & 0.001 \\
\hline bord7plus & -0.333 & 0.155 & -0.532 & -0.141 \\
\hline long_bi & -0.021 & 0.076 & -0.119 & 0.077 \\
\hline full_vacc & 0.114 & 0.068 & 0.029 & 0.200 \\
\hline hhmember & -0.013 & 0.007 & -0.022 & -0.004 \\
\hline prim_m & 0.055 & 0.117 & -0.095 & 0.195 \\
\hline second_m & 0.715 & 0.117 & 0.560 & 0.858 \\
\hline c_workin & -0.135 & 0.093 & -0.255 & -0.015 \\
\hline sindh & -0.652 & 0.088 & -0.763 & -0.534 \\
\hline nwfp & -0.547 & 0.088 & -0.658 & -0.436 \\
\hline baluchis & -0.691 & 0.121 & -0.850 & -0.535 \\
\hline residenc & -0.069 & 0.088 & -0.184 & 0.042 \\
\hline
\end{tabular}

Table A3. 8 Posterior means, S.D. and 80\% Credible Interval: Female children (above 2 years)

\begin{tabular}{|c|c|c|c|c|}
\hline \multirow[t]{2}{*}{ Variable } & \multirow[t]{2}{*}{ Mean } & \multirow[t]{2}{*}{ SD } & \multicolumn{2}{|c|}{$80 \%$ credible interval } \\
\hline & & & lower & upper \\
\hline const & -1.991 & 0.219 & -2.263 & -1.712 \\
\hline twin & -0.059 & 0.482 & -0.695 & 0.531 \\
\hline bord2 3 & 0.209 & 0.166 & -0.002 & 0.420 \\
\hline bord4 6 & 0.088 & 0.187 & -0.143 & 0.322 \\
\hline bord7plus & -0.190 & 0.247 & -0.505 & 0.137 \\
\hline long_bi & -0.047 & 0.115 & -0.192 & 0.099 \\
\hline full_vacc & 0.029 & 0.107 & -0.106 & 0.168 \\
\hline hhmember & -0.017 & 0.010 & -0.029 & -0.004 \\
\hline prim_m & 0.054 & 0.173 & -0.170 & 0.271 \\
\hline second_m & 0.818 & 0.186 & 0.569 & 1.062 \\
\hline c_workin & -0.333 & 0.144 & -0.513 & -0.150 \\
\hline $\operatorname{sindh}$ & -0.569 & 0.132 & -0.735 & -0.396 \\
\hline nwfp & -0.509 & 0.132 & -0.678 & -0.333 \\
\hline baluchis & -0.454 & 0.174 & -0.683 & -0.234 \\
\hline residenc & -0.042 & 0.130 & -0.211 & 0.126 \\
\hline
\end{tabular}

Table A3. 9 Posterior means, S.D. and $80 \%$ Credible Interval: Male children (above 2 years)

\begin{tabular}{|c|c|c|c|c|}
\hline \multirow[t]{2}{*}{ Variable } & \multirow[t]{2}{*}{ Mean } & \multirow[t]{2}{*}{ SD } & \multicolumn{2}{|c|}{$\underline{80 \%}$ credible interval } \\
\hline & & & lower & upper \\
\hline const & -1.639 & 0.194 & -1.893 & -1.394 \\
\hline twin & 0.164 & 0.321 & -0.264 & 0.571 \\
\hline bord2_3 & -0.138 & 0.147 & -0.338 & 0.048 \\
\hline bord4_6 & -0.415 & 0.166 & -0.633 & -0.198 \\
\hline bord7plus & -0.508 & 0.199 & -0.753 & -0.251 \\
\hline long_bi & 0.032 & 0.0999 & -0.096 & 0.161 \\
\hline full_vacc & 0.207 & 0.091 & 0.089 & 0.326 \\
\hline hhmember & -0.008 & 0.009 & -0.020 & 0.003 \\
\hline prim $m$ & 0.043 & 0.148 & -0.149 & 0.232 \\
\hline second_m & 0.581 & 0.157 & 0.373 & 0.775 \\
\hline c_workin & 0.012 & 0.120 & -0.140 & 0.161 \\
\hline sindh & -0.730 & 0.117 & -0.878 & -0.575 \\
\hline nwfp & -0.614 & 0.121 & -0.776 & -0.458 \\
\hline baluchis & -0.986 & 0.162 & -1.197 & -0.772 \\
\hline residenc & -0.098 & 0.111 & -0.245 & 0.048 \\
\hline
\end{tabular}




\subsection{Appendix B}

Child's Age

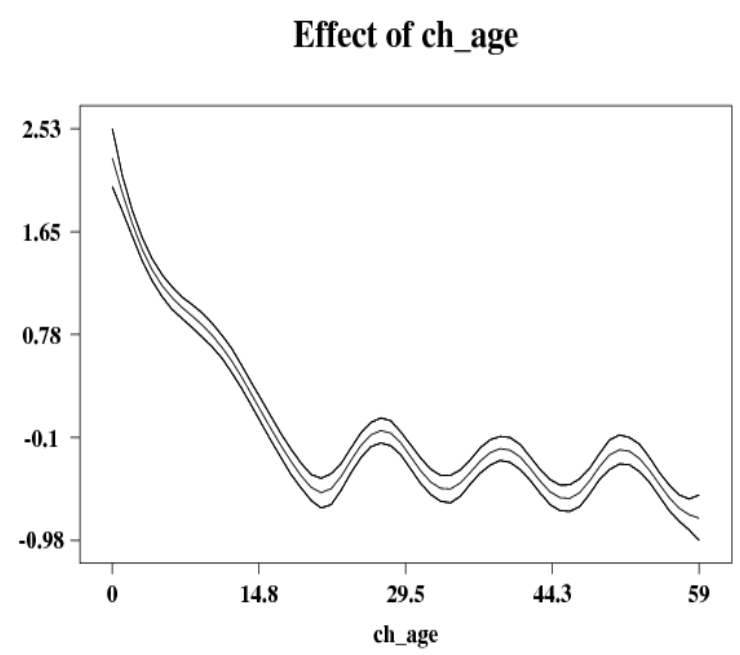

Mother's age (at child's birth)

\section{Effect of m_age}

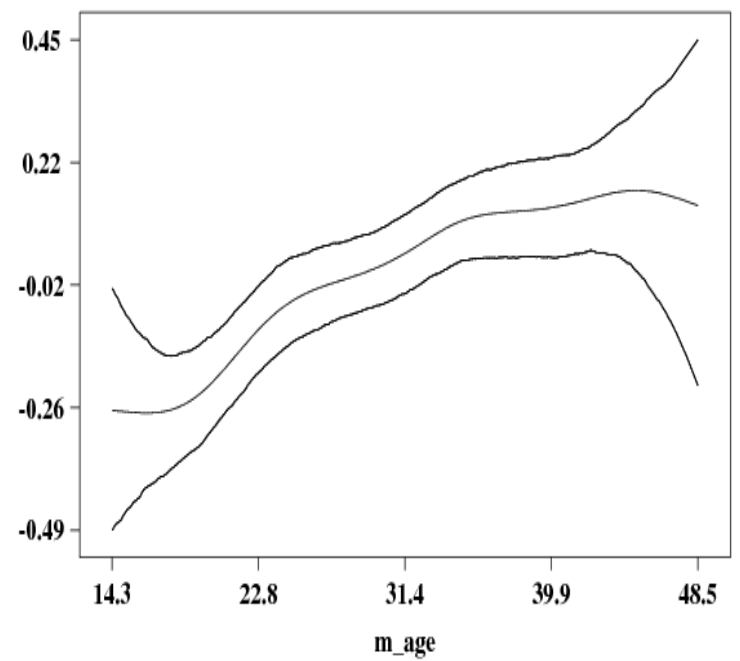

Asset Index

\section{Effect of ai}

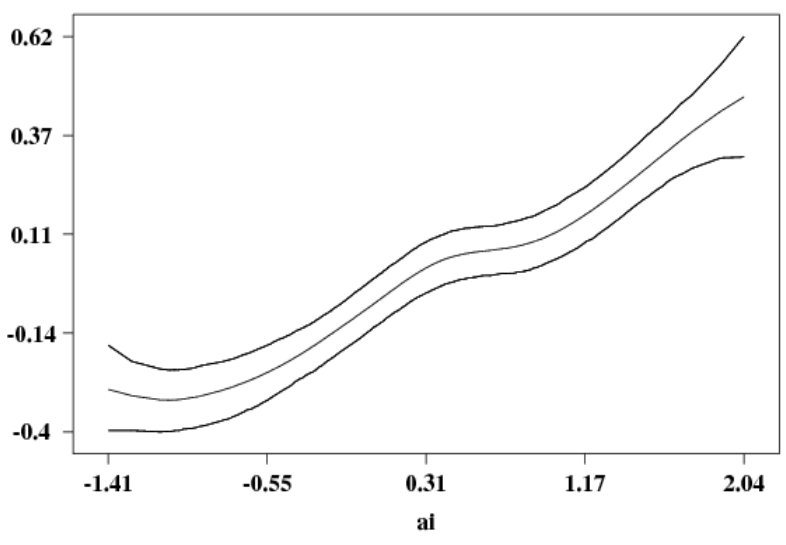

Mother's Health Seeking Behaviour

\section{Effect of hsb}

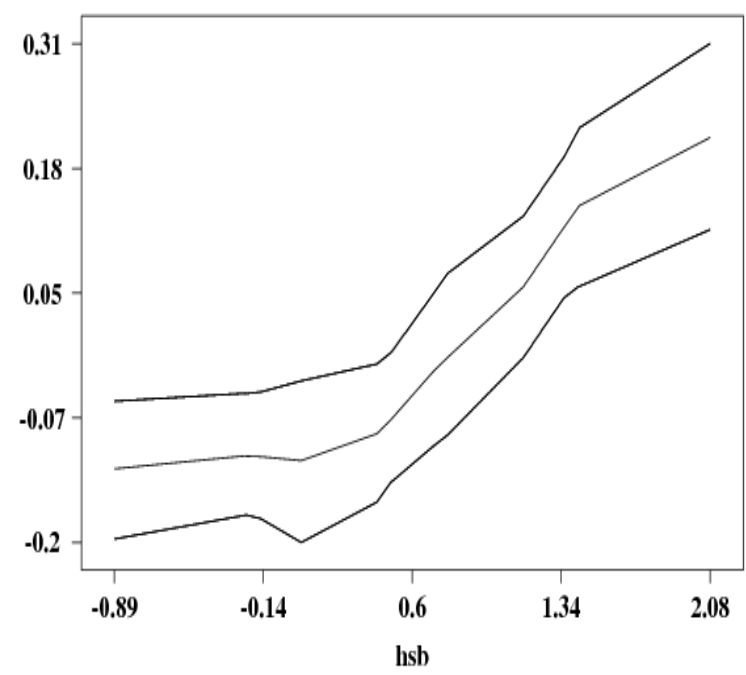

Figure B3. 1 Non-linear effects (All children) 
Child's age

\section{Effect of ch_age}

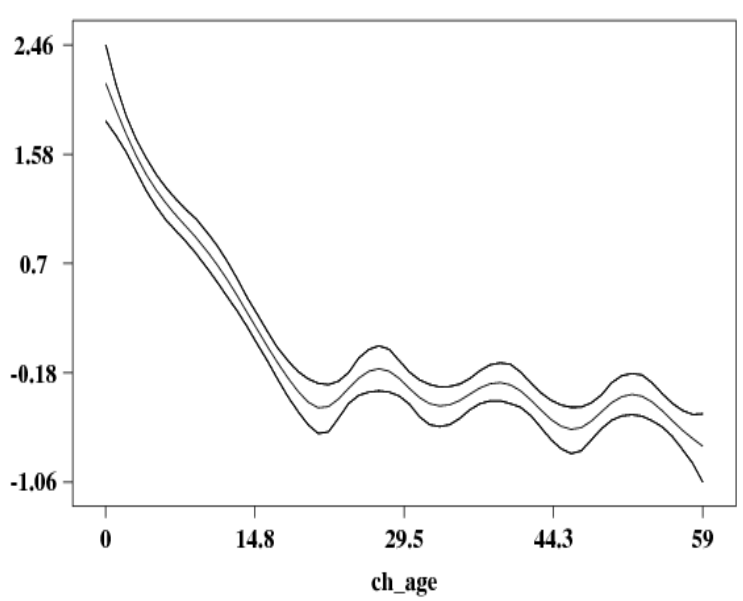

Mother's age (at child's birth)

\section{Effect of m_age}

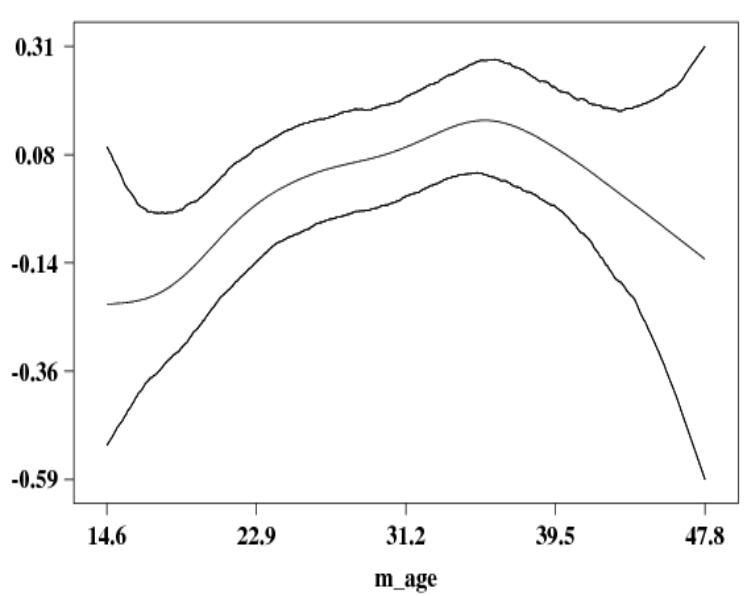

Asset Index

Effect of ai

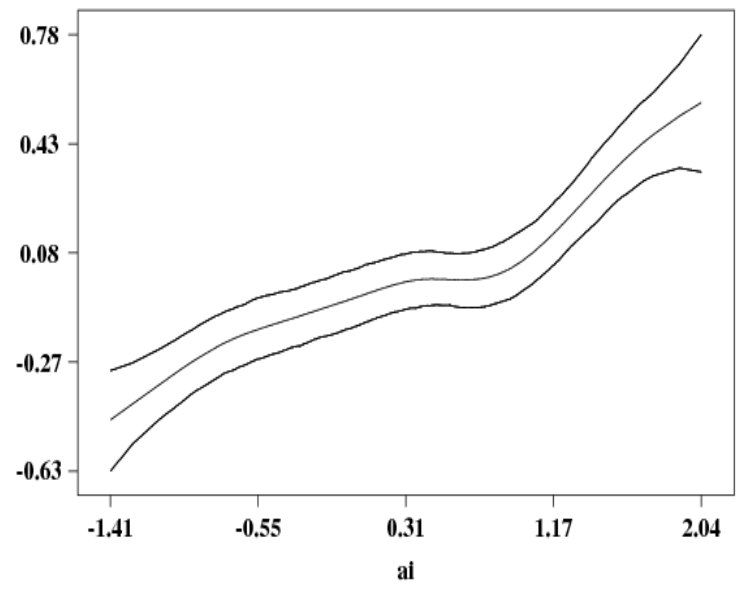

Mother's Health Seeking Behaviour

Effect of hsb

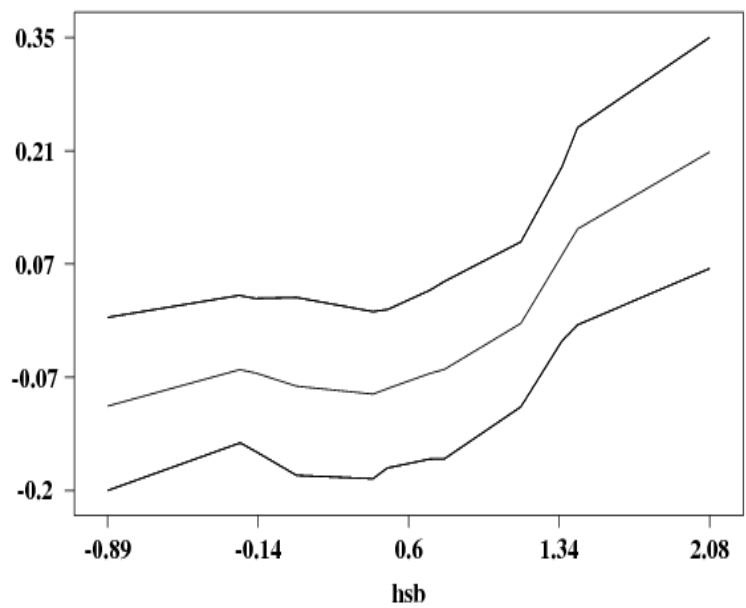

Figure B3. 2 Non-linear effects for female children 
Child's Age

\section{Effect of ch_age}

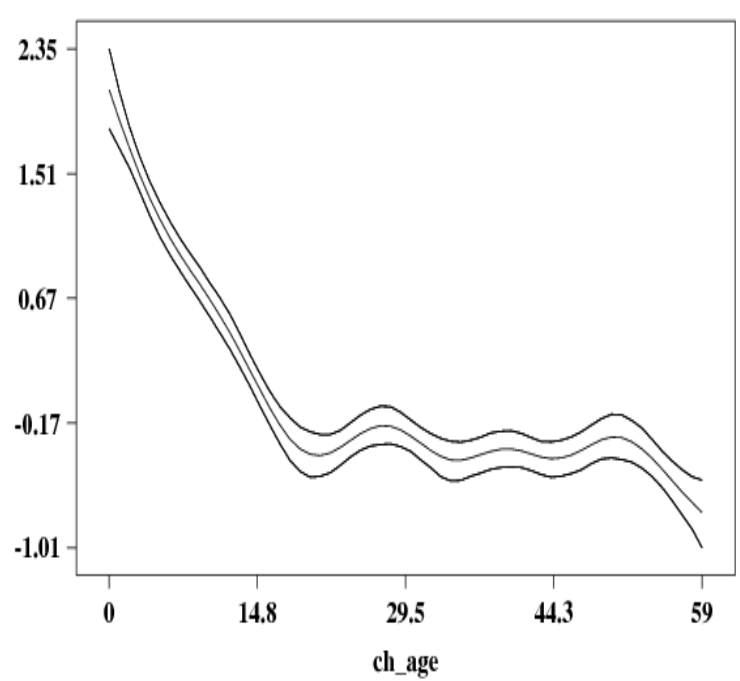

Mother's Age (at child's birth)

\section{Effect of $m \_$age}

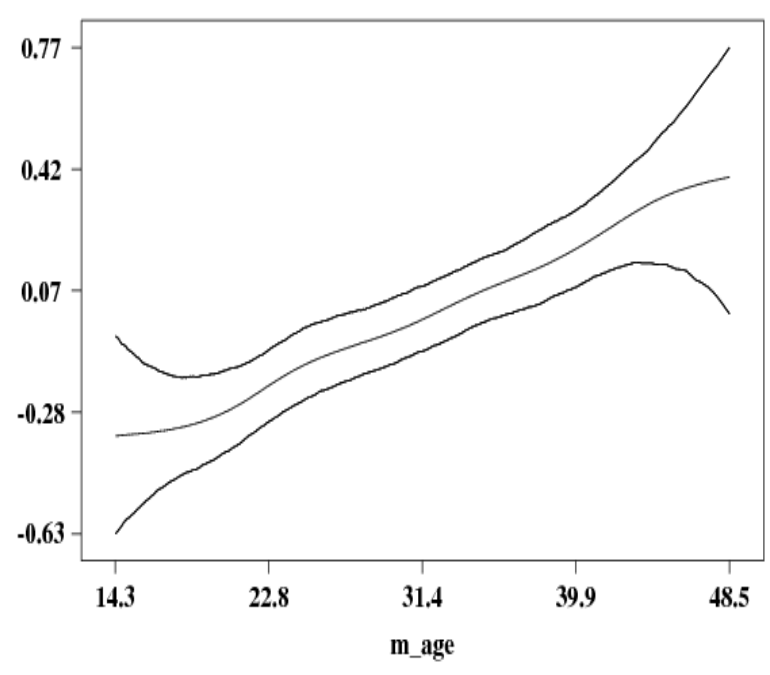

Asset Index

\section{Effect of ai}

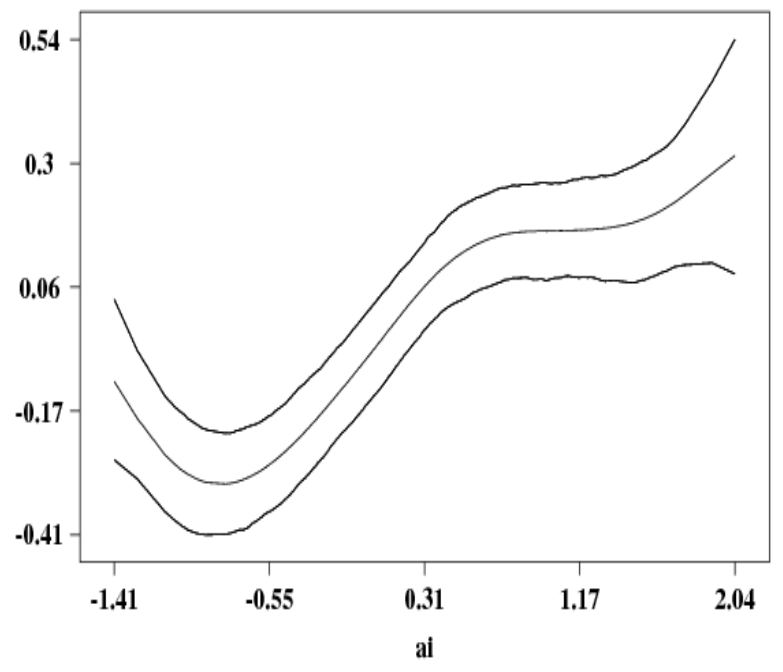

Mother's Health Seeking Behaviour

\section{Effect of hsb}

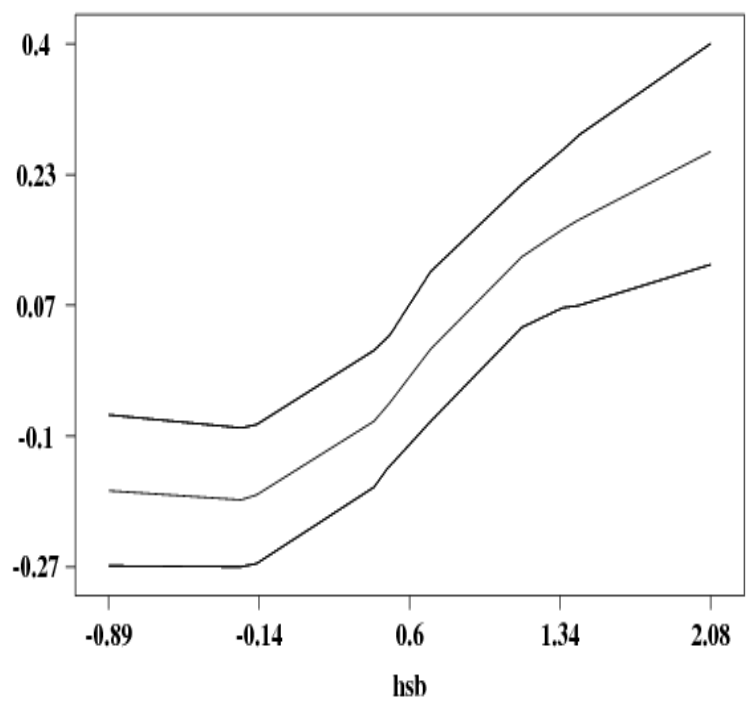

Figure B3. 3 Non-linear effects for Male children 
Child's age

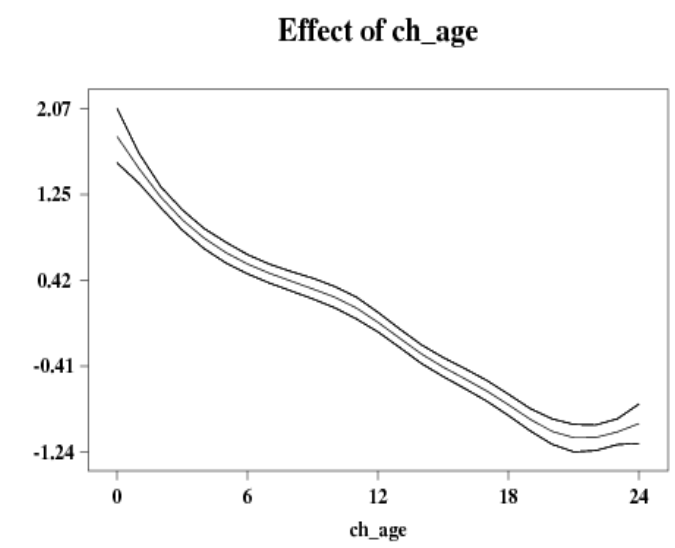

Mother's Age (at child's birth)

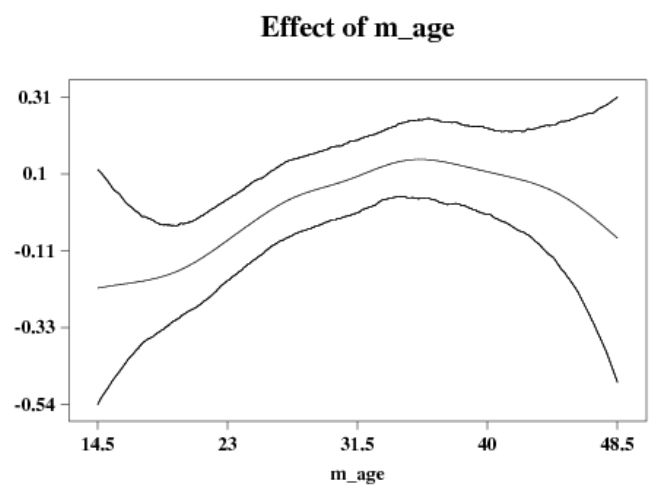

Asset Index

Effect of ai

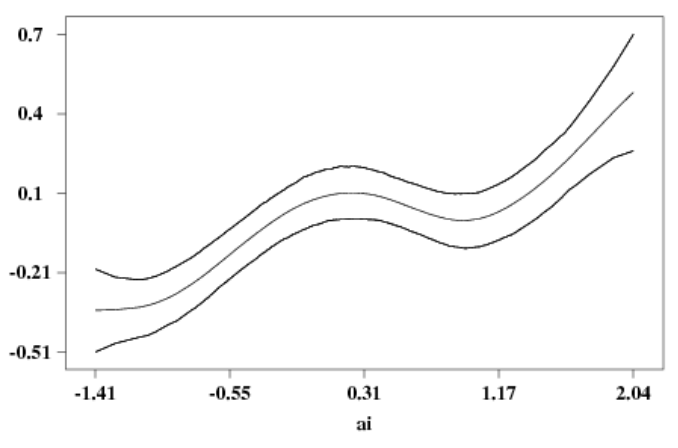

Mother's Health Seeking Behaviour

Effect of hsb

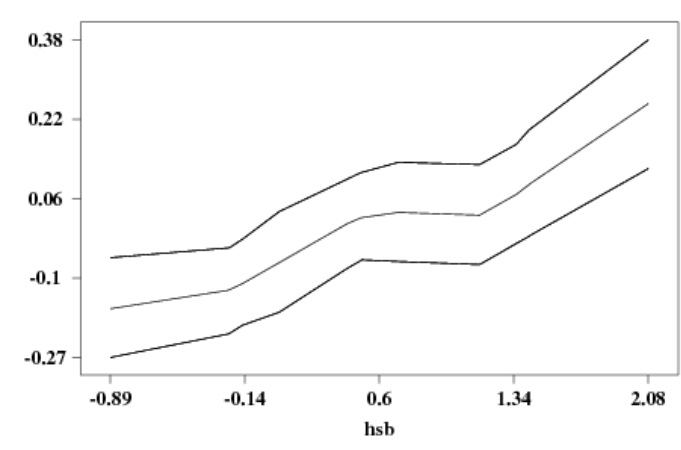

Figure B3. 4 Non-linear effects for Children (0-2 years) 
Child's age

Effect of ch_age

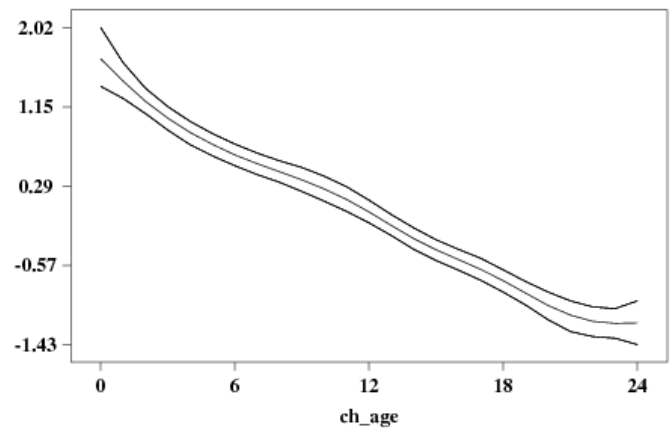

Mother's Age (at child's birth)

\section{Effect of m_age}

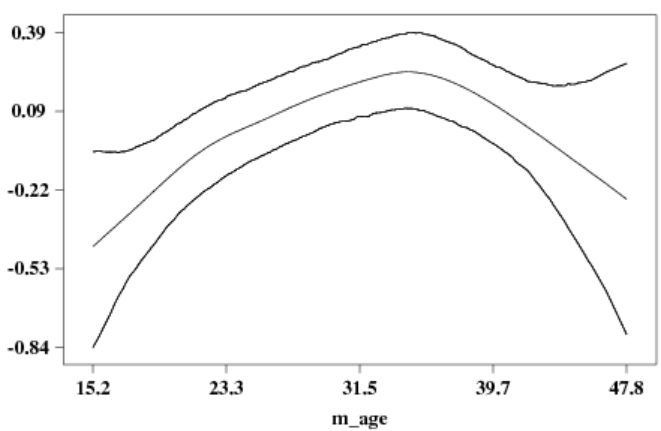

Asset Index

Effect of ai

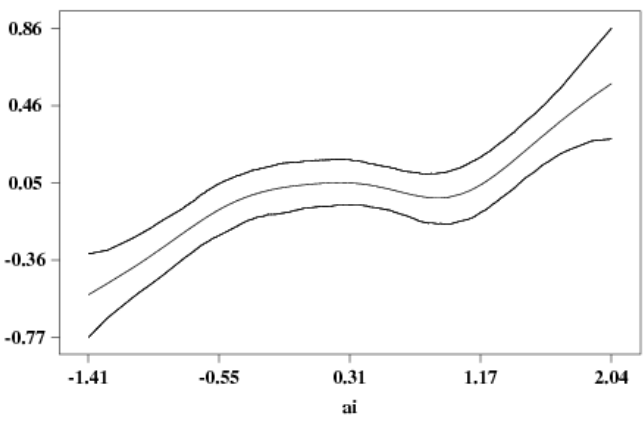

Mother's Health Seeking Behaviour

Effect of hsb

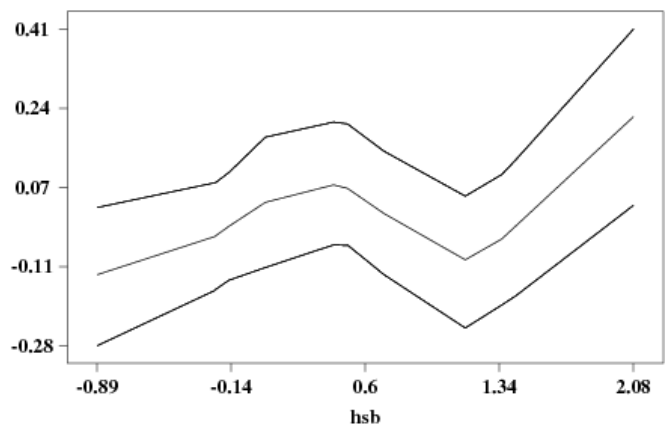

Figure B3. 5 Non-linear effects for Female Children (0-2 years) 
Child's age

Effect of ch_age

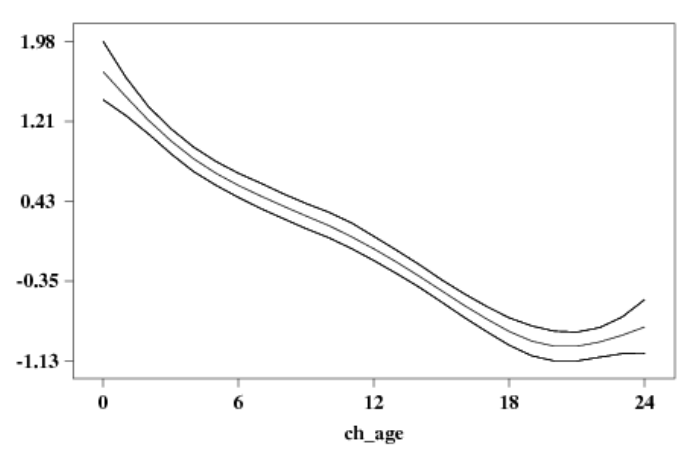

Mother's Age (at child's birth)

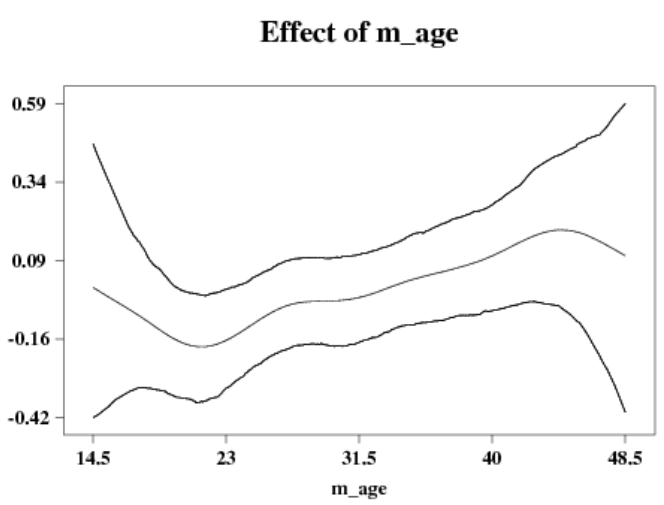

Asset Index

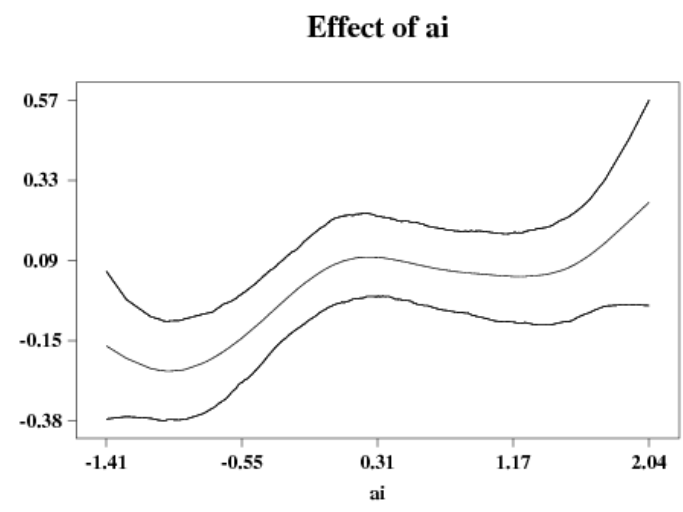

Mother's Health Seeking Behaviour

Effect of hsb

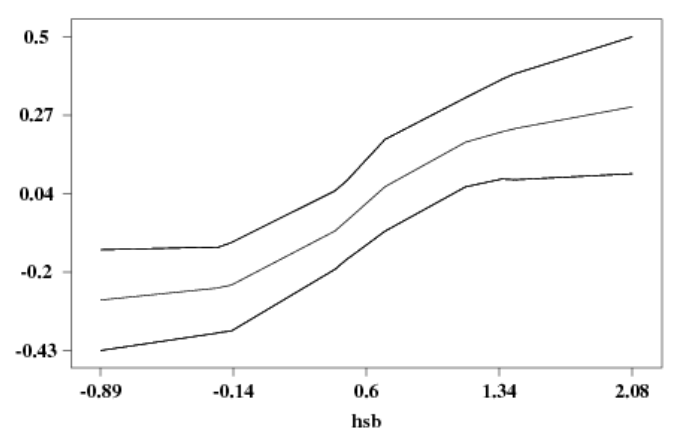

Figure B3. 6 Non-linear effects for Male Children (0-2 years) 
Child's age

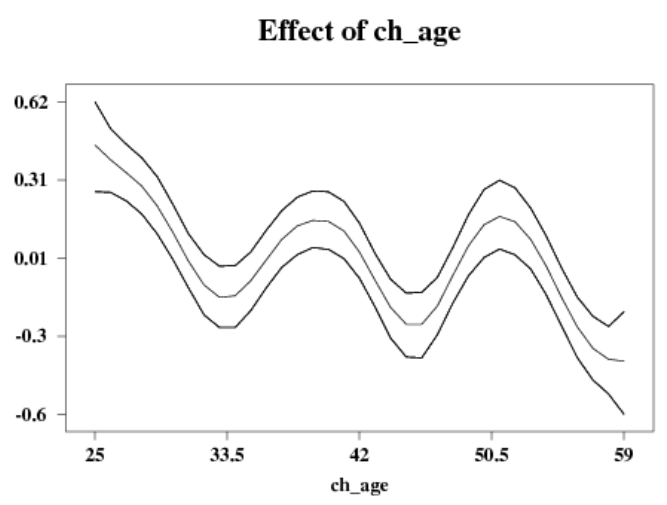

Mother's Age (at child's birth)

Effect of m_age

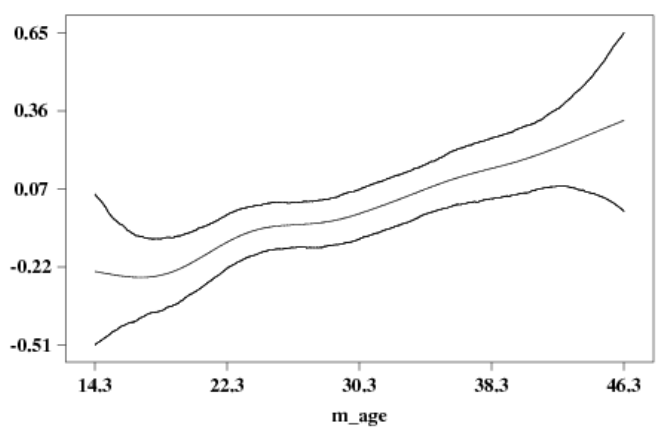

Asset Index

\section{Effect of ai}

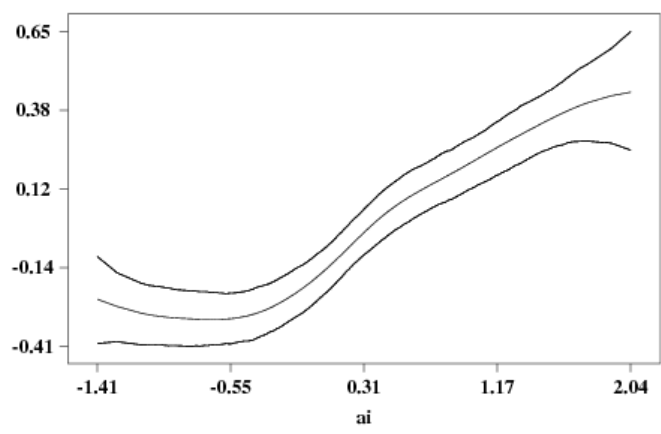

Mother's Health Seeking Behaviour

Effect of hsb

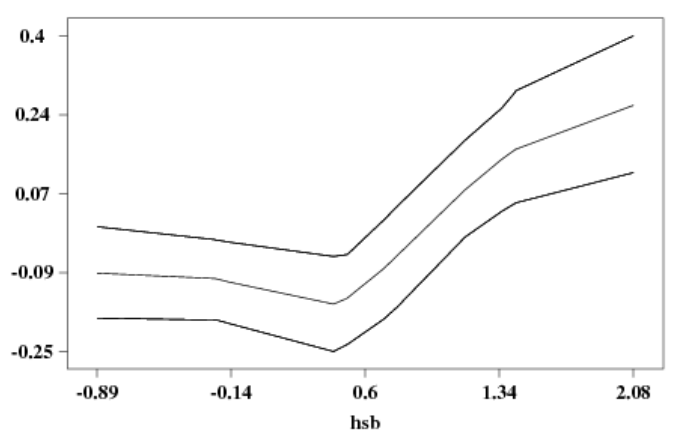

Figure B3. 7 Non-linear effects for children (above 2 years) 
Child's age

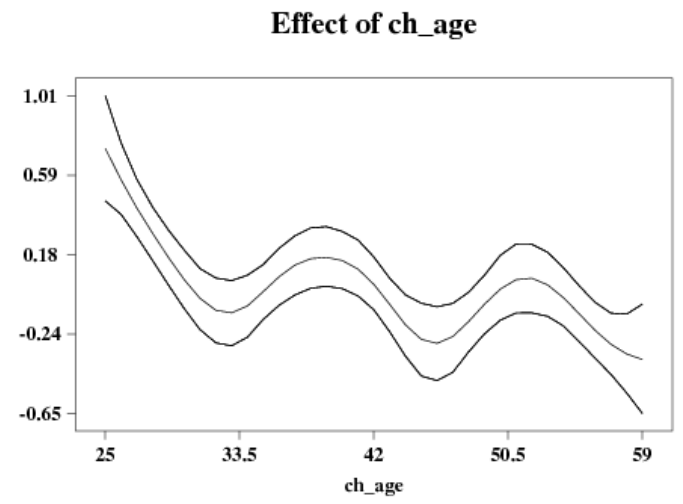

Mother's Age (at child's birth)

Effect of m_age

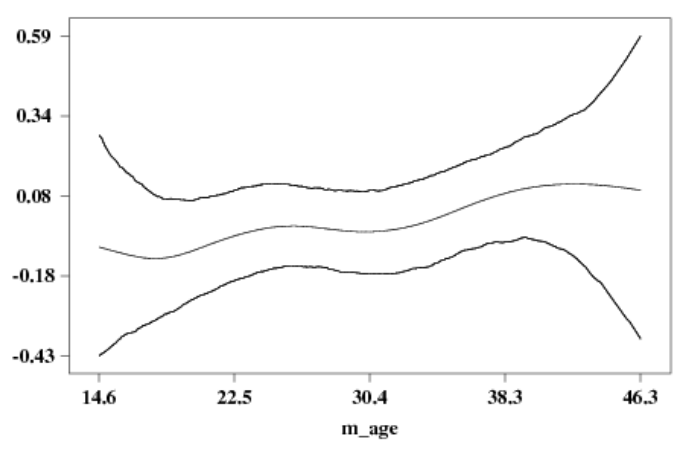

Asset Index

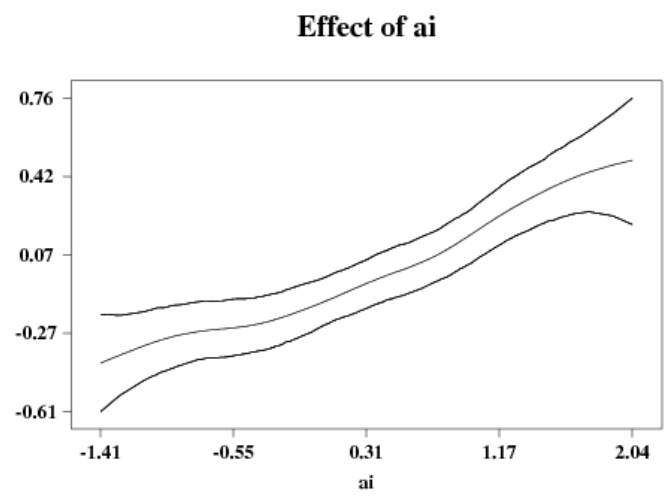

Mother's Health Seeking Behaviour

Effect of hsb

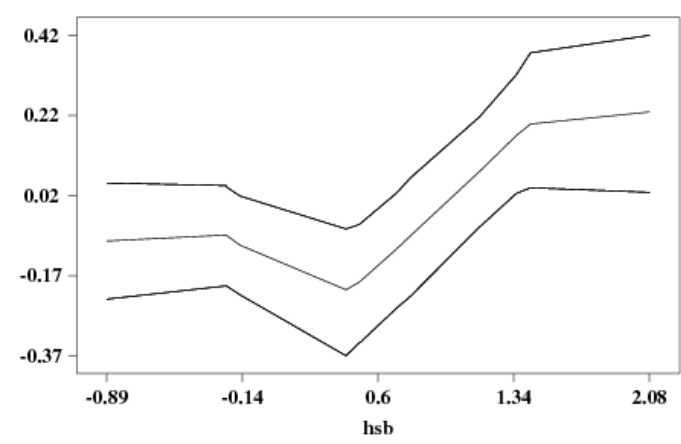

Figure B3. 8 Non-linear effects for Female children (above 2 years) 


\section{Child's age}

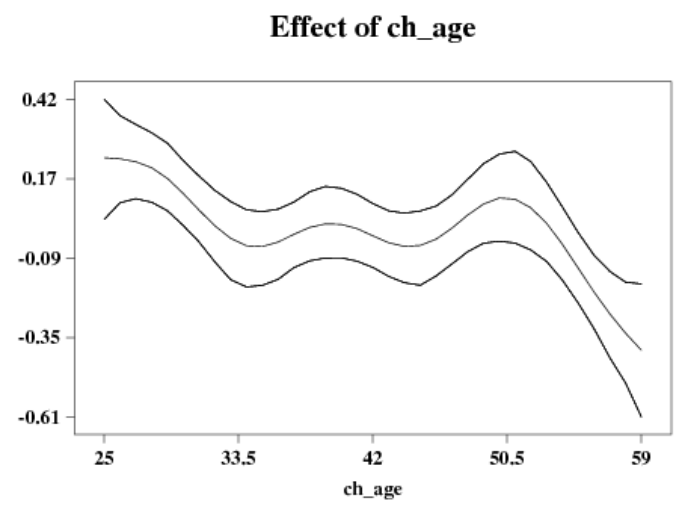

Mother's Age (at child's birth)

Effect of $m \_a g e$

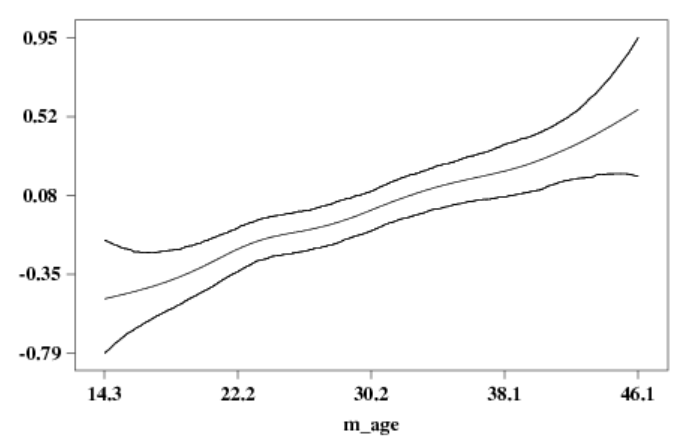

\section{Asset Index}

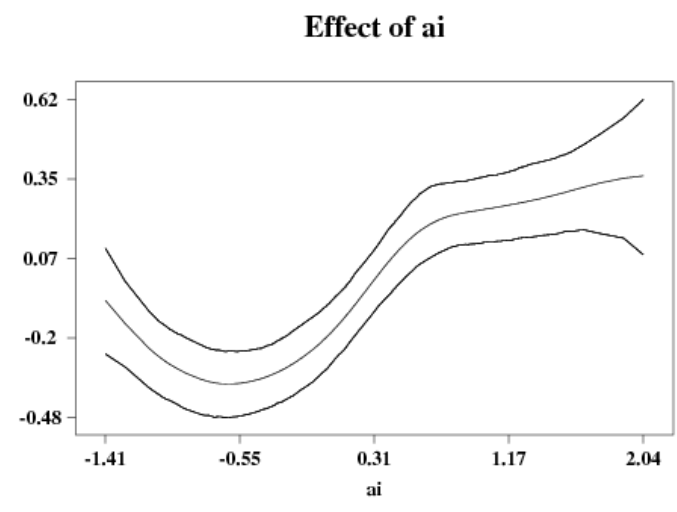

Mother's Health Seeking Behaviour

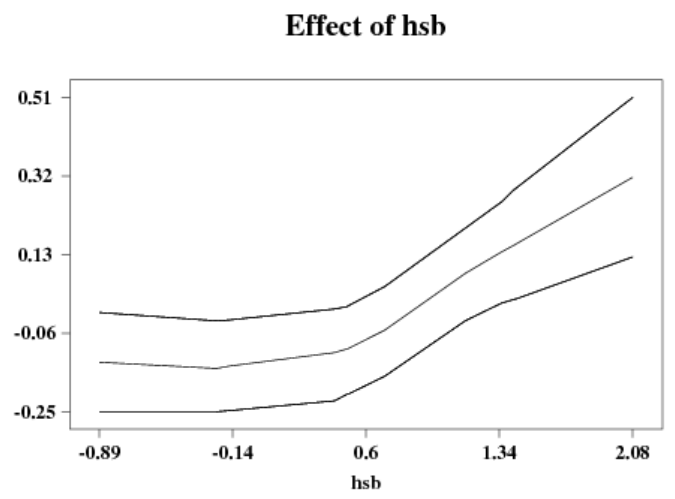

Figure B3. 9 Non-linear effects for Male children (above 2 years) 


\section{Curriculum Vitae}

\section{Personal Data}

\begin{tabular}{ll}
\hline Name: & Mohammad Asim Syed \\
Date of Birth: & March 28, 1970 \\
Nationality: & Pakistani
\end{tabular}

\section{Education}

2004-2008 University of Göttingen

Germany

Ph.D. Student, Centre for Statistics/ Department of

Development Economics

2002

M.Phil. (Statistics) at University of Peshawar

Pakistan

2001

M.A. (Economics), University of Peshawar

Pakistan

1992

M.Sc. (Statistics), University of Peshawar

Pakistan

1990

B.Sc. (Maths \& Statistics), University of Peshawar

Pakistan 


\section{Conferences and Seminars}

2007 Paper presented at the conference on "Determinants of Gender Bias in Survival and Health Access in South Asia”, in Göttingen.

2006 paper presented at a workshop in Munich

2006 Paper presented at the " 5 th EUDN Workshop on Development Research for Doctoral Students" in Bonn.

2001 paper presented at the "Islamic Countries Conference on Statistical Sciences" in Lahore, Pakistan.

\section{Additional Information}

Languages English, German, Urdu, Pashto (native speaker)

Software STATA, BayesX, MS Word, R 


\section{Eidesstattliche Erklärung}

Hiermit versichere ich an Eides statt, dass ich die eingereichte Dissertation

\section{Three Essays on the Gender Differentials in Mortality and Undernutrition in Pakistan}

selbständig verfasst habe. Anderer als der von mir angegebenen Hilfsmittel und Schriften habe ich mich nicht bedient. Alle wörtlich oder sinngemäß den Schriften anderer Autoren entnommenen Stellen habe ich kenntlich gemacht.

Göttingen, den 8. April 2008, Mohammad Asim Syed 